OTÁVIO FILIPE DA ROCHA

\title{
Caracterização de Filmes Finos de ÓXIDO DE Silício DePOSITADOS EM UM REATOR HD-PECVD A PARTIR DE TEOS a Ultra BaixA Temperatura
}

Dissertação de mestrado apresentada à Escola Politécnica da Universidade de São Paulo para a obtenção do titulo de Mestre em engenharia.

São Paulo 2007 


\section{OTÁVIO FILIPE DA ROCHA}

\section{Caracterização de Filmes Finos de ÓXIDO de SiLícIo Depositados EM UM REATOR HD-PECVD A PARTIR DE TEOS A Ultra Baixa Temperatura}

Dissertação de mestrado apresentada à Escola Politécnica da Universidade de São Paulo para a obtenção do titulo de mestre em engenharia. Área de concentração:

Microeletrônica

Orientador:

Dr. Carlos Eduardo Viana

São Paulo

2007 
Este exemplar foi revisado e alterado em relação à versão original, sob responsabilidade única do autor e com anuência de seu orientador.

São Paulo, 17 de setembro de 2007.

Assinatura do autor

Assinatura do orientador

FICHA CATALOGRÁFICA

Rocha, Otávio Filipe da

Caracterização de Filmes Finos de Óxido de Silício Depositados em um Reator HD-PECVD a partir de TEOS a Ultra Baixa Temperatura / O. F. Rocha -- ed. rev. -- São Paulo, 2007. $120 p$.

Dissertação (Mestrado) - Escola Politécnica da Universidade de São Paulo. Departamento de Engenharia de Sistemas Eletrônicos.

1. Filmes Finos 2. Plasma (microeletrônica) 3. Processos de microeletrônica. I. Universidade de São Paulo. Escola Politécnica. Departamento de Engenharia de Sistemas Eletrônicos II.t 
Em memória de Hugo D'Alessandro Jucosky, mais do que um grande amigo, um verdadeiro irmão de espírito.

Dedico este trabalho aos meus pais Janete Barboza da Rocha e José Abílio da Rocha Filho, que me demonstraram todo apoio, compreensão e incentivo durante mais essa etapa do meu percurso acadêmico e em todos os desafios e momentos de minha vida. 


\section{AGRADECIMENTOS}

Ao Prof. Dr. Carlos Eduardo Viana pela orientação deste trabalho, junto ao Laboratório de Sistemas Integráveis da Universidade de São Paulo, principalmente pelo seu incentivo, colaboração, paciência e proveitosas idéias e discussões.

Ao Prof. Dr. Luiz Carlos Donizetti Gonçalves pelas valiosas discussões e sugestões na análise dos resultados.

Ao Prof. Dr. Luiz da Silva Zambom pelas valiosas sugestões na análise dos resultados.

Ao colega Alex Nunes da Silva pelo auxílio prestado e incentivo.

Ao amigo Ricardo Luís Ohta pelo seu incansável e importante incentivo.

Aos técnicos Nelson Ordonez, Alexandre Marques Camponucci, Adir José Moreira, Rubens de Alcântara Pereira e Júlio César dos Santos pelo auxílio prestado durante a parte experimental.

A todo o pessoal do Laboratório de Sistemas Integráveis do PSI Departamento de Engenharia de Sistemas Eletrônicos - da Universidade de São Paulo por ter me "acolhido" durante a realização deste trabalho.

Ao pessoal do Centro de Componentes Semicondutores da UNICAMP pela receptividade e colaboração durante a realização da parte experimental.

A todas as outras pessoas que, de alguma forma, contribuíram para a realização deste trabalho e involuntariamente foram omitidas.

Ao Conselho Nacional de Desenvolvimento Científico e Tecnológico (CNPq) pelo apoio financeiro. 
"As lições mais difíceis são aquelas que valem realmente a pena aprender"

John Taylor 


\section{Resumo}

Este trabalho reporta o estudo e desenvolvimento do processo de deposição química a vapor enriquecida por plasma de alta densidade de filmes finos de óxido de silício obtidos em ultra baixa temperatura, inferior a $100^{\circ} \mathrm{C}$, tendo como fonte de silício o vapor de TEOS.

O principal objetivo deste trabalho é, além da obtenção de filmes de óxido de silício com propriedades elétricas adequadas para utilização em TFTs, compreender os fenômenos que regem o processo de deposição química sob um plasma de alta densidade a partir da caracterização estrutural e elétrica de filmes depositados sob diferentes condições de processo, de modo a poder-se controlar as propriedades dos materiais obtidos.

As técnicas de análise empregadas para a caracterização das amostras foram: elipsometria, FTIRS, RBS, curvas de taxa de deposição e corrosão, curvas capacitância versus tensão de alta freqüência, curvas corrente elétrica versus tensão.

Os principais resultados obtidos através da caracterização elétrica de capacitores MOS com área $9 \times 10^{-4} \mathrm{~cm}^{-2}$, construídos a partir dos filmes de $\mathrm{SiO}_{\mathrm{x}}$ depositados, são: $\mathrm{V}_{\mathrm{FB}}=-3,94 \mathrm{~V} ; \varepsilon_{\mathrm{OX}}=3,92$; $\mathrm{QSS}_{\mathrm{SS}} / \mathrm{q}=6,08 \cdot 10^{11} \mathrm{~cm}^{-2} ; \mathrm{E}_{\mathrm{BD}}=9,44 \mathrm{MV} / \mathrm{cm}$ e $J_{\mathrm{LK}}=2,50 \cdot 10^{-7} \mathrm{~A} / \mathrm{cm}^{-2}$ @ $4 \mathrm{MV} / \mathrm{cm}$. 


\section{“ABSTRACT”}

This work reports on the results obtained from high-density plasma enhanced chemical vapor deposited silicon oxide films at ultra low temperature, i.e. $30^{\circ} \mathrm{C}$, using TEOS vapor as the silicon source oxidized with assistance of argon.

The objectives of this work are: first, understand the phenomena that conducts the chemical vapor deposition in high density regime in order to control the deposited silicon oxide films properties, and also obtain silicon oxide films with adequate properties, from structural and electric characterization of films deposited under different process conditions, in order to control the properties of the deposited materials, for use in TFT's technology.

Different analysis techniques were applied to characterize the deposited layers: ellipsometry, FTIRS, RBS, deposition and etch rate curves, capacitance versus voltage in high-frequency curves and electric current versus voltage curves.

Obtained results were presented and subdivided in accordance with TEOS flow used in the deposition process: $0,5 \mathrm{sccm}$ (for temperatures of 30,150 and $250^{\circ} \mathrm{C}$ ), 1 and $4 \mathrm{sccm}$.

Characterization results were obtained by the different techniques employed suggests the adequate control of the silicon oxide films characteristics according HD-PECVD/TEOS process parameters which are: stoichiometry, density, $\mathrm{Si}-\mathrm{H}$ and $\mathrm{Si}-\mathrm{OH}$ bonds content, position of Si-O peak and absence of organic contamination.

The main results obtained from the electric characterization MOS capacitors with area $9 \times 10^{-4} \mathrm{~cm}^{-2}$, implemented with deposited $\mathrm{SiO}_{\mathrm{x}}$ films, are: $V_{\mathrm{FB}}=-3,94 \mathrm{~V} ; \quad \varepsilon_{0 \mathrm{OX}}=3,92 ; \quad \mathrm{Q}_{\mathrm{SS}} / \mathrm{q}=6,08 \cdot 10^{11} \mathrm{~cm}^{-2}$; $E_{B D}=9,44 \mathrm{MV} / \mathrm{cm}$ and $J_{L K}=2,50 \cdot 10^{-7} \mathrm{~A} / \mathrm{cm}^{-2} @ 4 \mathrm{MV} / \mathrm{cm}$. 


\section{SUMÁRIO}

Resumo

"Abstract"

Sumário

Lista de Figuras

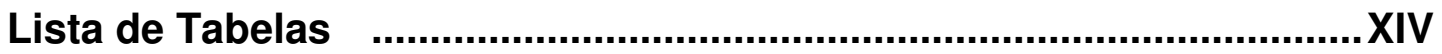

Lista de Siglas

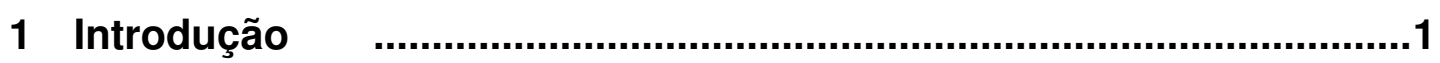

1.1 Resultados Anteriores do Grupo de Pesquisa...........................2

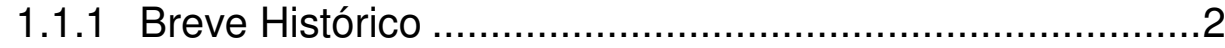

1.1.2 Características dos Filmes Depositados............................3

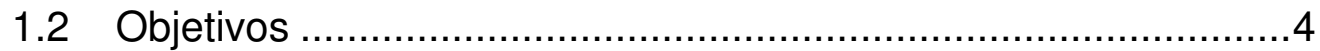

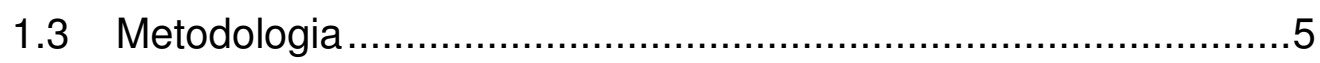

2 Revisão Bibliográfica sobre Filmes de Óxido de Silício Obtidos a Baixa Temperatura .......................................................................

2.1 Conceitos Básicos sobre Deposição Química a Vapor ................ 8

2.2 Os sistemas CVD e suas variantes .........................................11

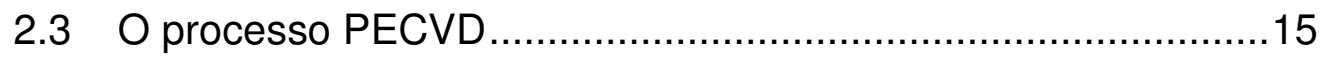

2.3.1 Reagentes utilizados na deposição de filmes de óxido de

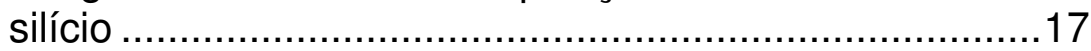

2.3.2 Reatores utilizados na técnica PECVD.........................18

2.3.3 Influência dos parâmetros de processo nas propriedades de filmes de óxido de silício ......................................20

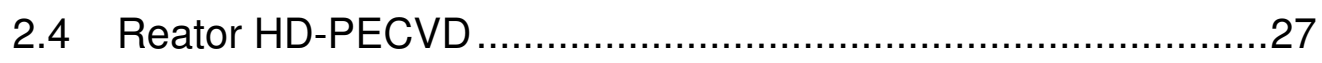

3 Técnicas Empregadas para a Caracterização.....................................33

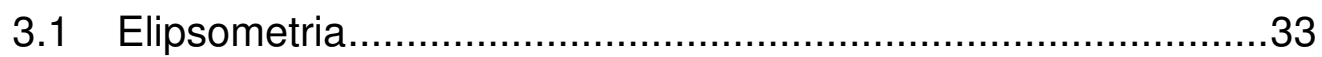

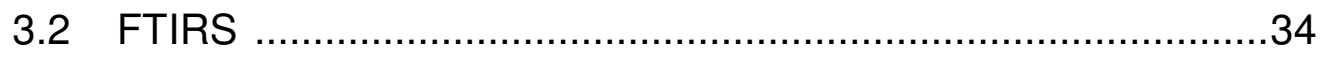

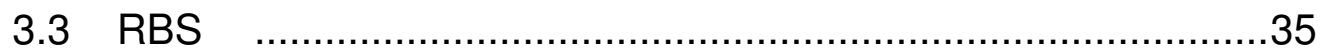

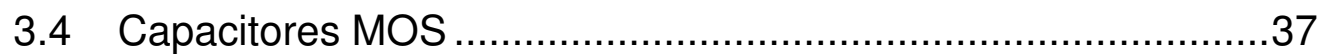

3.4.1 Capacitância x Tensão de Alta Freqüência (CV-AF) ........37

3.4.2 Corrente Elétrica x Tensão (I-V) …………………….....43

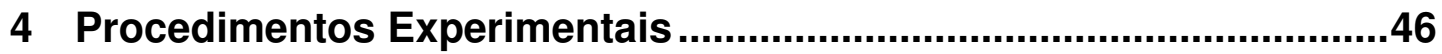


5 Resultados Obtidos e Discussões.....................................................55

5.1 Amostras depositadas com $\mathrm{F}_{\mathrm{TEOS}}=0,5 \mathrm{sccm} \ldots \ldots \ldots \ldots \ldots \ldots \ldots \ldots \ldots . . .55$

5.1.1 Temperatura do processo de deposição, $\mathrm{T}=30^{\circ} \mathrm{C} \ldots \ldots . .55$

5.1.2 Temperatura do processo de deposição, $\mathrm{T}=150^{\circ} \mathrm{C}$........70

5.1.3 Temperatura do processo de deposição, $\mathrm{T}=250^{\circ} \mathrm{C} \ldots \ldots .75$

5.2 Amostras depositadas com $\mathrm{F}_{\text {TEOS }}=1 \mathrm{sccm}$............................ 82

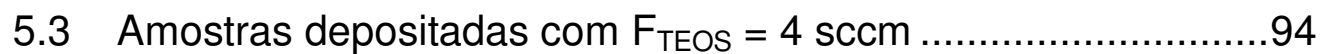

5.4 Influência do Fluxo de TEOS................................................100

5.5 Sumário das Principais Propriedades Elétricas .......................105

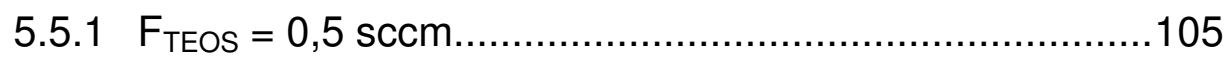

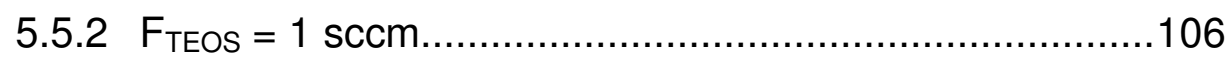

6 Conclusões e Considerações Finais ..............................................108

7 Sugestões para Futuros Trabalhos ................................................110

Anexo A - Modelo de Acoplamento Indutivo do Reator HD-PECVD.....112

Referências Bibliográficas ..............................................................116 


\section{LISTA DE FIGURAS}

Figura 1 Gráfico da taxa de deposição de um processo CVD em função do inverso da temperatura do sistema [9]. 11

Figura 2 Principais tipos de reatores empregados em CVD [9]. 12

Figura 3 Tipos de reatores LPCVD comumente utilizados: a) tubo horizontal (paredes quentes); b) isotérmico com fluxo vertical [9]. 14

Figura 4 Tipos de reatores PECVD comumente utilizados: a) placas paralelas; b) tubo horizontal; c) para lâmina individual [9].

Figura 5 Esquema do reator HD-PECVD. _ 30

Figura 6 Diferentes regiões do espectro eletromagnético.__ 34

Figura 7 Corte transversal de um capacitor MOS tipo-P polarizado na condição de inversão [38].

Figura 8 Comparação entre as curvas CV de alta e baixa freqüência [38].

Figura 9 Demonstração da obtenção da tensão de banda plana, a partir da curva CV-AF, através do valor da capacitância, Cox, na condição de banda plana do capacitor MOS [38].

Figura 10 Demonstração do processo de determinação das cargas efetivas a partir curva CV-AF [38].

Figura 11 Obtenção da tensão de ruptura da rigidez dielétrica do óxido de silício a partir de uma curva I-V teórica [38].

Figura 12 Índice de refração dos filmes de óxido de silício, em função do fluxo parcial de argônio, depositados a $30^{\circ} \mathrm{C}$ e com $\mathbf{F}_{\text {TEOS }}=0,5 \mathrm{sccm}$. Foram utilizadas as seguintes proporções de argônio, R: 20, 40, 50, 60 e 100.

Figura 13 Taxa de deposição e de corrosão dos filmes de óxido de silício, em função do fluxo parcial de argônio, depositados a $30^{\circ} \mathrm{C}$ e com $\mathbf{F}_{\text {TEOS }}=0,5 \mathrm{sccm}$. Foram utilizadas as seguintes proporções de argônio, R: 20, 40, 50, 60 e 100.

Figura 14 Espectros FTIRS dos filmes de óxido de silício, em função do fluxo parcial de argônio, depositados a $30^{\circ} \mathrm{C}$ e com $\mathbf{F}_{\text {TEOS }}=0,5 \mathrm{sccm}$. Foram utilizadas as seguintes proporções de argônio, R: 20, 40, 50, 60 e 100. 
Figura 15 Detalhe dos espectros FTIRS dos filmes de óxido de silício, em função do fluxo parcial de argônio, depositados a $30^{\circ} \mathrm{C}$ e com $F_{\text {TEOS }}=0,5 \mathrm{sccm}$. Foram utilizadas as seguintes proporções de argônio, R: $20,40,50,60$ e 100.

Figura 16 Comportamento da largura à meia altura (FWHM), atribuída a uma variação na composição estrutural e estresse residual, dos filmes de óxido de silício depositados a $30^{\circ} \mathrm{C}$ e com $\mathbf{F}_{\text {TEOS }}=0,5 \mathrm{sccm}$. Foram utilizadas as seguintes proporções de argônio, R: 20, 40, 50, 60 e 100.

Figura 17 Densidade e estequiometria dos filmes de óxido de silício, em função do fluxo parcial de argônio, depositados a $30^{\circ} \mathrm{C}$ e com $\mathbf{F}_{\text {TEOS }}=0,5 \mathrm{sccm}$. Foram utilizadas as seguintes proporções de argônio, R: $20,40,50,60$ e 100.

Figura 18 Curvas CV-AF de capacitores MOS implementados com filmes de óxido de silício, parametrizadas em função do fluxo parcial de argônio, depositados a $30^{\circ} \mathrm{C}$ e com $\mathbf{F}_{\text {TEOS }}=0,5 \mathrm{sccm}$. Foram utilizadas as seguintes proporções de argônio, R: 20, 40, 50 e 60.

Figura 19 Densidade efetiva de cargas obtidas a partir das curvas CV-AF de capacitores MOS implementados com filmes de óxido de silício, parametrizadas em função do fluxo parcial de argônio, depositados a $30^{\circ} \mathrm{C}$ e com $\mathbf{F}_{\text {TEOs }}=0,5 \mathrm{sccm}$. Foram utilizadas as seguintes proporções de argônio, R: 20, 40, 50 e 60. 65

Figura 20 Constante dielétrica obtida a partir das curvas CV-AF de capacitores MOS implementados com filmes de óxido de silício, parametrizadas em função do fluxo parcial de argônio, depositados a $30^{\circ} \mathrm{C}$ e com $\mathbf{F}_{\text {TEOS }}=0,5 \mathrm{sccm}$. Foram utilizadas as seguintes proporções de argônio, R: 20, 40, 50 e 60.

Figura 21 Densidade efetiva de cargas em função da espessura, obtidas a partir das curvas CV-AF de capacitores MOS implementados com filmes de óxido de silício em diferentes espessuras, parametrizadas em função do fluxo parcial de argônio, depositados a $30^{\circ} \mathrm{C}$ e com $\mathbf{F}_{\text {TEOS }}=0,5 \mathrm{sccm}$. Foram utilizadas as seguintes proporções de argônio, R: 20, 40, 50 e 60.

Figura 22 Curvas J-E obtidas a partir de capacitores MOS implementados com filmes de óxido de silício, parametrizadas em função do fluxo parcial de argônio, depositados a $30^{\circ} \mathrm{C}$ e com $\mathbf{F}_{\text {TEOS }}=0,5 \mathrm{sccm}$. Foram utilizadas as seguintes proporções de argônio, R: 20, 40, 50 e 60.

Figura 23 Densidade de corrente de fuga média obtida a partir das curvas J-E de capacitores MOS implementados com filmes de óxido de silício, parametrizadas em função do fluxo parcial de argônio, depositados a $30^{\circ} \mathrm{C}$ e com $\mathbf{F}_{\text {TEOS }}=0,5 \mathrm{sccm}$. Foram utilizadas as seguintes proporções de argônio, R: 20, 40, 50 e 60. 69 
Figura 24 Campo elétrico de ruptura da rigidez dielétrica médio obtidas a partir das curvas J-E de capacitores MOS implementados com filmes de óxido de silício, parametrizados em função do fluxo parcial de argônio, depositados a $30^{\circ} \mathrm{C}$ e com $\mathbf{F}_{\text {TEOs }}=0,5 \mathrm{sccm}$. Foram utilizadas as seguintes proporções de argônio, R: 20, 40, 50 e 60. 70

Figura 25 Índice de refração médio dos filmes de óxido de silício, em função do fluxo parcial de argônio, depositados a $150^{\circ} \mathrm{C}$ e com $\mathbf{F}_{\text {TEOS }}=0,5 \mathrm{sccm}$. Foram utilizadas as seguintes proporções de argônio, R: $20,40,50,60$ e 100.

Figura 26 Taxa de deposição e de corrosão dos filmes de óxido de silício, em função do fluxo parcial de argônio, depositados a $150^{\circ} \mathrm{C}$ e com $\mathbf{F}_{\text {TEOS }}=0,5 \mathrm{sccm}$. Foram utilizadas as seguintes proporções de argônio, R: $20,40,50,60$ e 100. 72

Figura 27 Espectros FTIRS dos filmes de óxido de silício, em função do fluxo parcial de argônio, depositados a $150^{\circ} \mathrm{C}$ e com $\mathbf{F}_{\text {TEOS }}=0,5 \mathrm{sccm}$. Foram utilizadas as seguintes proporções de argônio, R: 20, 40, 50, 60 e 100 .

Figura 28 Detalhe dos espectros FTIRS dos filmes de óxido de silício, em função do fluxo parcial de argônio, depositados a $150^{\circ} \mathrm{C}$ e com $\mathbf{F}_{\text {TEOS }}=0,5 \mathrm{sccm}$. Foram utilizadas as seguintes proporções de argônio, R: $20,40,50,60$ e 100.

Figura 29 Comportamento da largura à meia altura (FWHM), atribuída a uma variação na composição estrutural e estresse residual, dos filmes de óxido de silício depositados a $150^{\circ} \mathrm{C}$ e com $\mathbf{F}_{\text {TEOS }}=0,5 \mathrm{sccm}$. Foram utilizadas as seguintes proporções de argônio, R: 20, 40, 50, 60 e 100.

Figura 30 Índice de refração médio dos filmes de óxido de silício, em função do fluxo parcial de argônio, depositados a $250^{\circ} \mathrm{C}$ e com $\mathbf{F}_{\text {TEOS }}=0,5 \mathrm{sccm}$. Foram utilizadas as seguintes proporções de argônio, R: $20,40,50,60$ e 100.

Figura 31 Taxa de deposição e de corrosão dos filmes de óxido de silício, em função do fluxo parcial de argônio, depositados a $250^{\circ} \mathrm{C}$ e com $\mathbf{F}_{\text {TEOS }}=0,5 \mathrm{sccm}$. Foram utilizadas as seguintes proporções de argônio, R: 20, 40, 50, 60 e 100.

Figura 32 Espectros FTIRS dos filmes de óxido de silício, em função do fluxo parcial de argônio, depositados a $250^{\circ} \mathrm{C}$ e com $\mathbf{F}_{\text {TEOs }}=0,5 \mathrm{sccm}$. Foram utilizadas as seguintes proporções de argônio, R: 20, 40, 50, 60 e 100. 78

Figura 33 Detalhe dos espectros FTIRS dos filmes de óxido de silício, em função do fluxo parcial de argônio, depositados a $250^{\circ} \mathrm{C}$ e com $\mathbf{F}_{\text {TEOS }}=0,5 \mathrm{sccm}$. Foram utilizadas as seguintes proporções de argônio, R: $20,40,50,60$ e 100. 79 
Figura 34 Comportamento da largura à meia altura (FWHM), atribuída a uma variação na composição estrutural e estresse residual, dos filmes de óxido de silício depositados a $250^{\circ} \mathrm{C}$ e com $\mathbf{F}_{\text {TEOS }}=0,5 \mathrm{sccm}$. Foram utilizadas as seguintes proporções de argônio, R: 20, 40, 50, 60 e 100.

Figura 35 Variação do pico Si-O "stretching" dos filmes de óxido de silício, em função do fluxo parcial de argônio, parametrizados de acordo com a temperatura de deposição: 30,150 e $250^{\circ} \mathrm{C}$ e com $\mathbf{F}_{\text {TEOS }}=0,5 \mathrm{sccm}$. Foram utilizadas as seguintes proporções de argônio, R: 20, 40, 50, 60 e 100.

Figura 36 Índice de refração dos filmes de óxido de silício, em função do fluxo parcial de argônio, depositados a $30^{\circ} \mathrm{C}$ e com $\mathbf{F}_{\text {TEOS }}=1 \mathrm{sccm}$. Foram utilizadas as seguintes proporções de argônio, R: 20, 40, 50, 60 e 100.

Figura 37 Taxa de deposição e de corrosão dos filmes de óxido de silício, em função do fluxo parcial de argônio, depositados a $30^{\circ} \mathrm{C}$ e com $\mathbf{F}_{\text {TEOS }}=1 \mathrm{sccm}$. Foram utilizadas as seguintes proporções de argônio, R: $20,40,50,60$ e 100.

Figura 38 Espectros FTIRS dos filmes de óxido de silício, em função do fluxo parcial de argônio, depositados a $30^{\circ} \mathrm{C}$ e com $\mathbf{F}_{\text {TEOS }}=1 \mathrm{sccm}$. Foram utilizadas as seguintes proporções de argônio, R: 20, 40, 50, 60 e 100. 85

Figura 39 Detalhe dos espectros FTIRS dos filmes de óxido de silício, em função do fluxo parcial de argônio, depositados a $30^{\circ} \mathrm{C}$ e com $F_{\text {TEOS }}=1 \mathrm{sccm}$. Foram utilizadas as seguintes proporções de argônio, R: $20,40,50,60$ e 100. 86

Figura 40 Comportamento da largura à meia altura (FWHM), atribuída a uma variação na composição estrutural e estresse residual, dos filmes de óxido de silício depositados a $30^{\circ} \mathrm{C}$ e com $\mathbf{F}_{\mathrm{TEOS}}=1 \mathrm{sccm}$. Foram utilizadas as seguintes proporções de argônio, R: 20, 40, 50, 60 e 100.

Figura 41 Curvas CV-AF de capacitores MOS implementados com filmes de óxido de silício, parametrizadas em função do fluxo parcial de argônio, depositados a $30^{\circ} \mathrm{C}$ e com $\mathbf{F}_{\text {TEOS }}=1 \mathrm{sccm}$. Foram utilizadas as seguintes proporções de argônio, R: 20, 40, 50 e 60. 88

Figura 42 Constante dielétrica obtidas a partir das curvas CV-AF de capacitores MOS implementados com filmes de óxido de silício, parametrizadas em função do fluxo parcial de argônio, depositados a $30^{\circ} \mathrm{C}$ e com $\mathbf{F}_{\mathrm{TEOS}}=1 \mathrm{sccm}$. Foram utilizadas as seguintes proporções de argônio, R: 20, 40, 50 e 60. 89 
Figura 43 Densidade efetiva de cargas obtidas a partir das curvas CV-AF de capacitores MOS implementados com filmes de óxido de silício, parametrizadas em função do fluxo parcial de argônio, depositados a $30^{\circ} \mathrm{C}$ e com $\mathbf{F}_{\text {TEOS }}=1 \mathrm{sccm}$. Foram utilizadas as seguintes proporções de argônio, R: 20, 40, 50 e 60. 90

Figura 44 Densidade efetiva de cargas em função da espessura, obtidas a partir das curvas CV-AF de capacitores MOS implementados com filmes de óxido de silício em diferentes espessuras, parametrizadas em função do fluxo parcial de argônio, depositados a $30^{\circ} \mathrm{C}$ e com $\mathbf{F}_{\text {TEOS }}=1 \mathrm{sccm}$. Foram utilizadas as seguintes proporções de argônio, R: 20, 40, 50 e 60.

Figura 45 Curvas J-E obtidas a partir de capacitores MOS implementados com filmes de óxido de silício, parametrizadas em função do fluxo parcial de argônio, depositados a $30^{\circ} \mathrm{C}$ e com $\mathbf{F}_{\text {TEOS }}=1 \mathrm{sccm}$. Foram utilizadas as seguintes proporções de argônio, R: 20, 40, 50 e 60. _ 92

Figura 46 Densidade de corrente de fuga média obtida a partir das curvas J-E de capacitores MOS implementados com filmes de óxido de silício, parametrizadas em função do fluxo parcial de argônio, depositados a $30^{\circ} \mathrm{C}$ e com $\mathbf{F}_{\mathrm{TEOS}}=1 \mathrm{sccm}$. Foram utilizadas as seguintes proporções de argônio, R: 20, 40, 50 e 60.

Figura 47 Campo elétrico de ruptura da rigidez dielétrica médio obtidas a partir das curvas J-E de capacitores MOS implementados com filmes de óxido de silício, parametrizados em função do fluxo parcial de argônio, depositados a $30^{\circ} \mathrm{C}$ e com $\mathbf{F}_{\text {TEOs }}=1 \mathrm{sccm}$. Foram utilizadas as seguintes proporções de argônio, R: 20, 40, 50 e 60.

Figura 48 Índice de refração médio dos filmes de óxido de silício, em função do fluxo parcial de argônio, depositados a $30^{\circ} \mathrm{C}$ e com $F_{\text {TEOS }}=4 \mathrm{sccm}$. Foram utilizadas as seguintes proporções de argônio, R: $20,40,50$ e 60 . 95

Figura 49 Taxa de deposição e de corrosão dos filmes de óxido de silício, em função do fluxo parcial de argônio, depositados a $30^{\circ} \mathrm{C}$ e com $F_{\text {TEOS }}=4 \mathrm{sccm}$. Foram utilizadas as seguintes proporções de argônio, R: $20,40,50$ e 60. 96

Figura 50 Espectros FTIRS dos filmes de óxido de silício, em função do fluxo parcial de argônio, depositados a $30^{\circ} \mathrm{C}$ e com $F_{\text {TEOS }}=4 \mathrm{sccm}$. Foram utilizadas as seguintes proporções de argônio, R: 20, 40, 50 e 60.

Figura 51 Detalhe dos espectros FTIRS dos filmes de óxido de silício, em função do fluxo parcial de argônio, depositados a $30^{\circ} \mathrm{C}$ e com $\mathbf{F}_{\text {TEOS }}=4 \mathrm{sccm}$. Foram utilizadas as seguintes proporções de argônio, R: $20,40,50$ e 60 . 98 
Figura 52 Comportamento da largura à meia altura (FWHM), atribuída a uma variação na composição estrutural e estresse residual, dos filmes de óxido de silício depositados a $30^{\circ} \mathrm{C}$ e com $\mathbf{F}_{\text {TEOS }}=4 \mathrm{sccm}$. Foram utilizadas as seguintes proporções de argônio, R: 20, 40, 50, 60 e 100.

Figura 53 Densidade e estequiometria dos filmes de óxido de silício, em função do fluxo parcial de argônio, depositados a $30^{\circ} \mathrm{C}$ e com $F_{\text {TEOS }}=4 \mathrm{sccm}$. Foram utilizadas as seguintes proporções de argônio, R: $20,40,50$ e 60. 100

Figura 54 Espectros FTIRS dos filmes de óxido de silício, em função do fluxo de TEOS, depositados a $30^{\circ} \mathrm{C}$ e com $\mathbf{R}=50$. 101

Figura 55 Detalhe dos espectros FTIRS dos filmes de óxido de silício, em função do fluxo de TEOS, depositados a $30^{\circ} \mathrm{C}$ e com $\mathbf{R}=50$. 102

Figura 56 Comportamento da largura à meia altura (FWHM), atribuída a uma variação na composição estrutural e estresse residual, em função do fluxo de TEOS, de filmes de óxido de silício depositados a $30^{\circ} \mathrm{C}$ e com $\mathbf{R}=50$. 103

Figura 57 Densidade e estequiometria dos filmes de óxido de silício, em função em função do fluxo de TEOS, depositados a $30^{\circ} \mathrm{C}$ e com $\mathbf{R}=50$. 104

Figura 58 Circuito elétrico equivalente ao modelo de acoplamento indutivo do reator HD-PECVD. 112 


\section{LISTA DE TABELAS}

Tabela 1 Lista dos principais gases utilizados na deposição de óxido de silício por PECVD [11].

Tabela 2 Parâmetros de processo utilizados na deposição dos filmes de óxido de silício.

Tabela 3 Condições utilizadas na etapa processos de litografia para definição das regiões de contato de porta dos capacitores MOS. 52

Tabela 4 Volume dos reagentes da solução de corrosão de alumínio._ 52

Tabela 5 Parâmetros de tensão aplicados entre os eletrodos dos capacitores MOS durante a medida das curvas CV-AF.

Tabela 6 Parâmetros de tensão aplicados entre os eletrodos dos capacitores MOS durante a medida das curvas IV.

Tabela 7 Propriedades elétricas obtidas através de curvas CV-AF de capacitores MOS implementados com filmes de óxido de silício, parametrizadas em função do fluxo parcial de argônio, depositados a $30^{\circ} \mathrm{C}$ e com $\mathbf{F}_{\text {TEOs }}=0,5 \mathrm{sccm}$. Foram utilizadas as seguintes proporções de argônio, R: 20, 40, 50 e 60. 105

Tabela 8 Propriedades elétricas obtidas através de curvas J-E de capacitores MOS implementados com filmes de óxido de silício, parametrizadas em função do fluxo parcial de argônio, depositados a $30^{\circ} \mathrm{C}$ e com $\mathbf{F}_{\text {TEOS }}=0,5 \mathrm{sccm}$. Foram utilizadas as seguintes proporções de argônio, R: 20, 40, 50 e 60. 106

Tabela 9 Propriedades elétricas obtidas através de curvas CV-AF de capacitores MOS implementados com filmes de óxido de silício, parametrizadas em função do fluxo parcial de argônio, depositados a $30^{\circ} \mathrm{C}$ e com $\mathbf{F}_{\text {TEOS }}=1 \mathrm{sccm}$. Foram utilizadas as seguintes proporções de argônio, R: 20, 40, 50 e 60. 106

Tabela 10 Propriedades elétricas obtidas através de curvas J-E de capacitores MOS implementados com filmes de óxido de silício, parametrizadas em função do fluxo parcial de argônio, depositados a $30^{\circ} \mathrm{C}$ e com $\mathbf{F}_{\text {TEOS }}=1 \mathrm{sccm}$. Foram utilizadas as seguintes proporções de argônio, R: 20, 40, 50 e 60. 107 


\section{LISTA DE SIGLAS}

$\begin{array}{ll}\text { APCVD } & \text { Atmospheric Pressure Chemical Vapor Deposition } \\ \text { CVD } & \text { Chemical Vapor Deposition } \\ \text { CV-AF } & \text { Capacitância versus Tensão em alta freqüência } \\ \text { DI } & \text { Deionizada } \\ \text { ECR } & \text { Electron Cyclotron Resonance } \\ \text { FTIRS } & \text { Fourier Transform Infra Red Spectroscopy } \\ \text { FWHM } & \text { Full Width at Half Maximum } \\ \text { HD-PECVD } & \text { High-Density Plasma Enhanced Chemical Vapor Deposition } \\ \text { IPA } & \text { Isopropanol } \\ \text { I-V } & \text { Corrente elétrica versus Tensão } \\ \text { J-E } & \text { Densidade de Corrente elétrica versus Campo elétrico } \\ \text { LAMFI } & \text { Laboratório de Análise de Materiais por Feixes lônicos } \\ \text { LPCVD } & \text { Low Pressure Chemical Vapor Deposition } \\ \text { LSI } & \text { Laboratório de Sistemas Integráveis } \\ \text { MEMS } & \text { Micro Electrical Mechanical Systems } \\ \text { MFC } & \text { Mass Flow Controllers } \\ \text { MOS } & \text { Metal-Óxido-Semicondutor } \\ \text { PECVD } & \text { Plasma Enhanced Chemical Vapor Deposition } \\ \end{array}$




$\begin{array}{ll}\text { RBS } & \text { Rutherford Backscattering Spectrometry } \\ \text { RF } & \text { Rádio Freqüência } \\ \text { RPECVD } & \text { Remote Plasma Enhanced Chemical Vapor Deposition } \\ \text { TEOS } & \text { Tetraetilortosilicato } \\ \text { TFT } & \text { Thin Film Transistor } \\ \text { TMAH } & \text { Tetra Methyl Ammonium Hydroxide } \\ \text { UV } & \text { Ultravioleta } \\ \text { VLSI } & \text { Very Large Scale Integration }\end{array}$




\section{INTRODUÇÃo}

O óxido de silício é um material dielétrico bastante empregado em microeletrônica devido às suas propriedades elétricas e físicas. Filmes de óxido de silício obtidos por deposição química a vapor (CVD - "Chemical Vapor Deposition") são abordados em uma vasta área de estudos para aplicações como: dielétrico na construção de componentes discretos tais como transistores de filmes finos (TFTs - "Thin Film Transistors"), na implementação de camadas isolantes na interconexão elétrica de circuitos integrados em alta escala de integração, em camadas sacrificiais na tecnologia MEMS ("Micro Electrical Mechanical Systems"), entre outros [1]-[11].

A deposição de filmes de óxido de silício utilizando vapor de TEOS [Si $\left.\left(\mathrm{OC}_{2} \mathrm{H}_{5}\right)_{4}\right]$, como fonte de silício, em sistemas PECVD ("Plasma Enhanced Chemical Vapor Deposition") de acoplamento capacitivo tem sido bastante estudada nas últimas décadas. Em alguns casos, devido a baixa temperatura de deposição $\left(<400^{\circ} \mathrm{C}\right)$, essa técnica tornou-se uma alternativa de grande interesse para a obtenção de filmes finos de óxido de silício, depositados através da reação entre TEOS e $\mathrm{O}_{2}$, empregados na construção de TFTs. Porém, alguns estudos mostraram que o comportamento elétrico destes filmes não atendia às exigências mínimas para sua aplicação como dielétrico de porta de dispositivos MOS [3]-[7]. A principal razão para este 
desempenho se deve à presença indesejada de subprodutos das reações químicas do TEOS resultando na incorporação de ligações químicas do tipo O-H, carbono e água, degradando, desta maneira, as propriedades estruturais e elétricas dos filmes depositados [5],[6],[12],[20],[21].

Desta maneira, este trabalho foi desenvolvido tendo como principal objetivo a caracterização de um sistema HD-PECVD para a deposição de filmes finos de óxido de silício com propriedades elétricas e estruturais adequadas à tecnologia de TFTs, a baixas temperaturas (menores que $100^{\circ} \mathrm{C}$ ) e utilizando TEOS como fonte de silício.

\subsection{Resultados Anteriores do Grupo de Pesquisa}

Este trabalho é continuidade de trabalhos anteriores e está inserido no grupo de pesquisa de processos CVD do Laboratório de Sistemas Integráveis (LSI), departamento de sistemas eletrônicos (PSI) da Escola Politécnica da Universidade de São Paulo (EPUSP).

\subsubsection{Breve Histórico}

Inicialmente, um sistema de deposição do tipo "cluster tools" foi projetado e desenvolvido como trabalho de doutorado [13],[33]. Esse sistema era constituído de três câmaras de processo: uma câmara capacitiva com plasma de RF, uma com plasma remoto de microondas e uma câmara para recozimentos térmicos rápidos. Filmes de óxido de silício não dopados a partir de TEOS eram obtidos a baixas temperaturas $\left(<400^{\circ} \mathrm{C}\right)$. A deposição de filmes de óxido de silício dopados (boro e fósforo) 
era possível através de duas outras fontes orgânicas.

Diversos trabalhos de mestrado e doutorado foram realizados e muitas modificações e variações foram propostas e realizadas no sistema [14] - [18],[22],[47].

Em 2002, foi produzida uma tese de doutorado apresentou uma proposta de modificação da câmara a microondas e a transformou em um reator ICP*, para a realização de processos do tipo HD-PECVD [23],[24], e os resultados iniciais são apresentados.

\subsubsection{Características dos Filmes Depositados}

Neste item, são apresentados os resultados iniciais, anteriormente obtidos no sistema HD-PECVD, recém modificado. Os parâmetros de deposição dos filmes de óxido de silício com as melhores propriedades são: $F_{\text {TEOS }}=0,5 \mathrm{sccm}, \mathrm{F}_{\mathrm{O} 2}=60 \mathrm{sccm}, \mathrm{P}=30 \mathrm{mtorr}, \mathrm{T}=375^{\circ} \mathrm{C}$ e $\mathrm{W}_{\mathrm{RF}}=200 \mathrm{~W}$. As propriedades elétricas obtidas para esses filmes foram: "QSS $=2,0 \times 10^{12} \mathrm{~cm}^{-2 n}, \quad " E_{B D}=10,6 \mathrm{MV} / \mathrm{cm}^{\prime}$ e "J $\mathrm{JKK}_{\mathrm{LK}}=2,8 \times 10^{-5} \mathrm{~A} / \mathrm{cm}^{2 n}$ para um campo elétrico de $4 \mathrm{MV} / \mathrm{cm}$.

Assim sendo, o atual trabalho contribui para a evolução dos trabalhos do grupo, realizando a caracterização dos filmes de óxido de silício, através do referido sistema, em uma região de processamento que ainda não foi estudada.

"ICP - Induced Coupled Plasma. 


\subsection{Objetivos}

Além de se obter filmes de óxido de silício com as propriedades elétricas e estruturais adequadas para a fabricação de transistores de filmes finos, pretende-se sobretudo, compreender os fenômenos que regem o processo de deposição química sob um plasma de alta densidade. Assim sendo, este objetivo faz parte de um contexto maior, que busca encontrar o caminho adequado para a obtenção de filmes de óxido de silício depositados a partir de TEOS com propriedades elétricas de alta qualidade. Ou seja, com uma densidade efetiva de cargas da ordem de $10^{10} \mathrm{~cm}^{-2}$, densidade de corrente de fuga abaixo de $10^{-9} \mathrm{~A} / \mathrm{cm}^{2}$ e tensão de ruptura superior a $10 \mathrm{MV} / \mathrm{cm}[2],[4]$.

Assim, para a realização deste trabalho, foi utilizado um reator de plasma de alta densidade de acoplamento indutivo planar e como fonte de silício o TEOS (tetraetilortosilicato) misturado a um fluxo de oxigênio e um fluxo adicional de argônio. Este sistema, permite deposições de filmes de óxido de silício a temperaturas muito baixas, desde a ambiente até $300^{\circ} \mathrm{C}$. Em microeletrônica, processos de fabricação realizados em baixas temperaturas garantem uma diminuição significativa nos custos de fabricação e na complexidade de processos subseqüentes [1]. Desta forma, neste trabalho, uma maior atenção foi dada ao estudo dos filmes obtidos em temperatura ambiente ou temperaturas menores que $100^{\circ} \mathrm{C}$. Uma otimização do processo de deposição será realizada de modo que os filmes estudados neste trabalho sejam utilizados como dielétrico em transistores de filmes finos de futuros trabalhos. 


\subsection{Metodologia}

Este trabalho foi desenvolvido de acordo com a seqüência apresentada a seguir:

Revisão bibliográfica: são abordados os conceitos teóricos que descrevem os principais processos pelos quais os filmes de óxido de silício são obtidos, tais como os processos de deposição química a vapor a baixas pressões e suas variantes, com maior ênfase aos processos que utilizam o plasma como fonte auxiliar de energia, onde serão discutidas as influências dos principais parâmetros de deposição sobre as características dos filmes de óxido de silício depositado. Finalizando a revisão bibliográfica, são apresentadas as técnicas utilizadas para a caracterização dos filmes finos de óxido de silício.

Parte Experimental e Resultados: Os filmes de óxido de silício foram depositados em um sistema de deposição química a vapor assistida por plasma de alta densidade (HD-PECVD - "High Density Plasma Enhanced Chemical Vapor Deposition") através de uma mistura gasosa de TEOS, oxigênio e argônio; em temperatura ambiente. Foram utilizadas as seguintes técnicas de caracterização: Espectrometria no infravermelho por transformada de Fourier (FTIRS - "Fourier Transform Infra-Red Spectrometry"); elipsometria; taxa de deposição e de corrosão, etc.; para a análise física e estrutural dos filmes obtidos. Além disso, capacitores MOS (Metal - Óxido - Semicondutor) foram implementados com os filmes de óxido de silício depositados para a extração dos parâmetros elétricos: tensão de banda plana, campo elétrico de ruptura da rigidez dielétrica, densidade de 
cargas efetivas, corrente de fuga, etc.; a partir de curvas "capacitância x tensão" (CV) de alta freqüência e curvas "corrente x tensão" (I-V). Os dados deste estudo são então discutidos e, por fim, são apresentadas as conclusões e considerações finais deste trabalho.

Perspectivas e Próximas Etapas: Na parte final deste trabalho, são expostos os dados mais relevantes dessa pesquisa e as próximas etapas a serem realizadas com a finalidade de, eventualmente, implementar os transistores de filmes finos com os filmes de oxido de silício estudados. 


\section{Revisão Bibliográfica sobre Filmes de Óxido de Silícıo Obtidos a BaiXa Temperatura}

Neste capítulo, são discutidos os conceitos básicos sobre o processo de deposição química a vapor, bem como, as técnicas existentes. Uma atenção especial é destinada aos processos PECVD, onde são tratadas as particularidades dessa técnica levando-se em consideração a influência dos seus principais parâmetros de processo nas características dos filmes de óxido de silício obtidos. Por fim, são abordadas as características do reator utilizado especificamente neste trabalho.

Os filmes de óxido de silício depositados representam, atualmente, materiais dielétricos bastante empregados em microeletrônica devido às suas propriedades elétricas, mecânicas, físicas e químicas. Filmes de óxido de silício obtidos pela técnica de deposição química a vapor e suas variantes (CVD - "Chemical Vapor Deposition") são abordados em uma vasta área de estudos para aplicações como: dielétrico na construção de componentes discretos, tais como, transistores de filmes finos [5],[6], bem como, na implementação de camadas isolantes para a interconexão elétrica de circuitos integrados em escala muito alta de integração (VLSI - "Very Large Scale Integration") [5], em camadas sacrificiais na tecnologia MEMS ("Micro Electrical Mechanical Systems"), na utilização de substratos sem estabilidade térmica, tais como: metais, cerâmicas, diversos tipos de plásticos e/ou polímeros, entre outros. 
$\mathrm{Na}$ primeira etapa deste trabalho, foram estudadas as propriedades elétricas e físicas de filmes de óxido de silício depositados através da técnica HD-PECVD em baixas temperaturas (menores do que $100^{\circ} \mathrm{C}$ ) e utilizando 0 TEOS $\left[\mathrm{Si}\left(\mathrm{OC}_{2} \mathrm{H}_{5}\right)_{4}\right]$ como fonte de silício para a deposição dos filmes. $\mathrm{O}$ TEOS possui vantagens em relação a silana $\left(\mathrm{SiH}_{4}\right)$ - amplamente utilizada para obtenção de filmes de óxido de silício através das variantes das técnicas CVD - em termos de cobertura de degrau de superfícies com diferentes níveis [5],[7], oferece maior segurança ao operador quanto à toxidade [5] e por não ser um reagente explosivo ou tóxico.

\subsection{Conceitos Básicos sobre Deposição Química a Vapor}

A deposição química a vapor vem se tornando, durante as últimas décadas, o método de deposição de filmes finos mais popular dentro da indústria de dispositivos semicondutores. Isso se deve à versatilidade e abrangência da técnica, principalmente no setor de microeletrônica [8],[9].

Basicamente, um processo de deposição química a vapor pode ser definido como sendo aquele onde a formação e/ou deposição de filmes sólidos não-voláteis, sobre a superfície de um substrato, ocorre através da reação físico-química dos gases reagentes e diluentes na fase vapor que contêm os compostos necessários para a deposição do filme do material desejado.

Tipicamente, um processo CVD obedece as seguintes etapas [10]:

a. O transporte dos reagentes e diluentes, em fase gasosa, para a câmara de processos onde se encontra o substrato; 
b. A reação dos gases para a formação de moléculas e espécies ativas que farão parte do filme depositado;

c. O transporte dos reagentes para a superfície da amostra;

d. Ocorrência das reações químicas próximas ou na própria superfície do substrato;

e. Dessorção dos subprodutos da reação química da superfície da amostra;

f. Transporte dos subprodutos para longe da superfície da amostra;

g. Remoção dos subprodutos da câmara de processos.

As reações químicas descritas nas etapas anteriores não ocorrem de forma espontânea, para isso é necessário fornecer algum tipo de energia para o sistema. Para tanto, a energia pode advir de diferentes meios (energia térmica, fótons, elétrons, descargas elétricas, etc.). Geralmente, é adotada a energia térmica para favorecer o processo de deposição.

Existem dois tipos de reações químicas conhecidas em um processo CVD:

a. Reações homogêneas: são aquelas que ocorrem ainda em fase gasosa, isso é, as espécies ativas que irão compor o filme adquirem sua estrutura química final antes de chegar à superfície do substrato (geralmente essas reações ocorrem nas proximidades da superfície do substrato).

b. Reações heterogêneas: as espécies ativas concluem a reação química a partir do momento em que alcançam um sítio ativo na 
superfície do substrato.

Dentre as reações descritas anteriormente, é preferível que as reações químicas que resultarão no filme depositado sejam as heterogêneas uma vez que este tipo de reação oferece melhor qualidade para os filmes depositados em relação à composição química (maior grau de pureza) e uniformidade de espessura. Assim, em processos de deposição por CVD, procura-se o favorecimento das reações heterogêneas dentro do sistema, pois, as reações homogêneas podem gerar particulados sólidos indesejáveis [8]-[10].

Uma série de reações pode ocorrer na superfície aquecida de um substrato porém, de forma geral, podemos modelar a taxa de reação química $R$ através de uma relação de Arrhenius determinada por:

Eq. 1

$$
R=R_{0} \cdot e^{-\left(E_{A} / k T\right)}
$$

Onde:

$R_{0} \rightarrow$ constante;

$E_{A} \rightarrow$ energia de ativação $(\mathrm{eV})$

$k \quad \rightarrow$ constante de Boltzmann $\left(\mathrm{eV} . \mathrm{K}^{-1}\right)$;

$T \quad \rightarrow$ temperatura $(\mathrm{K})$.

Como indica a Eq. 1, se a temperatura da superfície do substrato (energia do sistema) for aumentada, um aumento na taxa de reação química será favorecido. Porém, se a temperatura atingir valores muitos altos de 
modo que a taxa de reação química superficial exceda a taxa de chegada dos reagentes na superfície do substrato, a deposição será limitada pela taxa de transporte de massa dos reagentes dentro do sistema de CVD. Por outro lado, se a temperatura for relativamente baixa, a taxa de reação química tende a ser reduzida e, consequentemente, a taxa de chegada de reagentes na superfície da amostra excede a taxa no qual os mesmos são consumidos pelas reações superficiais; dessa forma, a deposição passa a ser limitada pela taxa de reação química. Na Figura 1 pode ser observado o comportamento da taxa de deposição da técnica CVD em função do inverso da temperatura do sistema.

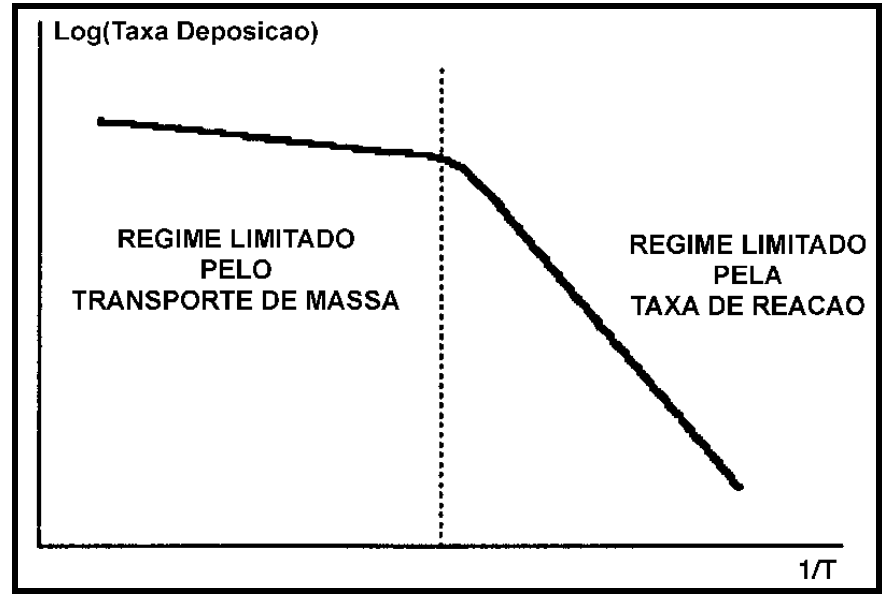

Figura 1 Gráfico da taxa de deposição de um processo CVD em função do inverso da temperatura do sistema [9].

\subsection{Os sistemas CVD e suas variantes}

Um sistema de CVD é composto basicamente por [9]:

a. Fontes de gases (reagentes e diluentes);

b. Linhas de gases (aquecidas ou não);

c. Controladores de fluxo em massa (MFC - "Mass Flow Controllers") 
que controlam o fluxo de gases e/ou vapores que alimentam o sistema de deposição;

d. Câmara de reações ou reator;

e. Fonte de energia para promoção das reações do processo, normalmente uma fonte térmica para o aquecimento do substrato;

f. Controladores de temperatura;

Para sistemas onde o processo de deposição ocorre em baixas pressões, é necessário um sistema de vácuo incluindo bombas e medidores de pressão.

$\mathrm{Na}$ Figura 2, são apresentados os principais tipos de reatores empregados em processos CVD:

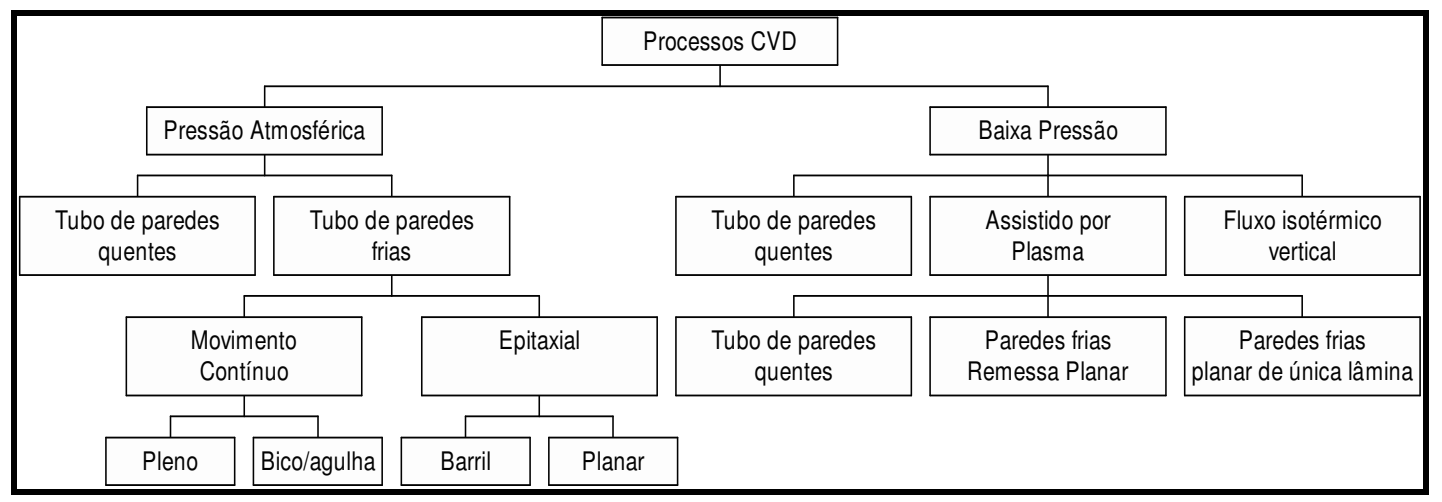

Figura 2 Principais tipos de reatores empregados em CVD [9].

Um dos primeiros sistemas de deposição química a vapor utilizados industrialmente foi o sistema de Deposição Química a Vapor à Pressão Atmosférica (APCVD - "Atmospheric Pressure CVD"). Um dos principais fatores que influenciou na aplicação de sistemas APCVD inicialmente foi o seu custo, pois, os equipamentos necessários para a implementação de tais sistemas eram tecnicamente bem mais simples e relativamente baratos. 
Além disso, a técnica APCVD possui como vantagem elevadas taxas de deposição. Por outro lado, em função dessa técnica oferecer uma maior probabilidade de ocorrência de reações homogêneas, os filmes obtidos por APCVD geralmente apresentam uma pobre cobertura de degrau e baixa aderência, além de produzir filmes com qualidade elétrica pobre [8]-[10]. Geralmente, para a obtenção de filmes de óxido de silício por APCVD, utiliza-se a reação entre silana e oxigênio, Eq. 2.

Eq. 2

$$
\mathrm{SiH}_{4}+\mathrm{O}_{2} \rightarrow \mathrm{SiO}_{2}+2 \mathrm{H}_{2}
$$

Com o avanço tecnológico, foi necessário implementar um sistema de deposição química a vapor que fornecesse filmes com qualidade superior aos obtidos por APCVD, principalmente em relação à cobertura de degrau e a aderência dos filmes. Assim, foi desenvolvida a técnica de Deposição Química a Vapor à Baixa Pressão (LPCVD - "Low Pressure CVD"). A deposição de filmes finos a baixa pressão é um processo que apresenta características superiores em termos de uniformidade, cobertura de degrau, aderência e contaminação por particulados sólidos quando comparado ao processo APCVD [8]-[10].

O processo de LPCVD, opera geralmente a pressões da ordem de 0,1 a 1 torr e a temperaturas relativamente altas (superiores a $500^{\circ} \mathrm{C}$ ) tornando, dessa forma, o processo de deposição em regime limitado pela taxa de reação da mistura gasosa; por isso, a técnica de LPCVD oferece taxas de deposição significativamente menores se comparadas aos processos APCVD. 
Na Figura 3, observam-se dois tipos de reatores LPCVD comumente utilizados.

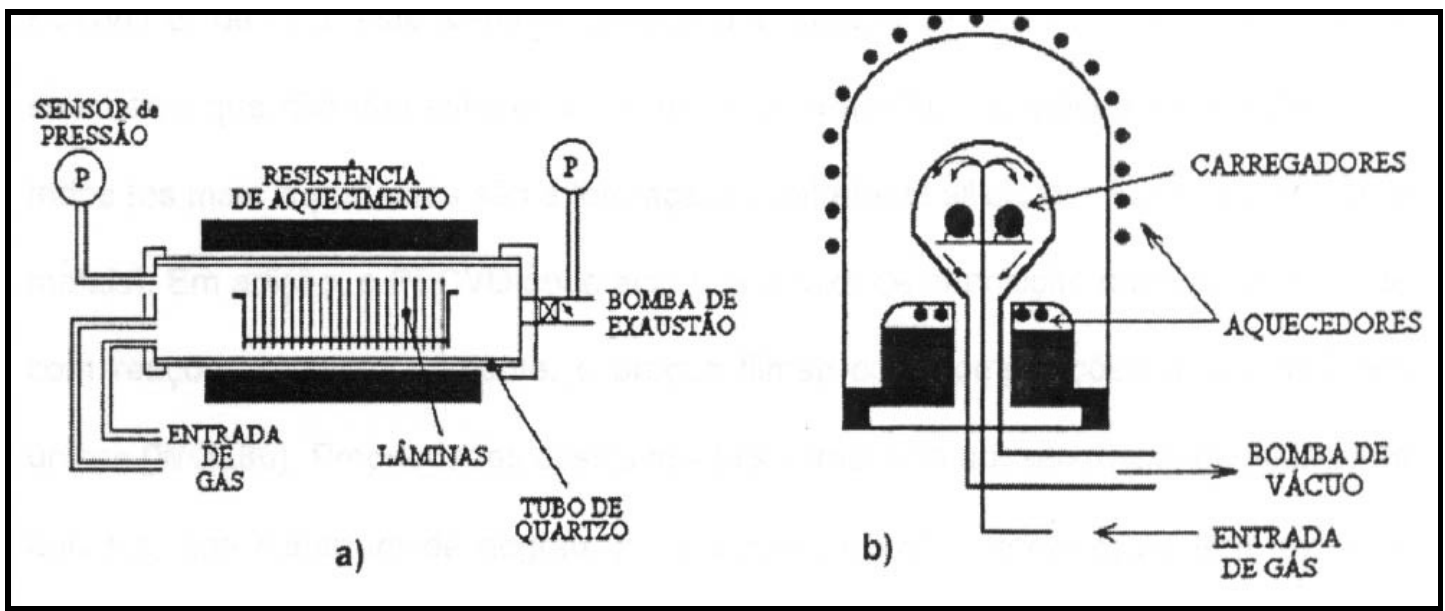

Figura 3 Tipos de reatores LPCVD comumente utilizados: a) tubo horizontal (paredes quentes); b) isotérmico com fluxo vertical [9].

A partir da técnica de deposição por LPCVD, é possível obter-se filmes com boas propriedades elétricas. Porém, por ser um processo realizado a temperaturas relativamente altas, a técnica de LPCVD não pode ser aplicada quando é necessário realizar a deposição de filmes finos sobre substratos que não possuam estabilidade térmica a temperaturas elevadas.

Em vista da necessidade da deposição de filmes finos em baixas temperaturas, foram desenvolvidos reatores de Deposição Química a Vapor Enriquecidos por Plasma (PECVD).

Os sistemas de PECVD, além de operarem sob baixas pressões, possuem como principal característica uma fonte auxiliar de energia para promover e sustentar as reações químicas entre as espécies gasosas. Além da energia térmica, utiliza-se um campo elétrico de rádio freqüência $(R F)$ que induz uma descarga elétrica que, por sua vez, transfere energia às 
moléculas dos gases reagentes e diluentes gerando radicais livres que promovem a deposição do filme. Dessa maneira, a temperatura do substrato durante 0 processo PECVD pode ser significativamente reduzida. Tal característica torna essa técnica um grande atrativo para processos de deposição de filmes finos sobre a superfície de materiais que possuam uma baixa estabilidade térmica. Um exemplo de aplicação da técnica de PECVD é a deposição de óxido de silício sobre alumínio ou substratos de materiais poliméricos.

Um outro fator importante da técnica de deposição química por PECVD é que ela oferece a possibilidade da variação da taxa de deposição dos filmes em função do controle de parâmetros do processo tais como: potência do sinal de RF, temperatura, fluxo dos gases, etc. Outra vantagem da aplicação da técnica de PECVD é a obtenção de filmes com boa cobertura de degrau, boa aderência, conformidade e uniformidade, além da qualidade elétrica adequada para diversas aplicações em microeletrônica [8]-[10].

\subsection{O processo PECVD}

O processo PECVD, além de um sistema de aquecimento do substrato, também utiliza o plasma como fonte auxiliar para fornecer energia para decompor as espécies gasosas que, por sua vez, servirão como fonte das espécies precursoras do filme depositado. O plasma é utilizado no processo PECVD por meio da aplicação de um campo eletromagnético, com freqüência na faixa de RF, a um gás confinado e mantido sob baixa pressão, 
por meio de eletrodos; com isso, criam-se elétrons livres, internamente à região dessa descarga elétrica dando-Ihe uma característica luminescente.

Os elétrons livres, que estão confinados entre a região dos eletrodos, sofrem a influência do campo elétrico e ganham energia suficiente para que, quando colidirem com as moléculas da mistura gasosa, auxiliem na dissociação e ionização das moléculas e espécies químicas.

É importante lembrar que o plasma, assim como outros fenômenos naturais, procura se manter na melhor condição de estabilidade, ou seja, apesar de manter a geração de íons e elétrons livres, o plasma se encontra em uma condição de neutralidade de cargas o que significa que, teoricamente, dentro do plasma existe a mesma densidade de elétrons e íons em todos os pontos sob a influência do campo de RF [8].

Dentre as espécies energéticas geradas no plasma, os radicais surgem em maior concentração e são altamente reativos, logo, são facilmente adsorvidos na superfície da amostra. Os radicais também possuem uma grande facilidade de migrar pela superfície do substrato após o processo de adsorção e possuem alto coeficiente de aderência. Estes fatores colaboram para que o resultado final do processo de deposição de filmes apresente excelente conformidade e aderência sobre toda a superfície das amostras.

À medida que os radicais são adsorvidos, a superfície da amostra também sofre um bombardeamento iônico ocorrendo, dessa forma, um rearranjo entre essas espécies e a reação físico-química com outras espécies adsorvidas favorecendo novas ligações, a formação e a deposição 
do filme. O rearranjo das espécies adsorvidas está relacionado com a difusão para posições estáveis ou sítios ativos que, por sua vez, estão associados à temperatura da amostra.

Em geral, os filmes depositados pela técnica PECVD não são estequiométricos, pois, as reações químicas que ocorrem durante o processo de deposição são muito variadas e complexas. Além disso, alguns subprodutos e diferentes espécies são incorporadas aos filmes juntamente com as espécies desejáveis, dependendo da concentração desses contaminantes, pode-se favorecer a ocorrência de problemas tais como trincas e descascamento do filme em eventuais processos de fabricação de componentes eletrônicos. Por isso, um bom controle dos parâmetros de processo tais como: pressão da câmara, potência do sinal de RF, fluxo e composição da mistura dos gases reagentes, temperatura do substrato, etc. faz-se necessário para garantir a qualidade e as características desejadas do filme depositado.

\subsubsection{Reagentes utilizados na deposição de filmes de óxido de silício}

São diferentes as possibilidades de obtenção de filmes de óxido de silício em vista das combinações possíveis de tipos de reagentes sob a forma gasosa e a concentração dos mesmos. Na Tabela 1 são observadas as combinações de reagentes mais utilizadas nos processos de deposição de óxido de silício por PECVD. 
Tabela 1 Lista dos principais gases utilizados na deposição de óxido de silício por PECVD [11].

\begin{tabular}{c}
\hline$\frac{\text { Gases utilizados no plasma }}{\mathrm{SiH}_{4}+\mathrm{N}_{2} \mathrm{O}}$ \\
$\frac{\mathrm{SiCl}_{4}+\mathrm{O}_{2}}{\mathrm{SiH}_{4}+\mathrm{O}_{2} \text { (com ou sem adição de } \mathrm{N}_{2} \text { ou } \mathrm{Ar} \text { ) }}$ \\
\hline$\underline{\left.\mathrm{Si}\left(\mathrm{OC}_{2} \mathrm{H}_{5}\right)_{4}+\mathrm{O}_{2} \text { (com ou sem adição de } \mathrm{N}_{2} \text { ou } \mathrm{Ar}\right)}$
\end{tabular}

\subsubsection{Reatores utilizados na técnica PECVD}

Atualmente, encontram-se na literatura, diversos tipos de configurações possíveis para sistemas de deposição por PECVD, porém alguns tipos de sistemas se tornaram mais conhecidos devido a fatores comerciais e, por isso, tornaram-se os sistemas de deposição PECVD mais comuns de serem encontrados e/ou utilizados [10]. Um tipo de sistema é o reator PECVD com paredes frias e acoplamento capacitivo.

Esse tipo de reator consiste basicamente em uma câmara de processo onde, em seu interior, existem duas placas paralelas cuja função é a de transmitir o sinal de RF para a geração do plasma. Em uma dessas placas encontra-se um porta-amostras que pode ser individual (com capacidade para apenas uma amostra) ou com capacidade para mais de uma amostra. Os porta-amostras, normalmente, possuem um sistema de aquecimento.

Uma das grandes vantagens deste sistema é a sua versatilidade e relativa facilidade de projeto. Existem ainda os reatores de placas paralelas cujas paredes da câmara são aquecidas. Tais reatores oferecem uma 
melhor uniformidade da distribuição de temperatura durante o processo de deposição e podem aumentar a uniformidade das propriedades do material depositado [8]. Na Figura 4 são mostrados os tipos de reatores PECVD mais comuns no setor industrial e na maior parte dos laboratórios de pesquisa [9].

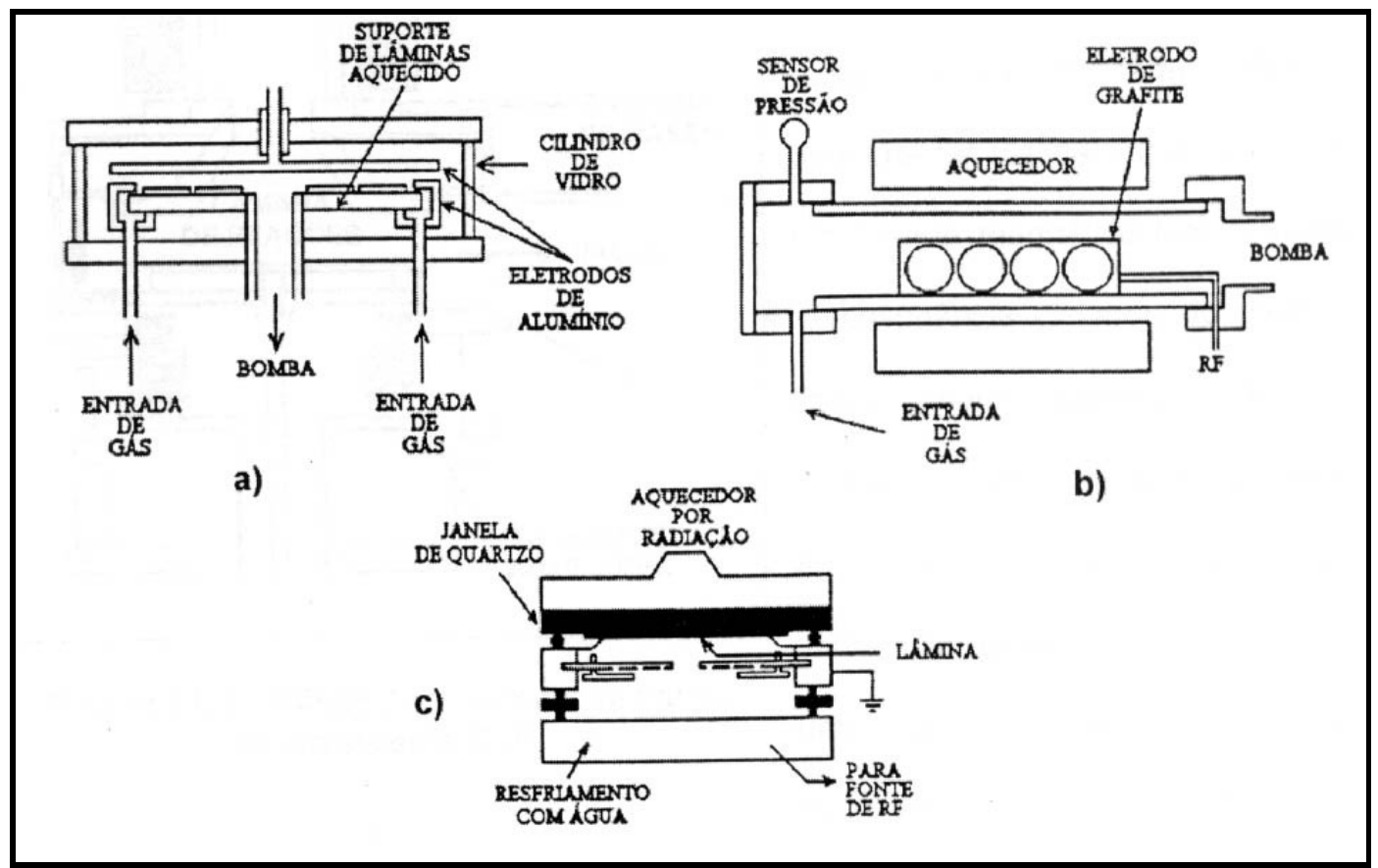

Figura 4 Tipos de reatores PECVD comumente utilizados: a) placas paralelas; b) tubo horizontal; c) para lâmina individual [9].

Existem ainda variações bastante conhecidas dos reatores PECVD, uma delas é o sistema RPECVD (“Remote Plasma Enhanced CVD”). Este sistema consiste de um reator CVD convencional assistido por plasma remoto que utiliza como fonte de energia um campo eletromagnético gerado por uma fonte de microondas.

No sistema RPECVD o plasma é gerado em um compartimento separado da câmara de deposição, ou seja, a amostra não fica diretamente exposta ao plasma, diferentemente dos reatores de PECVD convencionais. Tal sistema permite que as espécies (radicais) sejam transferidas para a 
amostra pela ação do próprio sistema de vácuo. Assim, como a amostra não é exposta ao plasma, não existe a ocorrência de bombardeamento iônico da superfície da amostra.

Os filmes obtidos por RPECVD apresentam, geralmente, características superiores quando comparados aos filmes obtidos por um sistema PECVD convencional. As principais desvantagens da técnica RPECVD são as baixas taxas de deposição e a dificuldade de se obter filmes com boa uniformidade em termos de espessura.

Um outro tipo de reator é o ECR ("Electron Cyclotron Resonance"). Este reator é semelhante aos reatores RPECVD, onde a grande diferença é que, junto à fonte de microondas, existem magnetos que geram um campo magnético intenso que, por sua vez, provoca a ressonância cíclotron dos íons dispersos no plasma. Este reator consegue oferecer um plasma até cem vezes mais denso em espécies reativas (comparado a um sistema PECVD convencional de acoplamento capacitivo), gerando altas taxas de deposição. As desvantagens deste sistema são o seu custo elevado e a dificuldade na obtenção de uma boa uniformidade na espessura dos filmes depositados.

\subsubsection{Influência dos parâmetros de processo nas propriedades de filmes de óxido de silício}

Para uma análise qualitativa da influência dos principais parâmetros de um processo PECVD sobre as características dos filmes de óxido de silício, será considerada como fonte de reagentes a mistura gasosa entre 
TEOS $+\mathrm{O}_{2}$. O TEOS é um composto orgânico que possui, além do silício e do oxigênio, átomos de carbono e hidrogênio.

Portanto, são necessárias certas medidas e precauções no que diz respeito ao controle dos principais parâmetros do processo de deposição assistido por plasma, a fim de diminuírem-se, da melhor maneira possível, as chances de ocorrência de moléculas de $\mathrm{H}_{2} \mathrm{O}$ e ligações do tipo $\mathrm{Si}-\mathrm{OH}$ na estrutura do óxido de silício depositado. Como consta na literatura [5]-[7],[12]-[22], a presença de tais ligações e espécies é a maior responsável pela degradação das propriedades elétricas e físicas dos filmes de óxido de silício depositados por PECVD.

\subsubsection{Fonte gasosa de silício}

As duas principais fontes gasosas utilizadas para a deposição de filmes de óxido de silício em processos CVD são: silana $\left(\mathrm{SH}_{4}\right)$ e o TEOS $\left[\mathrm{Si}\left(\mathrm{OC}_{2} \mathrm{H}_{5}\right)_{4}\right]$.

O TEOS possui a grande vantagem de não ser tóxico ou explosivo, garantindo melhores condições de segurança para manipulação e armazenagem. A silana é um gás que, além de possuir um alto grau de toxidade é muito volátil e pirofórico. Além disso, a silana, em contato com moléculas de água, reage produzindo grande quantidade de particulados que, por sua vez, podem tornar-se sérios candidatos a fontes de contaminação por partículas sólidas. Assim, o TEOS é uma alternativa mais segura, exigindo menores cuidados para o seu manuseio e estocagem.

O TEOS, em temperatura ambiente, é um líquido e vaporiza quando 
aquecido a $70^{\circ} \mathrm{C}$. Assim, para que o TEOS seja utilizado em um processo CVD, é necessária uma linha de transmissão aquecida e com controladores de fluxo de massa específicos para realizar o transporte do reagente até o reator.

A maior vantagem do TEOS em relação a silana é que, em sistemas de deposição a baixa pressão, os filmes de óxido de silício obtidos possuem uma melhor cobertura de degrau, tornando o TEOS um reagente de grande interesse para aplicações em tecnologia VLSI [8].

Além disso, podem ser obtidos filmes de óxido de silício com diferentes estequimometrias, controladas pelo processo de deposição, onde filmes ricos em silício ou ricos em oxigênio podem ser obtidos. Inúmeras aplicações na área de sensores químicos e ópticos, MEMS, entre outros são propostas na literatura.

Uma das desvantagens da utilização de TEOS é que, em processos cuja temperatura de deposição é inferior a $300^{\circ} \mathrm{C}$, os filmes de óxido de silício depositados podem apresentar uma concentração significativa de ligações do tipo Si-OH que, podem indicar incorporação de subprodutos de TEOS adsorvidos no filme de óxido de silício, farão com que a tensão de ruptura do filme ocorra em tensões cada vez menores [21].

Através de fontes literárias [5]-[7],[12]-[22], é possível constatar que quanto menor for a relação $\mathrm{TEOS} / \mathrm{O}_{2}$, durante o processo de deposição, menor será a probabilidade de formação das ligações do tipo Si-OH.

Por ser uma molécula orgânica complexa, o TEOS exige maiores precauções quanto ao controle de parâmetros tais como: potência do sinal 
de RF e pressão da câmara de processos para que seja evitada ao máximo possível a incorporação de subprodutos das reações químicas provenientes da dissociação do TEOS nos filmes de óxido de silício depositados.

\subsubsection{Temperatura do substrato}

O aumento da temperatura do processo de deposição, contribui para a diminuição da taxa de deposição dos filmes [21]. Em contrapartida, filmes de óxido de silício depositados com baixas taxas de deposição apresentam maior grau de compactação e menor incorporação de subprodutos indesejados oriundos da dissociação das moléculas de TEOS, pois, o processo de dessorção e remoção das espécies $\mathrm{H}_{2} \mathrm{O}$ e $\mathrm{OH}$ (geradas pela dissociação e oxidação das moléculas de TEOS) é favorecido pelo aumento da temperatura do substrato.

\subsubsection{Pressão}

O processo de deposição do filme de óxido de silício depende da dissociação e da taxa de reação entre moléculas de TEOS e o radical oxigênio, presentes no plasma.

Quando uma molécula de TEOS reage com o radical oxigênio, ocorre uma dissociação da mesma gerando fragmentos de espécies reativas que darão origem ao filme depositado. Um dos fatores limitantes dessa etapa é a disponibilidade de espécies reativas de oxigênio para cada molécula existente de TEOS, preferencialmente nas regiões próximas da superfície da amostra; quanto mais moléculas de TEOS sofrerem dissociação, maior será o número de espécies reativas e, conseqüentemente, maior será a taxa de 
deposição do filme de óxido de silício.

Com o aumento da pressão de processo, maior a probabilidade de interação entre as moléculas de TEOS e dos radicais de oxigênio e, conseqüentemente, poderá ocorrer um aumento da taxa de deposição sobre a amostra. Quando a pressão de processo é aumentada, ocorre simultaneamente um aumento da incorporação indesejada de subprodutos de TEOS por causa da dificuldade de remoção dessas espécies após a reação com a superfície da amostra. Assim, a superfície da amostra fica exposta a uma quantidade maior de reagentes na fase gasosa, de modo que moléculas adsorvidas na superfície do substrato acabam sendo incorporadas ao filme devido ao bombardeamento iônico ou por difusão favorecida pelo sistema de vácuo.

Apesar da taxa de deposição aumentar, nessa situação, o que é depositado ao final é um material repleto de contaminantes, com pobre cobertura de degrau, o que não significa uma maior desuniformidade em espessura, pois processos com pressões altas geram filmes uniformes em "espessura", porém não necessariamente em composição.

Quando a pressão de processo sofre uma diminuição, existe uma maior probabilidade de interação entre as espécies em fase gasosa com as paredes da câmara em conseqüência do aumento do livre caminho médio entre as moléculas. Como resultado, há uma diminuição da disponibilidade de radicais de oxigênio para reagir com as moléculas de TEOS e, por fim, a taxa de deposição do material tende a sofrer uma diminuição.

Em contrapartida, quando a deposição é realizada em baixas 
pressões, o tempo de residência dos radicais adsorvidos na superfície da amostra aumenta devido ao menor bombardeamento iônico que atinge a superfície da amostra. Desta forma, existe tempo suficiente para que os radicais encontrem sítios ativos e tenham condições de realizar a reação química que promoverá a formação do filme depositado.

Além disso, em baixas pressões, os subprodutos das reações de superfície podem ser mais facilmente evacuados da câmara de processos resultando na deposição de filmes mais compactos, com menor densidade de defeitos estruturais, livres da incorporação indesejada de subprodutos das reações químicas, com boa cobertura de degrau e mais uniformes.

\subsubsection{Potência do sinal de RF}

A influência da amplitude do sinal de RF aplicado à mistura gasosa é análoga à influência da temperatura de processo, uma vez que a função do sinal de RF é também a de fornecer energia para a ocorrência de reações físicas e químicas necessárias para o processo de deposição do filme.

O aumento da potência do sinal de RF favorece a quebra de moléculas de TEOS e a densidade de radicais que promoverão a deposição do filme. Juntamente com este processo, ocorre também um maior bombardeamento iônico da superfície da amostra, devido a presença de uma quantidade maior de íons de oxigênio, o que diminui o tempo de residência dos radicais de TEOS na superfície da amostra acarretando uma densificação do filme depositado e uma diminuição acentuada da taxa de deposição do filme [23]. 
Para menores valores da potência do sinal de RF, ocorre uma diminuição na geração de radicais de TEOS e eventualmente poderá ocorrer uma menor taxa de bombardeamento iônico da superfície da amostra. Desta forma, aumenta-se a probabilidade de incorporação de espécies não reagidas no filme depositado. Assim, a diminuição da amplitude do sinal de RF contribui para o aumento da taxa de deposição. Porém, as características estruturais e elétricas do filme depositado são afetadas pela incorporação indesejada de espécies não reagidas.

\subsubsection{Concentração de TEOS}

Considerando que a energia fornecida ao processo de deposição seja constante, a diminuição do fluxo de TEOS resulta em uma diminuição da taxa de deposição do filme de óxido de silício, devido à presença de poucas espécies ativas nas regiões próximas à superfície da amostra. Isso diminui a probabilidade de incorporação indesejada de subprodutos provenientes da reação entre as moléculas de TEOS e a superfície da amostra. Ou seja, com uma diminuição da quantidade de moléculas de TEOS na câmara de processos, ocorre o aumento do tempo de residência das espécies adsorvidas na superfície do substrato de modo que este se torne suficiente para que as mesmas encontrem sítios ativos para a formação do filme que, conseqüentemente, sofrerá um aumento significativo na sua densidade.

\subsubsection{Concentração de Oxigênio}

Para os processos de deposição de óxido de silício realizados com maiores fluxos de oxigênio, a probabilidade de dissociação de moléculas de 
TEOS sofre um aumento e provoca uma maior concentração de espécies ativas próximas à superfície do substrato. Assim, com uma dissociação mais efetiva das moléculas de TEOS, a incorporação indesejada de espécies não reagidas sofre uma diminuição e o filme depositado pode apresentar uma composição química mais homogênea.

Alguns estudos presumem que, para processos com excesso de oxigênio na mistura gasosa, ocorra a deposição de filmes de óxido de silício com índices elevados de tensão mecânica residual (estresse), pois, levandose em conta a presença de um maior número de íons de oxigênio próximos à superfície da amostra, existe um maior bombardeamento iônico da superfície do material depositado (óxido de silício) tornando-o repleto de pequenas "imperfeições" e causando, por fim, perturbações na estrutura interna do filme depositado [23].

De outra forma, a diminuição do fluxo de oxigênio reduz a concentração de radicais próximos da superfície da amostra. Isso afeta negativamente a taxa de reação química dos radicais provenientes das moléculas de TEOS, aumentando, desta maneira, a probabilidade de incorporação indesejada de espécies não reagidas na estrutura do material depositado.

\subsection{Reator HD-PECVD}

Uma das técnicas CVD que vem sendo estudada com grande ênfase nas últimas décadas é o processo de deposição química a vapor assistida por plasma de alta densidade (HD-PECVD) [25]. Um dos principais motivos 
para este interesse deve-se ao fato de que essa técnica oferece uma baixa incorporação de subprodutos indesejáveis da reação química nos filmes de óxido de silício depositados. Além disso, o processo de deposição pode ser realizado em temperaturas menores do que $300^{\circ} \mathrm{C}$, tornando essa técnica adequada para a deposição de filmes sobre os mais diferentes tipos de substratos [26].

O plasma de alta densidade aumenta a probabilidade de formação de íons de oxigênio e, conseqüentemente, a reação de oxidação dos fragmentos de TEOS com maior eficiência quando comparado a um processo PECVD comum (acoplamento capacitivo). Em processos com plasma de alta densidade realizados a baixas pressões, o mecanismo de difusão das espécies gasosas é favorecido, tornando, dessa maneira, mais efetiva a chegada de espécies reativas à superfície das amostras. Em pressões baixas, a remoção dos subprodutos das reações químicas também se torna mais eficiente resultando em uma menor incorporação de subprodutos nos filmes depositados [27],[28].

De um modo geral, os processos de deposição PECVD são basicamente controlados pela reação de superfície [29]. A decomposição da molécula de TEOS se inicia ainda em fase gasosa através de colisões sucessivas entre si e com espécies presentes no plasma, bem como por elétrons gerados no plasma. Assim sendo, os fragmentos das moléculas de TEOS gerados, adsorvem-se na superfície da amostra e, posteriormente, são oxidados por radicais de oxigênio.

Quando a oferta de radicais de oxigênio é pequena, fato algumas 
vezes observado em processos PECVD de acoplamento capacitivo, alguns fragmentos de TEOS poderão permanecer sem reagir na superfície da amostra e serem incorporados ao filme [30]. Além disso, também se observa uma má formação estrutural dos filmes depositados devido às altas taxas de deposição e bombardeamento iônico na superfície das amostras.

Em contrapartida, em sistemas HD-PECVD, o mecanismo de formação de radicais de oxigênio é favorecido e a reação de oxidação dos fragmentos de TEOS ocorre de forma mais efetiva [28].

A técnica HD-PECVD geralmente oferece uma densidade de plasma da ordem de $10^{11} \mathrm{~cm}^{-3}$ enquanto que técnicas convencionais de PECVD oferecem uma densidade de plasma relativamente menor (entre $10^{9} \mathrm{e}$ $\left.10^{10} \mathrm{~cm}^{-3}\right)$.

Além disso, processos HD-PECVD podem oferecer um potencial de plasma muito baixo (da ordem de $10 \mathrm{~V}$ ); enquanto que um processo PECVD convencional chega facilmente a potenciais de plasma entre $10^{2} \mathrm{e}$ $10^{3} \mathrm{~V}$ [31]. Por essa razão, os defeitos estruturais causados pelo bombardeamento iônico são consideravelmente menores em filmes obtidos por HD-PECVD.

Visando a obtenção de filmes de óxido de silício adequados para serem usados como dielétricos de porta de dispositivos TFTs, foi construída uma câmara de deposição do tipo HD-PECVD no sistema multicâmaras existente no Laboratório de Sistemas Integráveis [33].

Essa câmara consiste de um sistema HD-PECVD de acoplamento indutivo planar que é composto, basicamente, por uma câmara de reação e 
uma bobina planar polarizada com um sinal de $\mathrm{RF}(13,56 \mathrm{MHz})$ e que fica separada da região de vácuo por uma janela.

Na Figura 5, é possível observar um esquema ilustrando o reator HD-PECVD pertencente ao sistema multicâmaras do LSI.

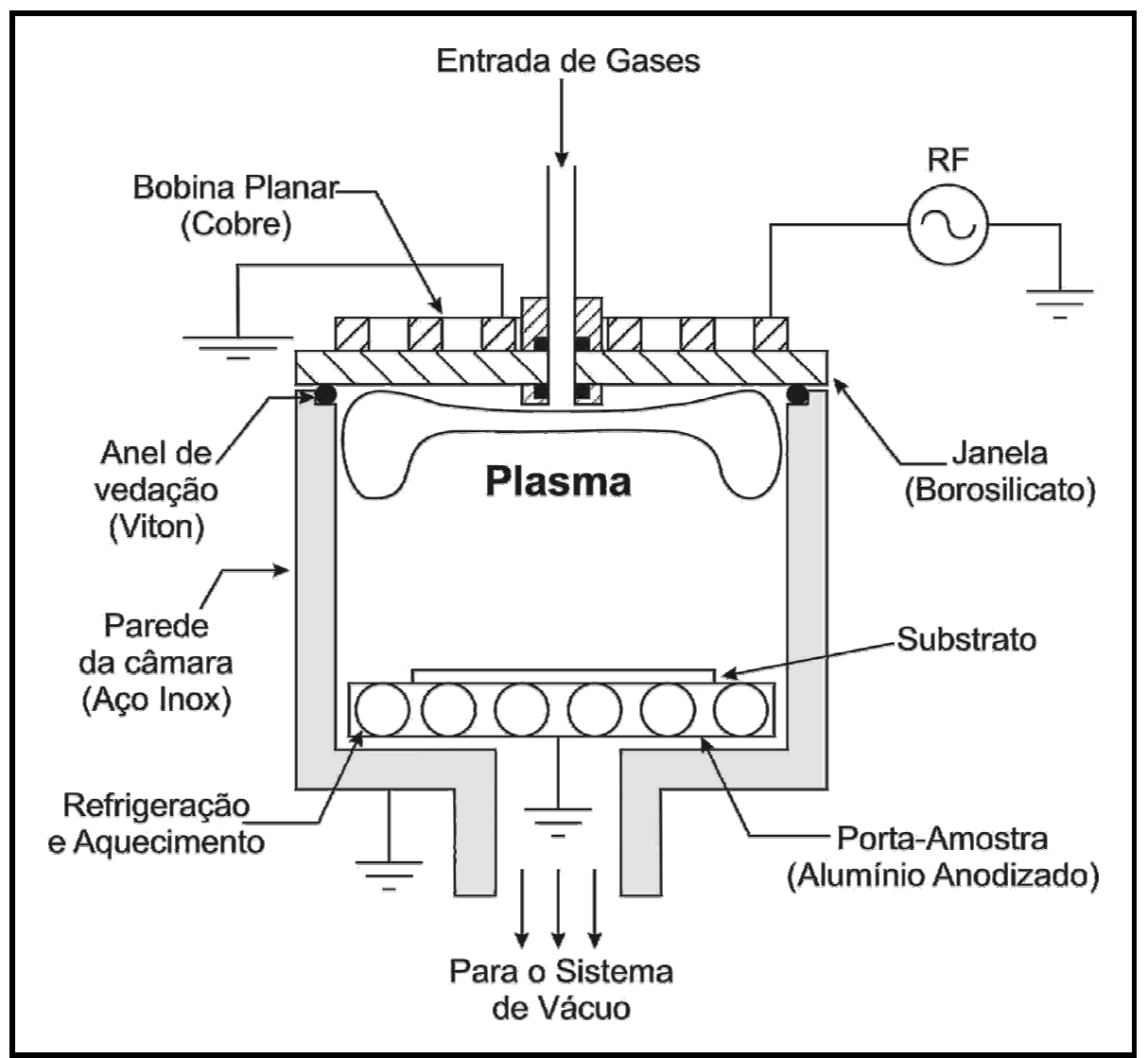

Figura 5 Esquema do reator HD-PECVD.

Como os dispositivos fabricados através dos processos de microeletrônica são sensíveis à contaminação metálica, o eletrodo superior (bobina planar) é isolado da região de vácuo através de uma janela de borosilicato temperado de $1 \mathrm{~cm}$ de espessura. Dessa forma, uma possível contaminação, principalmente por cobre, dos filmes a serem depositados é evitada.

A câmara de deposição é constituída de aço inox 316 com dimensões 
de $400 \mathrm{~mm}$ de diâmetro e $120 \mathrm{~mm}$ de altura; e foi projetada para operar em baixas pressões (menores que 500 mtorr).

O sistema de admissão de gases possui uma câmara para a mistura dos reagentes instalada entre os controladores de fluxo de massa e a entrada do reator. Essa câmara de mistura foi projetada para garantir a homogeneização dos gases reagentes antes que estes sejam injetados na câmara de processos [34].

Os gases são injetados dentro do reator através de um tubo de aço inox eletropolido posicionado no centro da bobina planar, na parte superior da câmara.

O porta-amostra possui um sistema de aquecimento, resistência elétrica posicionada abaixo do porta-amostra, que viabiliza processos com temperatura máxima de $600^{\circ} \mathrm{C}$ e também possui um sistema de refrigeração, conjunto de dutos construídos na parte interna do porta-amostra onde circula água destilada resfriada, que permite deposições em temperaturas menores que a ambiente. O porta-amostra é aterrado mas conta com a possibilidade de aplicação de um potencial elétrico. No eletrodo superior (bobina planar) é aplicado um sinal de RF (13,56 MHz). Este eletrodo fica a uma distância de $60 \mathrm{~mm}$ da amostra.

Neste trabalho, a fonte de silício é o TEOS $\left[\mathrm{Si}\left(\mathrm{OC}_{2} \mathrm{H}_{5}\right)_{4}\right]$. Como gases adicionais ao processo de deposição são utilizados: oxigênio, responsável pela decomposição das moléculas de TEOS e reação química com os radicais adsorvidos nos sítios ativos na superfície do substrato, e argônio, que promoverá uma maior eficácia na quebra de moléculas de TEOS e 
promove o aumento da energia de dissociação no plasma através do processo de ionização por impacto. 


\section{TÉCnICAS Empregadas PaRa a CARACterizaÇão}

É apresentado neste capítulo um resumo sobre as técnicas de caracterização física e de composição dos filmes depositados, bem como as técnicas de extração dos principais parâmetros elétricos dos filmes de óxido de silício $\left(\mathrm{Q}_{\mathrm{SS}}, \mathrm{V}_{\mathrm{FB}}, \varepsilon_{\mathrm{OX}}, \mathrm{E}_{\mathrm{BD}}, \mathrm{J}_{\mathrm{LK}}\right.$, etc. $)$.

\subsection{Elipsometria}

A elipsometria é um método que consiste em avaliar as mudanças no estado de polarização de feixes colimados de luz monocromática causadas pela reflexão em uma superfície. É um método óptico não destrutivo que permite medir:

a. O índice de refração (n) e o coeficiente de absorção $(k)$ de um substrato;

b. A espessura (d) e o índice de refração (n) de filmes finos transparentes ou absorventes sobre um substrato absorvedor ou refletor, cujos valores de $\mathrm{n}$ e $k$ sejam conhecidos.

A mudança no estado de polarização dos feixes de luz incidente e refletido pelo material é determinada por dois parâmetros de polarização: $\Delta \mathrm{e} \psi$

Onde: $0^{\circ}<\Delta<90^{\circ}$ e $0^{\circ}<\psi<360[35]$. 


\subsection{FTIRS}

A Espectrometria no Infravermelho por Transformada de Fourier (FTIRS - "Fourier Transform Infrared Spectrometry") é uma técnica de análise estrutural não destrutiva baseada na absorção da energia, transmitida por ondas eletromagnéticas com números de onda situados na região do infravermelho, por ligações químicas com momentos de dipolo elétrico diferentes de zero.

A região do infravermelho, situada entre o visível e microondas dentro do espectro eletromagnético da Figura 6, é geralmente subdivida em três regiões distintas: infravermelho próximo (cujo banda de número de onda situa-se entre 13.000 e $4.000 \mathrm{~cm}^{-1}$ ), o infravermelho médio (que abrange a região entre 4.000 e $200 \mathrm{~cm}^{-1}$ ) e o infravermelho afastado (que fica entre 200 e $10 \mathrm{~cm}^{-1}$ ). Na região do infravermelho médio, a radiação absorvida por uma molécula é convertida em energia vibracional. Os átomos de uma molécula vibram em freqüências baixas, na faixa do infravermelho com número de onda na região entre 3.000 e $300 \mathrm{~cm}^{-1}$, permitindo que ocorra uma interação entre a radiação infravermelha e as vibrações moleculares.

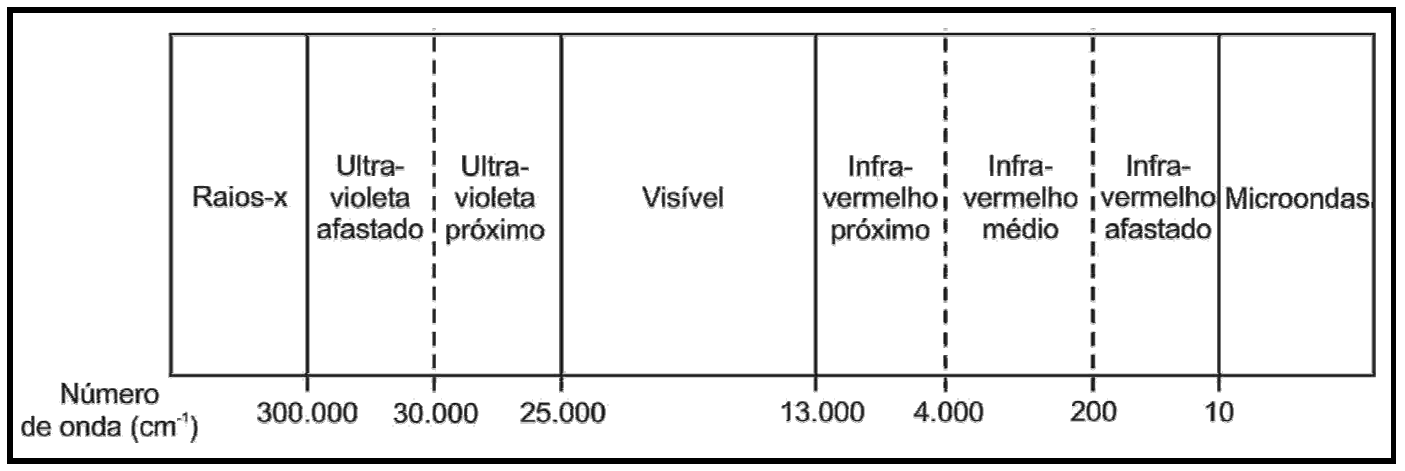

Figura 6 Diferentes regiões do espectro eletromagnético. 
Basicamente, o método de detecção consiste, inicialmente, na "divisão" de um feixe de luz infravermelho em duas partes ou dois feixes iguais. Um dos feixes segue direto para um sistema de detecção e serve como referência para um outro sistema de aquisição e tratamento de dados. O outro feixe é incidido sobre a amostra e, após sofrer a reflexão, é detectado por um sensor. Assim, se ocorrer a absorção de energia pela amostra, a diferença de intensidade entre esses dois feixes de luz é calculada para cada número de onda e, então, uma rotina de cálculos realiza um tratamento matemático por Transformada de Fourier dessa diferença [36].

É importante ressaltar que, para que ocorra uma variação na intensidade da radiação eletromagnética incidente, é necessário que a molécula sofra uma variação dipolar durante a absorção. Por isso, a técnica FTIRS, só detecta ligações químicas com momentos de dipolo elétrico diferentes de zero.

\subsection{RBS}

O método de análise de retro-espalhamento Rutherford, RBS ("Rutherford Backscattering Spectrometry"), faz parte de um conjunto de métodos nuclear-espectroscópicos mais amplo, denominado genericamente de métodos de análise de materiais por feixe iônico. Esses métodos têm em comum a utilização de feixes de íons $\left(\mathrm{H}^{+}, \mathrm{He}^{+}, \mathrm{He}^{2+}\right.$, etc.), acelerados com energias da ordem de alguns $\mathrm{MeV}$ e dezenas de nA de corrente, sendo usados para a determinação de composição elementar e perfil elementar em 
profundidade de filmes finos e materiais em geral.

Na técnica de RBS, partículas monoenergéticas de um feixe de íons colidem com átomos de uma amostra, são retro-espalhadas, detectadas e amplificadas, por um sistema que mede a energia através da separação por canais. No processo de colisão, a energia é transferida da partícula incidente (íon acelerado) para o átomo estacionário (amostra). A taxa de redução da energia da partícula espalhada depende da razão das massas da partícula incidente para o átomo alvo de modo que a interação física entre estas duas espécies permita determinar a identidade do átomo estacionário localizado na estrutura da amostra. Quando o átomo alvo é identificado, sua densidade em átomos $/ \mathrm{cm}^{2}$ pode ser determinada a partir da probabilidade de colisão entre as partículas incidentes e os átomos estacionários, medindo-se o número total de partículas detectadas para um certo número de partículas incidentes.

Quando um íon se move através da matéria, ele perde energia por meio de inúmeras colisões com os elétrons no material alvo. Essa perda de energia é diretamente proporcional ao comprimento da trajetória percorrida pela partícula no interior da amostra permitindo, desta maneira, estabelecer uma escala de profundidade e associar a energia da partícula detectada ao local em que ocorreu a colisão. Através de uma rotina de cálculos, detalhada na literatura [37], e com o auxílio de métodos iterativos e programas de computador, que permitem simular espectros RBS para uma dada composição/estrutura da amostra (alvo), é possível determinar a estequiometria de um filme ou material analisado. 


\subsection{Capacitores MOS}

Capacitores MOS (Metal-Óxido-Semicondutor) são comumente utilizados como ferramentas para a obtenção de características e parâmetros elétricos e físicos de filmes de óxido de silício ou então outros tipos de materiais isolantes.

Diferente dos capacitores tradicionais (Metal-Isolante-Metal), a distribuição de carga no silício não é pelicular, o que gera uma capacitância, dentro da estrutura do silício sob a região do dispositivo, em série com a capacitância do óxido. Essa capacitância, do silício, se altera em função da tensão aplicada nos terminais da estrutura do capacitor MOS. Este efeito, da capacitância do óxido associada à capacitância do silício, pode ser analisado na curva Capacitância x Voltagem (CV).

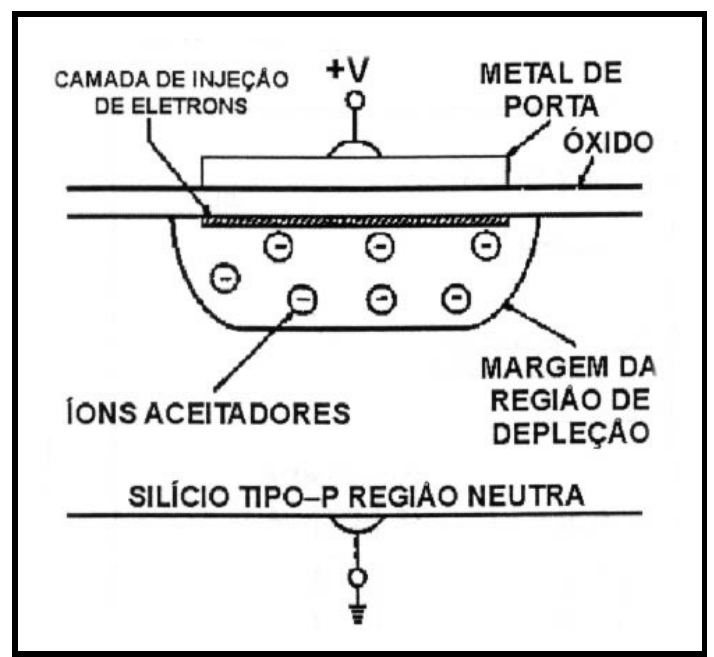

Figura 7 Corte transversal de um capacitor MOS tipo-P polarizado na condição de inversão [38].

\subsubsection{Capacitância x Tensão de Alta Freqüência (CV-AF)}

Uma rampa de tensão contínua, para a polarização do capacitor 
MOS, é aplicada para a obtenção da curva CV de alta freqüência, e um sinal alternado de alta freqüência (cerca de $1 \mathrm{MHz}$ ) de baixa amplitude para a realização da medida da capacitância diferencial da estrutura nas regiões de polarização (acumulação, depleção e inversão).

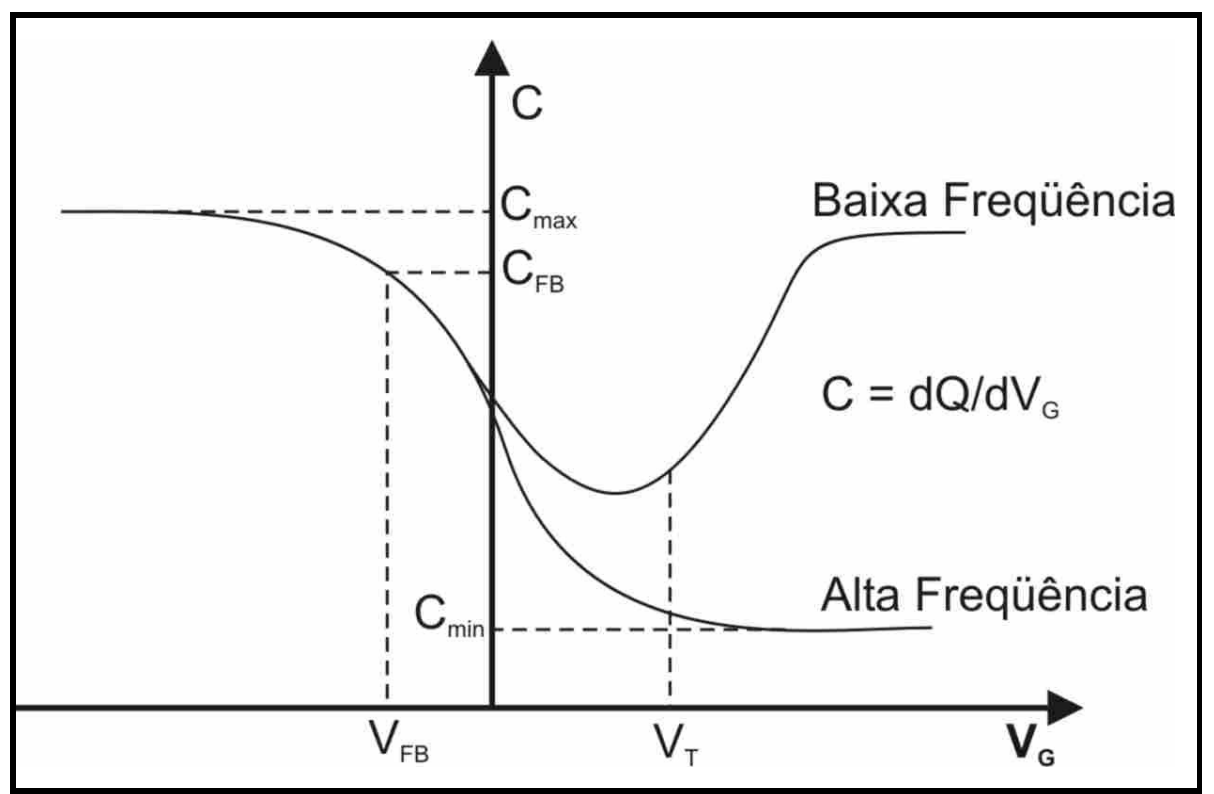

Figura 8 Comparação entre as curvas CV de alta e baixa freqüência [38].

Onde, $C$ é a capacitância em função de $V_{G}$ (tensão aplicada ao capacitor MOS); $V_{T}$ é a tensão de limiar ou de inversão forte; $C_{F B}$ é a capacitância de banda plana; $V_{\mathrm{FB}}$ é a própria tensão de banda plana; $\mathrm{C}_{\mathrm{máx}}$ é a capacitância máxima do sistema MOS e $\mathrm{C}_{\min }$ é a capacitância mínima (que caracteriza a região de inversão forte).

Assim, a partir da Figura 8, as faixas de operação do capacitor MOS (tipo-P) podem ser divididas da seguinte maneira:

a. Para $\mathbf{V}_{\mathrm{G}}<\mathbf{V}_{\mathrm{FB}}$ : acumulação (carga no silício, $\mathrm{Q}_{\mathrm{Si}}$ maior que zero, devido à presença de portadores majoritários no silício). Toda variação de tensão aplicada na porta $\left(\mathrm{dV}_{\mathrm{G}}\right)$ será respondida por 
uma variação de cargas móveis $d Q_{m}=-d Q_{S i}$ de lacunas (portadores majoritários) em acumulação na interface $\mathrm{Si} / \mathrm{SiO}_{2}$. Como o comprimento da região de depleção $d$ tende a zero, a capacitância do sistema tende a ser praticamente a própria capacitância do óxido.

b. Para $\mathbf{V}_{\mathrm{G}}=\mathrm{V}_{\mathrm{FB}}$ : temos a condição de banda plana $\left(\mathrm{Q}_{\mathrm{Si}}=0\right)$ onde $\mathrm{a}$ estrutura entra numa condição de equilíbrio elétrico entre a tensão aplicada ao dispositivo e o potencial elétrico interno da estrutura provocado pela presença de cargas no óxido e da diferença das funções trabalho entre o metal e o semicondutor.

c. Para $\mathbf{V}_{\mathrm{FB}}<\mathrm{V}_{\mathrm{G}}<\mathrm{V}_{\mathrm{T}}$ : depleção e inversão fraca $\left(\mathrm{Q}_{\mathrm{Si}}<0\right.$; carga fixa no silício $Q_{\mathrm{Sif}}<0$ e carga móvel no silício $Q_{\mathrm{Sim}} \approx 0$ ). A partir deste instante, tem início o surgimento de uma camada de depleção no silício. Por causa disso, associa-se em série à capacitância do óxido $C_{o x}$, uma capacitância do silício "C $\mathrm{SS}_{\mathrm{Si}}$ ", dada por: $\mathrm{C}_{\mathrm{Si}}=\varepsilon_{\mathrm{Si}} / \mathrm{d}$, onde $\varepsilon_{S i}$ é a permissividade elétrica do silício e d é o comprimento da camada de depleção no semicondutor.

d. Para $\mathbf{V}_{\mathbf{G}} \geq \mathbf{V}_{\mathbf{T}}$ : inversão forte $\left(Q_{\mathrm{Si}} \ll 0\right.$; onde $Q_{\mathrm{Sif}}<0$ e $\left.Q_{\mathrm{Sim}} \ll 0\right)$. Em alta freqüência, os portadores minoritários da região de depleção (elétrons, no caso do capacitor MOS do tipo-P) não têm tempo o suficiente para responderem à variação de tensão $d V_{G}$ aplicada no dispositivo pois, desde a geração e a locomoção de um portador minoritário até a interface $\mathrm{Si} / \mathrm{SiO}_{2}$, leva um determinado intervalo de tempo que pode impossibilitar essa 
resposta do sistema MOS. Assim, serão as cargas fixas $\left(Q_{\text {Sif }}\right)$, da camada de depleção, que serão as responsáveis por responder ao sinal aplicado na porta do dispositivo.

\subsubsection{Tensão de Banda Plana $\left(V_{F B}\right)$}

A tensão de banda plana $\left(\mathrm{V}_{\mathrm{FB}}\right)$ é obtida a partir da capacitância de banda plana $\left(\mathrm{C}_{\mathrm{FB}}\right)$ através da Eq. 3 .

\section{Eq. 3}

$$
C_{F B}=\varepsilon_{O X} \cdot \varepsilon_{0} \cdot \frac{A}{x_{O X}+\frac{\varepsilon_{O X}}{\varepsilon_{S i}} \cdot \sqrt{\frac{k T}{q^{2}} \cdot \frac{\varepsilon_{S i} \cdot \varepsilon_{0}}{N}}}
$$

Onde: $C_{F B}$ é a tensão de banda plana, $\varepsilon_{O X}$ é a permissividade elétrica do óxido, $\varepsilon_{0}$ é a permissividade elétrica no vácuo, $A$ é a área do capacitor, $x_{O x}$ é a espessura do óxido, $\varepsilon_{S i}$ é a permissividade elétrica do silício, $k$ é a constante de Boltzmann, $T$ é a temperatura, $q$ é a carga elementar e $N$ é o valor de concentração de impurezas do substrato (dopantes). Essa equação é obtida a partir da aproximação do comprimento da camada de depleção "d". Com o valor obtido, a partir da curva CV-AF o valor da tensão de banda plana $\left(\mathrm{V}_{\mathrm{FB}}\right)$ é determinado conforme indicado na Figura 9. 


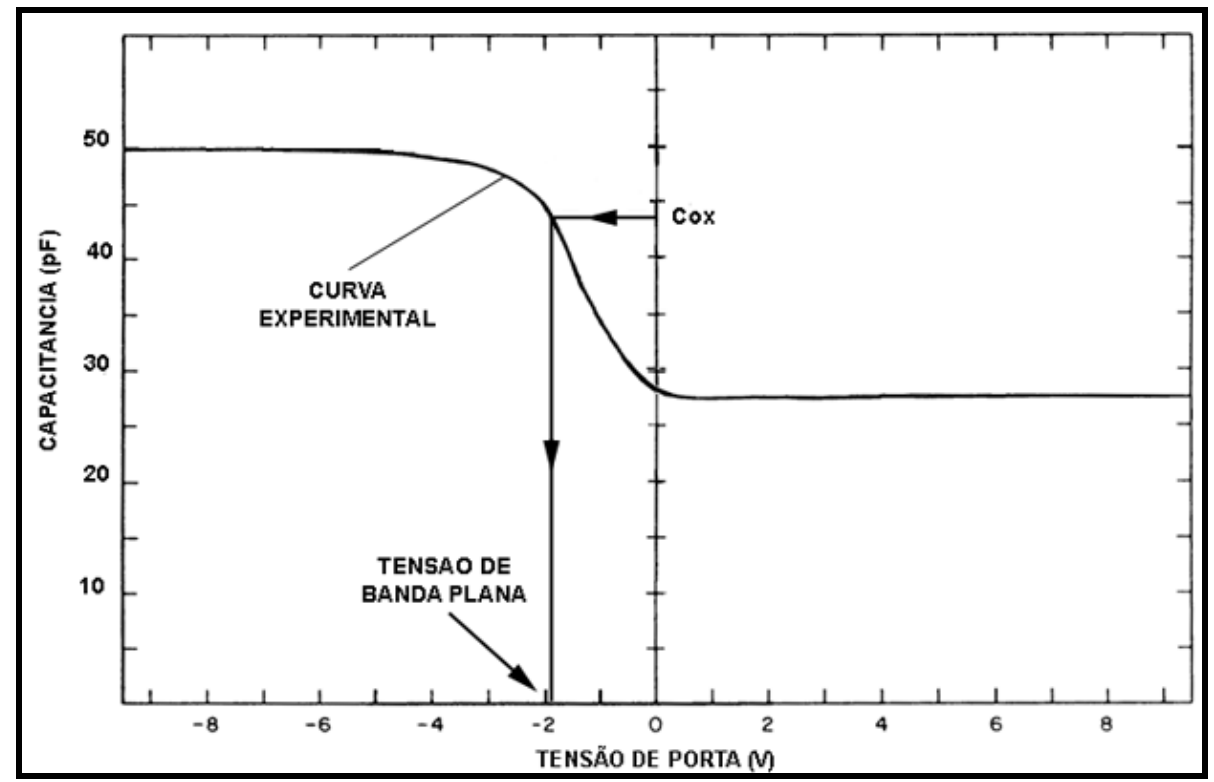

Figura 9 Demonstração da obtenção da tensão de banda plana, a partir da curva CV-AF, através do valor da capacitância, $\mathrm{C}_{\mathrm{Ox}}$, na condição de banda plana do capacitor MOS [38].

\subsubsection{Permissividade Elétrica $\left(\varepsilon_{o x}\right)$}

Com o valor da capacitância corrigida na região de forte acumulação $\left(C_{A}\right)$, que tende ao valor da capacitância do óxido do capacitor MOS, e da espessura $x_{o x}$, é possível se obter o valor da permissividade elétrica do óxido $\left(\varepsilon_{0 x}\right)$, através da Eq. 4 :

Eq. 4

$$
\varepsilon_{o x}=\frac{1}{\varepsilon_{0}} \cdot \frac{C_{A} \cdot x_{o x}}{A_{g}}
$$

Onde $A_{g}$ corresponde ao valor da área do contato elétrico da porta do capacitor MOS.

\subsubsection{Capacitância do Óxido (Cox)}

Considerando que a capacitância total $(C)$ do capacitor MOS é uma 
associação em série da capacitância do óxido $\left(C_{O X}\right)$ com a capacitância da camada de depleção do silício $\left(C_{S i}\right)$, temos:

Eq. 5

$$
\frac{1}{C}=\frac{1}{C_{O X}}+\frac{1}{C_{S i}}
$$

onde:

Eq. 6

$$
C_{o X}=\frac{\varepsilon_{o x}}{x_{o x}}
$$

Eq. 7

$$
C_{S i}=\frac{\varepsilon_{S i}}{d}
$$

Onde: $d$ é a largura da região de depleção no semicondutor.

Portanto, na região de acumulação, temos que a capacitância total tende ao valor da capacitância do óxido ( $\left.C_{O x}\right)$ uma vez que o comprimento da camada de depleção do silício tende a zero. A capacitância máxima $\left(C_{\text {máx }}\right)$, que é o valor da capacitância na região de acumulação, pode ser então aproximada pelo valor da capacitância do óxido de silício, como mostra a Eq. 8:

Eq. 8

$$
C_{\text {máx }}=C_{o X} \cdot A_{g}
$$

\subsubsection{Densidade Efetiva de Cargas no Sistema MOS (QSS)}

Essa grandeza é obtida pela comparação entre as curvas 
experimental e teórica, no ponto correspondente à banda plana do capacitor, como indica a Figura 10:

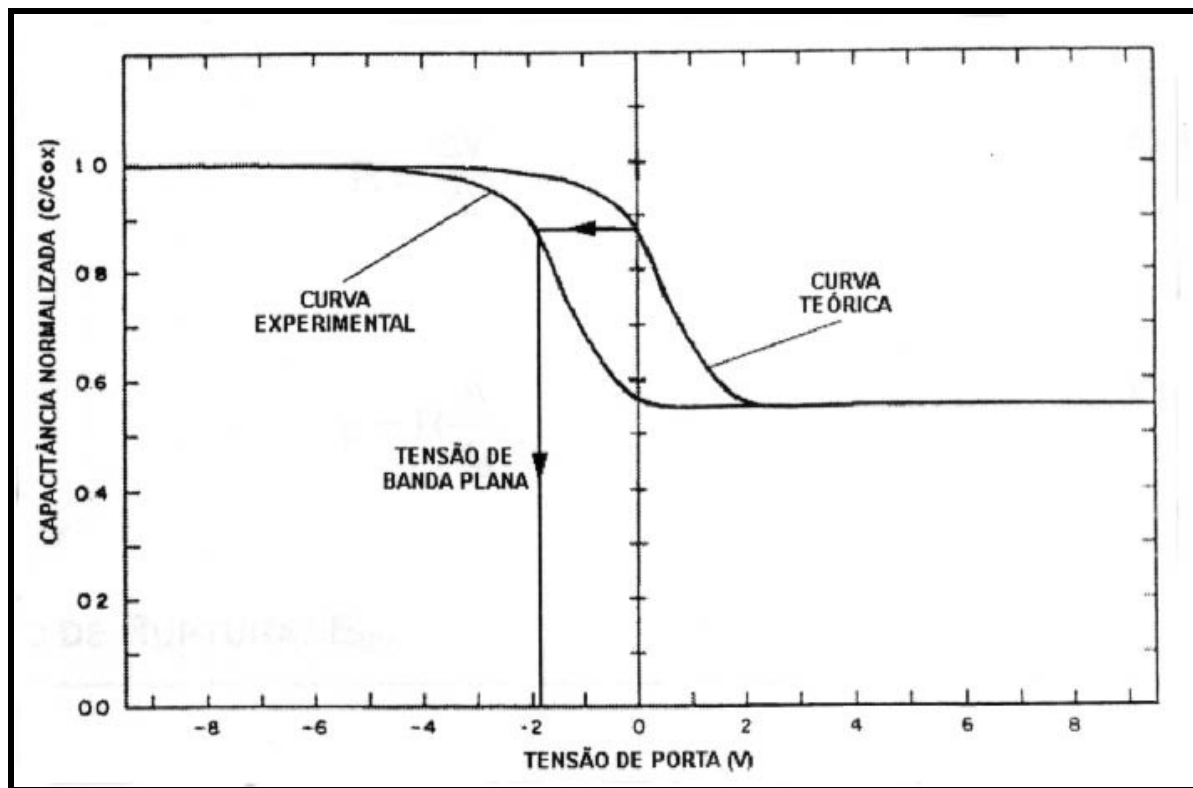

Figura 10 Demonstração do processo de determinação das cargas efetivas a partir curva CV-AF [38].

Este valor pode, ainda, ser calculado através da seguinte relação:

Eq. 9

$$
\frac{Q_{S S}}{q}=\left(\phi_{M S}-V_{F B}\right) \cdot \frac{C_{O X}}{q}
$$

Onde: $\phi_{M S}$ é a diferença entre as funções de trabalho do metal e do semicondutor e $Q_{S S} / q$ é o valor da densidade efetiva de cargas por $\mathrm{cm}^{-2}$.

\subsubsection{Corrente Elétrica $\times$ Tensão $(I-V)$}

A curva Corrente elétrica $x$ Tensão $(\mathrm{I}-\mathrm{V})$ é obtida polarizando-se 0 capacitor MOS até atingir-se a ruptura da rigidez dielétrica definitiva do dispositivo. Nesta técnica, aplica-se uma tensão alta o suficiente para dar-se origem a uma queda de tensão total no óxido. Assim o capacitor é polarizado 
na região de acumulação, de modo a evitar que a região de depleção do substrato influencie na resistência total medida.

Este tipo de análise permite a extração da resistividade $\rho$, da carga de ruptura $Q_{B D}$ e da rigidez dielétrica do óxido que está relacionada ao campo de ruptura $E_{B D \text {. }}$

\subsubsection{Campo de Ruptura ( $\left.E_{B D}\right)$}

$\mathrm{Na}$ curva I-V, haverá um ponto onde ocorre a ruptura do óxido. A tensão onde este efeito ocorre é chamada de tensão de ruptura $V_{B D}$, que pode ser visualizada na Figura 11:

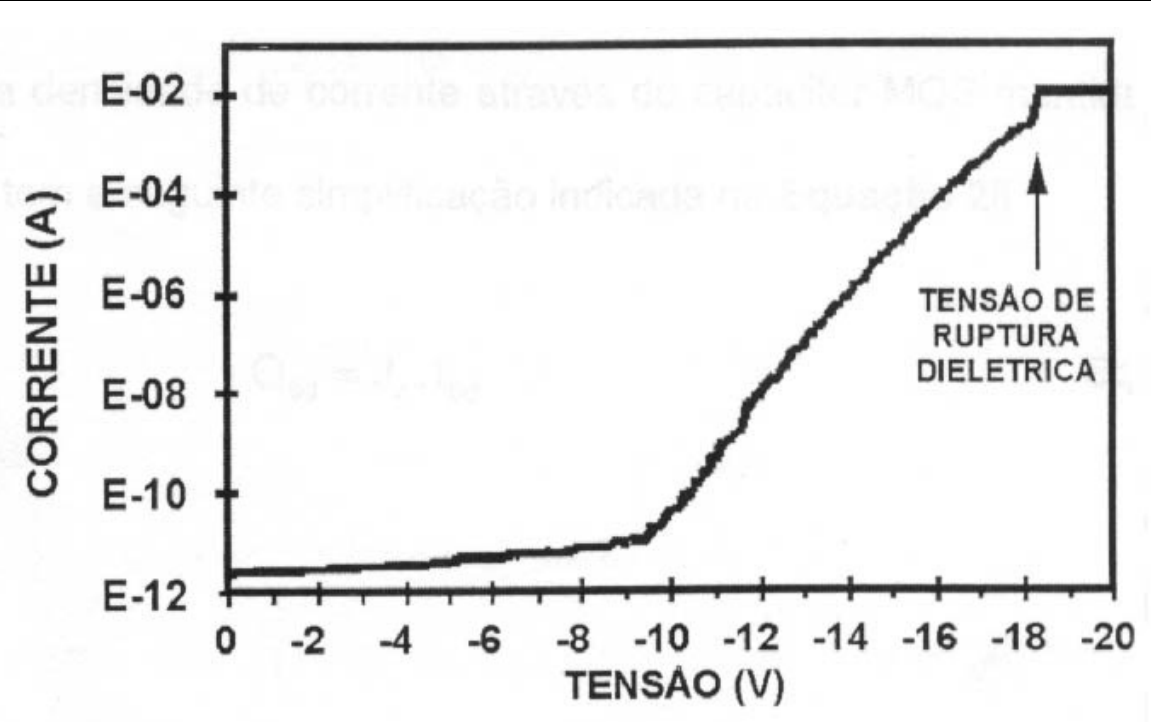

Figura 11 Obtenção da tensão de ruptura da rigidez dielétrica do óxido de silício a partir de uma curva I-V teórica [38].

Através da tensão de ruptura $\left(V_{B D}\right)$, podemos calcular o campo elétrico necessário para a ruptura da rigidez do dielétrico com as seguintes relações:

Eq. 10

$$
\left|V_{B D-o x}\right|=\left|V_{B D}\right|-R_{S} \cdot I_{G}+\phi_{M S}
$$


Eq. 11

$$
E_{B D}=\frac{\left|V_{B D-o x}\right|}{x_{o x}}
$$

Onde $\left|V_{B D \text {-ox }}\right|$ é a tensão de ruptura real do óxido, $R_{S}$ é a resistência em série associada ao dispositivo e $I_{G}$ é a corrente elétrica aplicada ao óxido. 


\section{Procedimentos Experimentals}

Neste capitulo são apresentados os procedimentos experimentais utilizados para a preparação das amostras, bem como os parâmetros adotados para as técnicas de caracterização das amostras.

Foram utilizadas lâminas de silício com $75 \mathrm{~mm}$ de diâmetro, orientação cristalográfica $<100\rangle$ e dopagem do tipo-P apresentando resistividade entre 1 e $10 \Omega \cdot \mathrm{cm}$. Todas as lâminas foram submetidas a uma etapa de limpeza química padrão. O procedimento de limpeza química compreendeu as seguintes etapas:

a. Lavagem em água deionizada*(DI) por 5 min;

b. Imersão em solução aquecida de $4 \mathrm{H}_{2} \mathrm{SO}_{4}+\mathrm{H}_{2} \mathrm{O}_{2}$ a $115^{\circ} \mathrm{C}$ por 10 min;

c. Lavagem em água DI por 5 min;

d. Imersão em solução de $20 \mathrm{H}_{2} \mathrm{O}+1 \mathrm{HF}$ a temperatura ambiente, durante 15 seg. ou até que as lâminas saiam da solução completamente secas;

e. Lavagem em água DI por 5 min;

f. Imersão em solução aquecida de $5 \mathrm{H}_{2} \mathrm{O}+1 \mathrm{H}_{2} \mathrm{O}_{2}+1 \mathrm{NH}_{4} \mathrm{OH}$ a

* Água deionizada, água DI: possui resistividade de $18 \mathrm{M} \Omega \cdot \mathrm{cm}$. 
$80^{\circ} \mathrm{C}$ por $10 \mathrm{~min}$;

g. Lavagem em água DI por 5 min;

h. Imersão em solução aquecida de $4 \mathrm{H}_{2} \mathrm{O}+1 \mathrm{H}_{2} \mathrm{O}_{2}+1 \mathrm{HCl}$ a $80^{\circ} \mathrm{C}$ por $10 \mathrm{~min}$;

i. Lavagem em água DI por 5 min;

j. Imersão em solução de $20 \mathrm{H}_{2} \mathrm{O}+1 \mathrm{HF}$ a temperatura ambiente, durante 15 seg. ou até que as lâminas saiam da solução completamente secas.

Os filmes de óxido de silício foram depositados por HD-PECVD em diferentes condições de processo. Antes de cada processo de deposição, foi realizada uma etapa de limpeza das paredes e partes internas do reator, utilizando um plasma de uma mistura de tetrafluoreto de carbono (95 sccm) e oxigênio (16 sccm) com uma potência RF de $150 \mathrm{~W}$ e com uma pressão variando entre 130 e 60 mtorr. O tempo dessa etapa de limpeza depende da quantidade de resíduos depositados nas paredes da câmara de reação, e pode variar entre 5 a 20 minutos. Assim garantem-se as mesmas condições iniciais do processo de deposição para todas as amostras.

Neste trabalho, a mistura gasosa $\mathrm{Ar}+\mathrm{O}_{2}$ utilizada nas etapas de deposição será referenciada pelo fluxo parcial de argônio $(\boldsymbol{R})$ definido como:

Eq. 12

$$
R=100 \cdot \mathrm{F}_{\mathrm{Ar}} /\left(\mathrm{F}_{\mathrm{Ar}}+\mathrm{F}_{\mathrm{O} 2}\right)
$$

Onde $F_{\mathrm{Ar}}$ e $\mathrm{F}_{\mathrm{O} 2}$ correspondem ao fluxo de argônio e fluxo de oxigênio (expresso em sccm), respectivamente.

Na Tabela 2, são apresentados os parâmetros utilizados durante a 
etapa de deposição dos filmes de óxido de silício.

Tabela 2 Parâmetros de processo utilizados na deposição dos filmes de óxido de silício.

\begin{tabular}{|c|c|c|c|c|}
\hline \hline F $_{\text {TEOS }}(\mathbf{s c c m})$ & $\begin{array}{c}\text { Fluxo Parcial } \\
\text { de Ar, } \boldsymbol{R}\end{array}$ & $\mathbf{W}_{\mathbf{R F}}(\mathbf{W})$ & $\mathbf{P}$ (mtorr) & $\mathbf{T}\left({ }^{\circ} \mathbf{C}\right)$ \\
\hline & $20^{\dagger}$ & 500 & & \\
& $40 \dagger$ & 450 & & 30 \\
0,5 & $50 \dagger$ & 450 & 60 & $\mathrm{a}$ \\
& $60 \dagger$ & 450 & & 250 \\
& $100^{* *}$ & 450 & & \\
\hline & $20 \dagger$ & 500 & & \\
& $40 \dagger$ & 450 & & \\
1 & $50 \dagger$ & 450 & 60 & 30 \\
& $60 \dagger$ & 450 & & \\
& $100^{* *}$ & 450 & & \\
\hline 2 & $50 \dagger$ & 450 & 60 & 30 \\
\hline 3 & $50 \dagger$ & 450 & 60 & 30 \\
\hline & $20 \dagger$ & 500 & & \\
& $40 \dagger$ & 450 & & \\
& $50 \dagger$ & 450 & 60 & 30 \\
& $60 \dagger$ & 450 & & \\
\hline \hline & $100^{* *}$ & 450 & & \\
\hline
\end{tabular}

Como o foco deste trabalho é a realização de uma análise geral do processo de deposição em um sistema HD-PECVD a partir da caracterização dos filmes de óxido de silício depositados a partir do TEOS, e levando-se em consideração que muitos parâmetros de processo podem influenciar nas características dos filmes depositados, a pressão e a

$$
\begin{aligned}
& { }^{\dagger} \mathrm{F}_{\mathrm{Ar}}+\mathrm{F}_{\mathrm{O} 2}=100 \mathrm{sccm} \\
& { }^{\star *} \mathrm{~F}_{\mathrm{Ar}}+\mathrm{F}_{\mathrm{O} 2}=60 \mathrm{sccm} .
\end{aligned}
$$


potência do sinal de RF foram praticamente constantes em todas as séries de amostras de modo que a influência do fluxo dos gases e da temperatura do processo, em algumas amostras, fosse verificada. Assim, a partir dos resultados obtidos para as séries de experimentos estabelecidas na Tabela 2, é possível avaliar e compreender alguns dos principais mecanismos envolvidos em um processo de deposição de filmes finos realizado em regime de alta densidade a partir de um composto orgânico.

Para garantir a proteção da superfície das amostras contra o contato direto com as moléculas de TEOS não oxidadas, em todas as etapas de deposição, as lâminas de silício foram expostas ao plasma de oxigênio e argônio sem a adição do TEOS por 1 minuto. Após este período e sem interromper o processo, o fluxo de TEOS foi admitido na câmara de reações, dando início à deposição do óxido de silício

Ao final da deposição, as amostras foram novamente expostas ao plasma composto de oxigênio e argônio por 1 minuto, para a garantir que a superfície das amostras não entrassem em contato direto com o TEOS em fase vapor e assegurar que os subprodutos remanescentes das reações químicas fossem completamente oxidados e removidos pelo sistema de vácuo.

Para a realização da medida de espessura e do índice de refração

₹ A exposição direta da amostra ao vapor de TEOS aumenta a probabilidade de incorporação não desejável de espécies orgânicas que, por sua vez, é prejudicial principalmente para a formação interface $\mathrm{Si} / \mathrm{SiO}_{2}$. 
dos filmes de óxido de silício, foi utilizado um elipsômetro da empresa "Rudolph Research", modelo Auto-EL NIR3, com um feixe de luz de comprimento de onda $\lambda=6.328 \AA$.

A técnica FTIRS foi utilizada para verificar a presença de ligações do tipo: $\mathrm{Si}-\mathrm{O}-\mathrm{Si}, \mathrm{Si}-\mathrm{CH}_{3}$, Si-OH e de radicais $-\mathrm{OH}$ entre outros, adsorvidos no filme de óxido de silício depositado. As medidas FTIRS foram realizadas em um espectrômetro modelo FTS-40 da empresa "BIORAD" em uma banda de número de onda compreendida entre 4.000 e $400 \mathrm{~cm}^{-1}$ e resolução de $4 \mathrm{~cm}^{-1}$.

A estequiometria e a densidade dos filmes de óxido de silício depositados foram obtidas através da análise de espectros RBS feita através do um programa simulador RUMP§. Essas medidas foram realizadas no LAMFI (Laboratório de Análise de Materiais por Feixes lônicos) do Instituto de Física da Universidade de São Paulo, através de um procedimento de medida padronizado com um feixe de $\mathrm{He}^{2+}$ de 2,2 MeV de energia, e carga de $40 \mu \mathrm{C}$. Para a análise dos espectros RBS, especificamente, a espessura das amostras foram obtidas através de um perfilômetro modelo DEKTAK 3030 da "Veeco Instruments Inc.".

A taxa de corrosão dos filmes depositados foi obtida através de uma solução "tampão" comercial "BOE Etchant (25 - 4) Class-10", contendo 49\%

\footnotetext{
$\S$ RUMP - faz parte de um pacote de aplicativos para compreensão, análise e
} simulação de espectros RBS incluso no programa GENPLOT 2.0, desenvolvido por Michael O. Thompson ( 
de ácido fluorídrico (HF) e $40 \%$ de fluoreto de amônia $\left(\mathrm{NH}_{4} \mathrm{~F}\right)$, em temperatura ambiente.

Capacitores MOS ("Metal Oxide Semiconductor") foram implementados com os filmes de óxido de silício depositados por HD-PECVD. Sobre os filmes de óxido de silício, depositou-se uma camada de alumínio como metal de porta.

Nos processos de deposição de alumínio, foram utilizados filetes de alumínio evaporados pelo aquecimento de um filamento de tungstênio (efeito Joule) em uma evaporadora modelo AUTO 306 da "BOC-Edwards" a uma pressão de $8 \cdot 10^{-6}$ mbar. A espessura média obtida para os filmes de alumínio foi de $300 \mathrm{~nm} \pm 20$.

Para a definição da área dos capacitores MOS, foi realizada uma etapa fotolitográfica. Nessa etapa foram utilizados fotoresiste positivo, ONPR 5000 da "Tokyo Ohka Kogyo Co. Ltd.", e o revelador AZ ${ }^{\circledR} 312$ MIF $^{* *}$ da "Clariant" diluído em uma proporção de 1:1 em água deionizada. A exposição do fotoresiste em $\mathrm{UV}^{\dagger \dagger}$ foi realizada em uma fotoalinhadora modelo MJB3 da "Karl Suss".

A Tabela 3 apresenta as condições utilizadas na etapa de litografia.

\footnotetext{
** TMAH: "Tetra Methyl Ammonium Hydroxide".

${ }^{\dagger+}$ UV: Ultravioleta
} 
Tabela 3 Condições utilizadas na etapa processos de litografia para definição das regiões de contato de porta dos capacitores MOS.

\begin{tabular}{cc}
\hline \hline Limpeza em IPA ${ }^{\ddagger \ddagger}$ a $3500 \mathrm{rpm}$ & $20 \mathrm{~s}$ \\
\hline Deposição do Fotoresiste a $3500 \mathrm{rpm}$ & $20 \mathrm{~s}$ \\
\hline Tempo da pré-cura a $105^{\circ} \mathbf{C}$ & $90 \mathrm{~s}$ \\
\hline Tempo de exposição em luz U.V. & $15 \mathrm{~s}$ \\
\hline Tempo de revelação & $25 \mathrm{~s}$ \\
\hline Tempo da cura final a $130^{\circ} \mathrm{C}$ & $5 \mathrm{~min}$ \\
\hline \hline
\end{tabular}

A corrosão dos filmes de alumínio fotogravados foi realizada utilizando-se uma solução com os reagentes e proporções indicadas na Tabela 4.

Tabela 4 Volume dos reagentes da solução de corrosão de alumínio.

\begin{tabular}{cc}
\hline \hline Ácido fosfórico $\left(\mathrm{H}_{3} \mathrm{PO}_{4}\right)$ & $350 \mathrm{ml}$ \\
\hline Ácido nítrico $\left(\mathrm{HNO}_{3}\right)$ & $30 \mathrm{ml}$ \\
\hline Água Deionizada & $140 \mathrm{ml}$ \\
\hline \hline
\end{tabular}

Com a utilização dos reagentes nas proporções apresentadas na Tabela 4 obtém-se uma solução cuja taxa de corrosão mantém-se constante em $200 \mathrm{~nm} / \mathrm{min}$ para uma temperatura de $45^{\circ} \mathrm{C}$.

Após a corrosão do alumínio e subseqüente remoção do fotoresiste, foi realizada uma etapa de evaporação de alumínio para a implementação do contato elétrico nas costas das lâminas de silício. Essa etapa é essencial para a diminuição do efeito de resistência elétrica em série associada na

\footnotetext{
‡¥ IPA: Isopropanol $\left(\mathrm{C}_{3} \mathrm{H}_{8} \mathrm{O}\right)$.
} 
extração das curvas CV-AF (capacitância versus tensão em alta freqüência).

A partir de capacitores MOS com área de $9 \cdot 10^{-4} \mathrm{~cm}^{2}$, foi realizada a caracterização elétrica dos filmes de óxido de silício em uma estação HP ("Hewlett-Packard”), composta pelo "4281 A 1 MHz C Meter/C-V Plotter" e pelo picoamperímetro "4140 pA Meter/DC/Voltage", juntamente com um programa especialmente elaborado para a aquisição e manipulação dos dados.

As curvas CV-AF foram realizadas mediante a aplicação de uma rampa de tensão que polariza o capacitor MOS da inversão para a acumulação em uma freqüência de $1 \mathrm{MHz}$. Na Tabela 5 são indicados os parâmetros de tensão utilizados durante as medidas das curvas CV-AF.

Tabela 5 Parâmetros de tensão aplicados entre os eletrodos dos capacitores MOS durante a medida das curvas CV-AF.

\begin{tabular}{cc}
\hline \hline Tempo de espera ("Hold”) & $5 \mathrm{~s}$ \\
\hline Passo de tensão ("Step") & $0,1 \mathrm{~V}$ \\
\hline Intervalo entre pontos ("Delay") & $0,5 \mathrm{~s}$ \\
\hline \hline
\end{tabular}

As medidas I-V (corrente elétrica versus tensão), que consistem na aplicação de uma tensão de porta polarizando o capacitor MOS na região de acumulação até que se atinja a ruptura da rigidez dielétrica definitiva do filme de óxido de silício, foram realizadas a partir dos parâmetros apresentados na Tabela 6. 
Tabela 6 Parâmetros de tensão aplicados entre os eletrodos dos capacitores MOS durante a medida das curvas IV.

\begin{tabular}{cc}
\hline \hline Tempo de espera ("Hold”) & $5 \mathrm{~s}$ \\
\hline Varredura de tensão ("Range”) & $0 \rightarrow-100 \mathrm{~V}$ \\
\hline Passo de tensão ("Step") & $0,5 \mathrm{~V}$ \\
\hline Período de integração ("dV/dt") & $0,1 \mathrm{~V} / \mathrm{s}$ \\
\hline \hline
\end{tabular}

As curvas I-V foram convertidas [39] em curvas J-E (Densidade de Corrente versus Campo Elétrico) para que uma comparação imediata fosse realizada entre amostras com filmes de óxido de silício de diferentes espessuras. 


\section{Resultados Obtidos e Discussões}

Neste capítulo são apresentados os resultados experimentais obtidos a partir do estudo dos filmes de óxido de silício depositados por HD-PECVD de acordo com as condições indicadas na Tabela 2.

Os resultados obtidos estão apresentados de acordo com o fluxo de TEOS utilizado para a deposição dos filmes (0,5, 1 e 4 sccm). Para o menor fluxo de TEOS o efeito da temperatura foi estudado.

\subsection{Amostras depositadas com $F_{\mathrm{TEOS}}=0,5 \mathrm{sccm}$}

Filmes de óxido de silício foram depositados a partir de um fluxo de $0,5 \mathrm{sccm}$ de TEOS e a temperatura ligeiramente superior a ambiente $\left(\sim 30^{\circ} \mathrm{C}\right)$, de modo a evitar flutuações indesejáveis de temperatura durante o processo. O efeito da temperatura de deposição, ou seja 150 e $250^{\circ} \mathrm{C}$, também foi avaliado para esta série de amostras.

\subsubsection{Temperatura do processo de deposição, $T=30^{\circ} \mathrm{C}$}

Inicialmente os filmes de óxido de silício foram depositados a temperatura ambiente. Na Figura 12 é apresentado o índice de refração das amostras analisadas. 


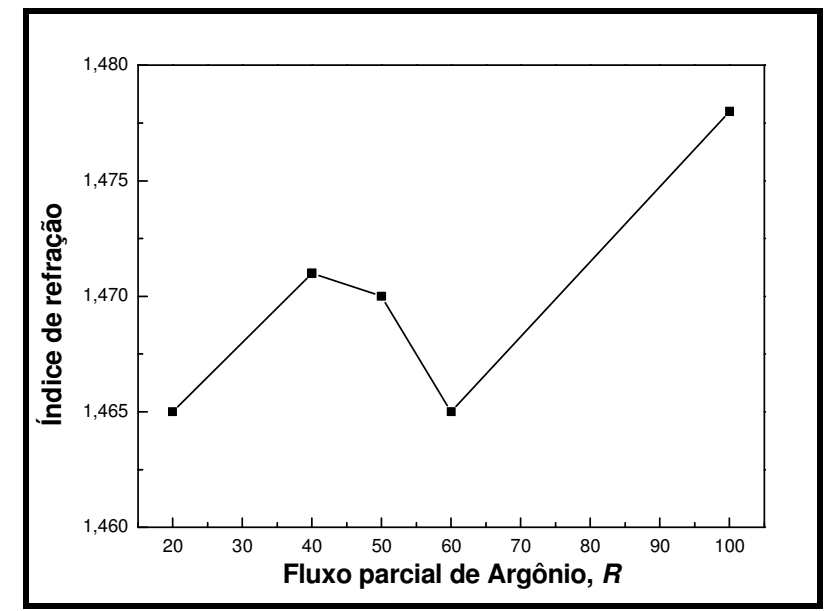

Figura 12 Índice de refração dos filmes de óxido de silício, em função do fluxo parcial de argônio, depositados a $30^{\circ} \mathrm{C}$ e com $\mathbf{F}_{\text {TEOS }}=0,5 \mathrm{sccm}$. Foram utilizadas as seguintes proporções de argônio, R: 20, 40, 50, 60 e 100.

Pode-se observar que existe uma tendência para valores superiores de índice de refração de acordo com o aumento do conteúdo de argônio no processo de deposição. Isso indica que a quantidade de silício contida no filme (estequiometria) tende a ultrapassar de 1 na relação $1 \mathrm{Si}: 2 \mathrm{O}$. Ou seja, com o aumento do fluxo parcial de argônio e diminuição do fluxo parcial de oxigênio, os filmes depositados tornam-se ricos em silício.

Na Figura 13 são apresentados o comportamento tanto da taxa de deposição quanto da taxa de corrosão dos filmes de óxido de silício. 


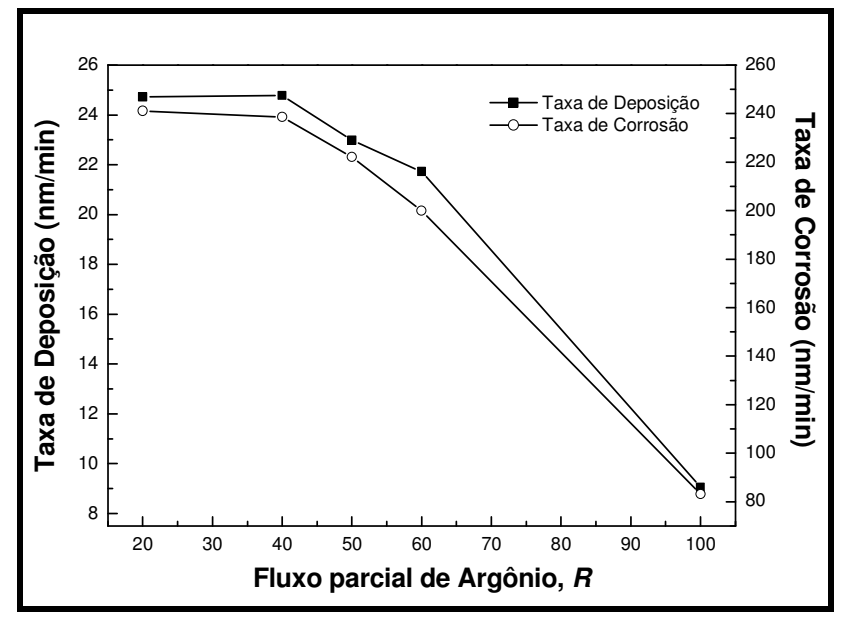

Figura 13 Taxa de deposição e de corrosão dos filmes de óxido de silício, em função do fluxo parcial de argônio, depositados a $30^{\circ} \mathrm{C}$ e com $\mathbf{F}_{\text {TEOS }}=0,5 \mathrm{sccm}$. Foram utilizadas as seguintes proporções de argônio, R: $20,40,50,60$ e 100.

A partir das curvas apresentadas na Figura 13, nota-se que a taxa de deposição diminui com o aumento do fluxo parcial de argônio na mistura gasosa, e o mesmo ocorre com a taxa de corrosão. Dessa forma, observase um comportamento indicativo da mudança estrutural do filme depositado onde, em processos realizados com maior conteúdo de argônio e menor parcela de oxigênio, o material apresenta uma concentração maior de silício e, conseqüente, alteração na estequiometria.

Estes resultados estão de acordo com os obtidos para as medidas de índice de refração (Figura 12), pois, com a diminuição da taxa de deposição, existe o favorecimento da incorporação de silício (maiores valores de índice de refração). Esse aumento de silício na composição dos filmes é, supostamente, o responsável pela diminuição na taxa de corrosão.

Na Figura 14 é apresentado o espectro FTIRS obtido para as amostras de acordo com o fluxo de argônio contido na mistura gasosa. 


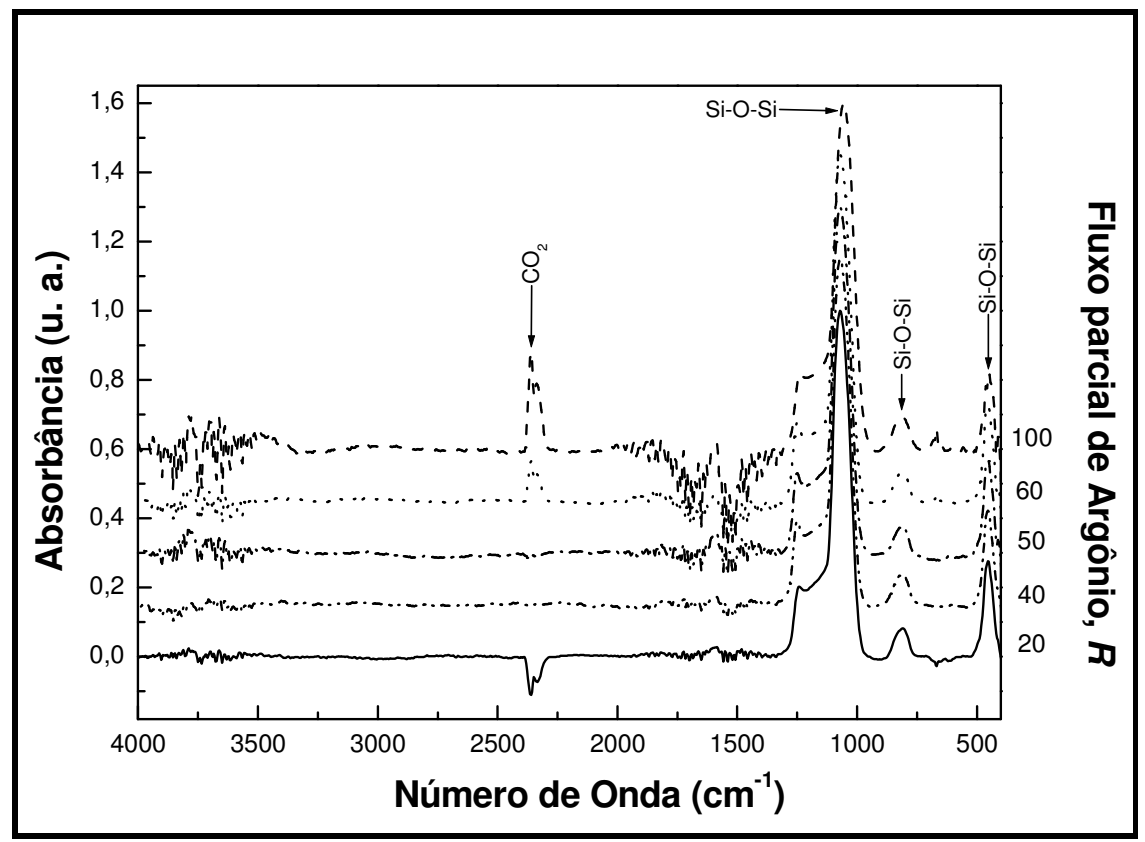

Figura 14 Espectros FTIRS dos filmes de óxido de silício, em função do fluxo parcial de argônio, depositados a $30^{\circ} \mathrm{C}$ e com $\mathbf{F}_{\text {TEOS }}=0,5 \mathrm{sccm}$. Foram utilizadas as seguintes proporções de argônio, R: 20, 40, 50, 60 e 100.

Observa-se nas curvas da Figura 14, os picos Si-O-Si relativos aos modos vibracionais "stretching", "bending" e "rocking" identificados nas regiões próximas a 1070, 810 e $460 \mathrm{~cm}^{-1}$ respectivamente.

Nota-se a presença de $\mathrm{CO}_{2}$, pico duplo na região compreendida entre $2200-2300 \mathrm{~cm}^{-1}$, juntamente com picos relacionados à presença de $\mathrm{H}_{2} \mathrm{O}$ e ligações $\mathrm{C}=\mathrm{O}$ e $\mathrm{CH}_{\mathrm{x}}$ na região entre 1300 e $1800 \mathrm{~cm}^{-1}$ [40]-[42]. A intensidade destes picos diminui nas amostras onde $R=40$ e 50, indicando que os filmes depositados nestas condições de processo possuem uma menor incorporação de subprodutos das reações do TEOS e também uma menor probabilidade de defeitos estruturais provocados pela presença destas espécies.

Nas curvas, são observados picos característicos de espécies $\mathrm{OH}$ na 
região compreendida entre 3500 e $3800 \mathrm{~cm}^{-1}$ [40],[41]. A presença destas espécies reforça o fato da incorporação de subprodutos de TEOS durante a deposição dos filmes. Além disto, verifica-se que a amostra obtida com $R=100$ é a mais comprometida em relação à presença de espécies advindas da incorporação de subprodutos de TEOS. Este fato se deve a ausência do fluxo adicional de oxigênio durante a etapa de deposição, resultando em um filme com menor densidade, com maior concentração de defeitos estruturais e, provavelmente, rico em silício.

Observa-se nas curvas da Figura 14, a presença de bandas de absorção de ligações do tipo Si-H na região $650-660 \mathrm{~cm}^{-1}$, nas amostras onde $R=20,60$ e 100, relativo ao modo vibracional "bending" [43]-[45]. A não verificação do pico relativo ao modo vibracional "stretching" das ligações $\mathrm{Si}-\mathrm{H}$, localizado na região próxima a $2250 \mathrm{~cm}^{-1}$, provavelmente se deve a uma sobreposição do pico relacionado ao $\mathrm{CO}_{2}$ que se faz presente na mesma banda de absorção. A presença de ligações Si-H pode indicar uma deficiência na distribuição de energia para a oxidação de radicais e formação de ligações Si-O.

$\mathrm{Na}$ Figura 15, observa-se com maior detalhe a banda de absorção correspondente ao modo vibracional "bending" da ligação Si-H. 


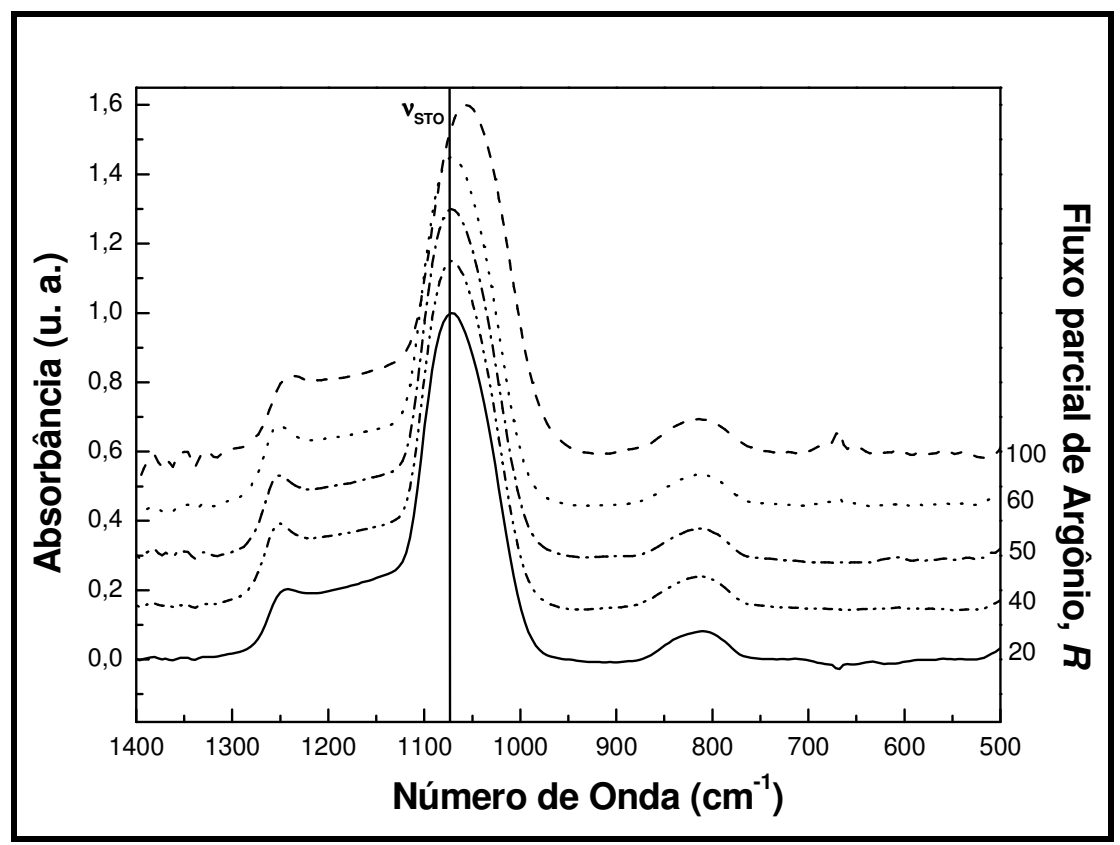

Figura 15 Detalhe dos espectros FTIRS dos filmes de óxido de silício, em função do fluxo parcial de argônio, depositados a $30^{\circ} \mathrm{C}$ e com $\mathbf{F}_{\text {TEOS }}=0,5 \mathrm{sccm}$. Foram utilizadas as seguintes proporções de argônio, $\mathbf{R}$ : $20,40,50,60$ e 100.

Na Figura 15, nota-se que a intensidade dos picos característicos do modo vibracional "bending" das ligações $\mathrm{Si}-\mathrm{H}$ torna-se maior para filmes depositados com uma maior concentração de argônio e conseqüente diminuição de concentração de oxigênio durante a etapa de deposição. A presença de espécies Si-H pode comprometer o desempenho elétrico dos filmes proporcionando instabilidade e estresse elétrico de estruturas MOS e de dispositivos TFT [3].

Na amostra depositada com $R=100$, a posição do pico Si-O-Si "stretching" ( $\left.v_{\text {STO }}\right)$ sofre um deslocamento, indicando estresse residual causado, provavelmente, pela alteração na densidade e estequiometria do material [46],[47]. 


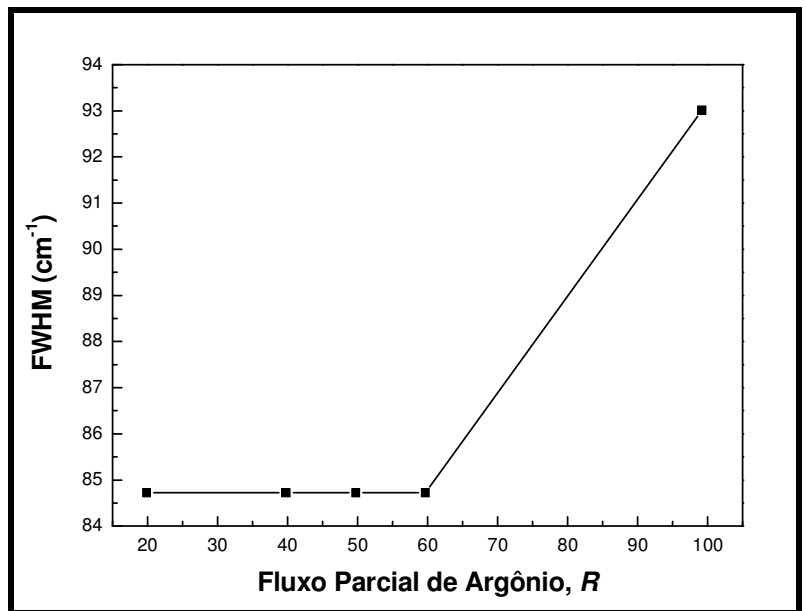

Figura 16 Comportamento da largura à meia altura (FWHM), atribuída a uma variação na composição estrutural e estresse residual, dos filmes de óxido de silício depositados a $30^{\circ} \mathrm{C}$ e com $\mathbf{F}_{\text {TEOS }}=0,5 \mathrm{sccm}$. Foram utilizadas as seguintes proporções de argônio, R: 20, 40, 50, 60 e 100.

Na Figura 16, observa-se um aumento no valor de FWHM ("Full Width at Half Maximum") para a amostra onde $R=100$, indicando uma provável variação na estequiometria do filme $\mathrm{SiO}_{x}(x<2)$. Quanto maiores forem os valores de FWHM $\left(>80 \mathrm{~cm}^{-1}\right)$, a estequiometria assume valores diferentes de 1:2 [46]. Estes resultados são confirmados através das curvas de densidade e estequiometria, obtidas pela análise RBS dos filmes depositados, que são apresentadas na Figura 17. 


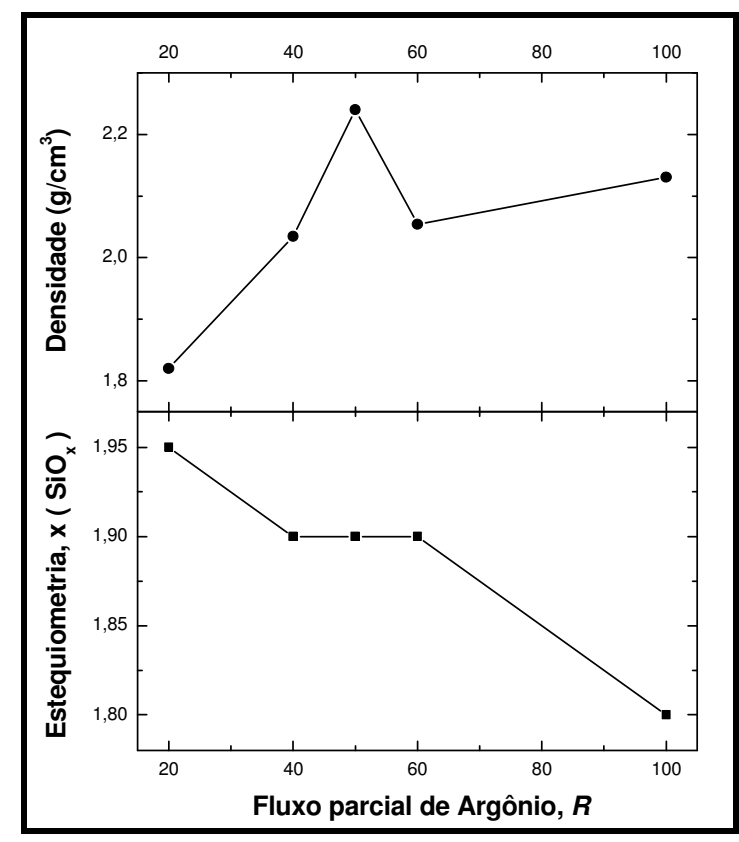

Figura 17 Densidade e estequiometria dos filmes de óxido de silício, em função do fluxo parcial de argônio, depositados a $30^{\circ} \mathrm{C}$ e com $\mathbf{F}_{\text {TEOS }}=0,5 \mathrm{sccm}$. Foram utilizadas as seguintes proporções de argônio, $\mathbf{R}$ : $20,40,50,60$ e 100.

A partir das curvas apresentadas na Figura 17, observa-se que: enquanto a densidade aumenta, o contrário ocorre com a estequiometria, indicando um provável aumento da incorporação de átomos de silício na composição estrutural dos filmes depositados em processos com maiores fluxos parciais de argônio ou um aumento no estresse residual dos filmes. Portanto, sendo resultado da deficiência de espécies responsáveis pela oxidação de radicais advindos da decomposição das moléculas de TEOS, os filmes obtidos em processos de deposição realizados com maior quantidade de argônio apresentam maior densidade e um menor número de ligações do tipo Si-O em sua composição estrutural.

Observa-se, na condição onde $R=50$, um valor de densidade que se destaca em relação às outras amostras; indicando que nesta condição o 
material depositado pode apresentar um estresse residual maior uma vez que não existe variação significativa na estequiometria obtida para os filmes depositados com $R=40,50$ e 60 .

Na Figura 18 são representadas curvas as CV-AF obtidas a partir de 18 capacitores MOS construídos sobre filmes finos de óxido de silício depositados por HD-PECVD.

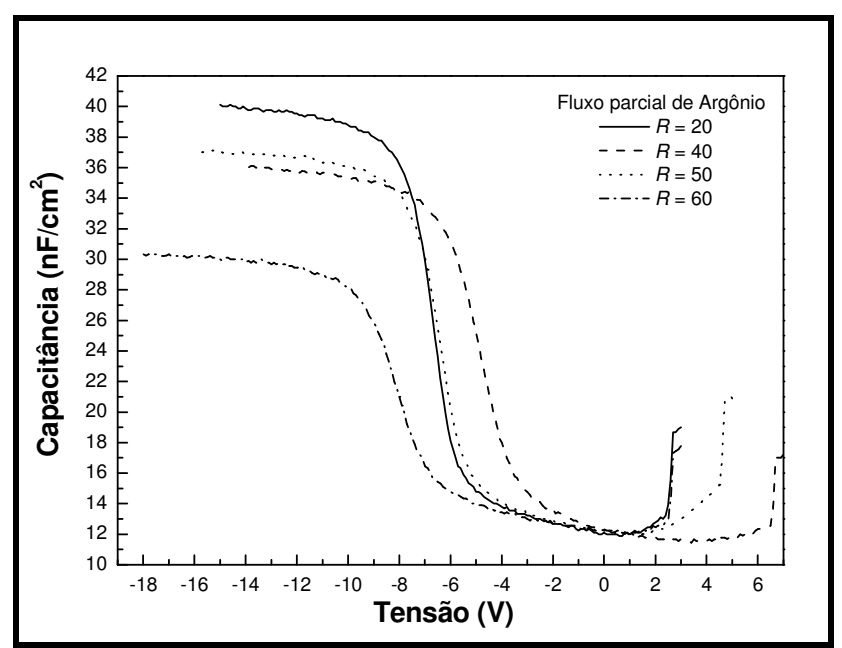

Figura 18 Curvas CV-AF de capacitores MOS implementados com filmes de óxido de silício, parametrizadas em função do fluxo parcial de argônio, depositados a $30^{\circ} \mathrm{C}$ e com $\mathbf{F}_{\text {TEOs }}=0,5 \mathrm{sccm}$. Foram utilizadas as seguintes proporções de argônio, R: 20, 40, 50 e 60.

Nessa série de amostras, representada pela Figura 18, foram verificados efeitos injeção lateral, principalmente nas amostras depositadas com $R>50$. Os efeitos de injeção lateral são evidenciados pela deformação da curva CV-AF na região de inversão, onde se observa um afundamento da curva após a inversão e, logo em seguida, uma tendência de aumento para maiores valores positivos da tensão aplicada. Este efeito é resultado de uma contribuição adicional de portadores minoritários, que provém da região lateral ao capacitor, provocada pela influência de cargas fixas presentes na 
região da interface $\mathrm{Si} / \mathrm{SiO}_{\mathrm{X}}$. Este comportamento evidencia uma má formação da interface nos filmes depositados em processos onde exista menos oxigênio e maior concentração de argônio.

Foi observado, para amostras onde $R>50$, um estiramento das curvas CV-AF, é associado principalmente à presença de cargas armadilhadas na região de interface $\mathrm{Si} / \mathrm{SiO}_{x}$. Além disso, a inclinação dessa região também está associada a espessura do filme. Conforme observado nos espectros de infravermelho (Figura 14), além de haver evidências de ligações do tipo Si-OH, foi observada a presença de ligações do tipo $\mathrm{Si}-\mathrm{H}$, principalmente nas amostras depositadas com fluxos parciais de argônio maiores. A presença destas espécies resulta na formação de cargas fixas no filme principalmente pelo surgimento de "dangling bonds" e ligações químicas incompletas entre os átomos de silício e a rede de Si-O.

O filme depositado com fluxo parcial de argônio $R=40$ apresentou 0 menor valor médio de tensão de banda plana $\left(\mathrm{V}_{\mathrm{FB}}=-5,34 \mathrm{~V}\right)$ e também o menor valor médio da densidade efetiva de cargas $\left(Q_{s s} / q=9,5 \cdot 10^{11} \mathrm{~cm}^{-2}\right.$ - Figura 19). Mesmo assim, ainda são valores relativamente elevados para aplicações como dielétrico de porta em dispositivos TFTs [4]. 


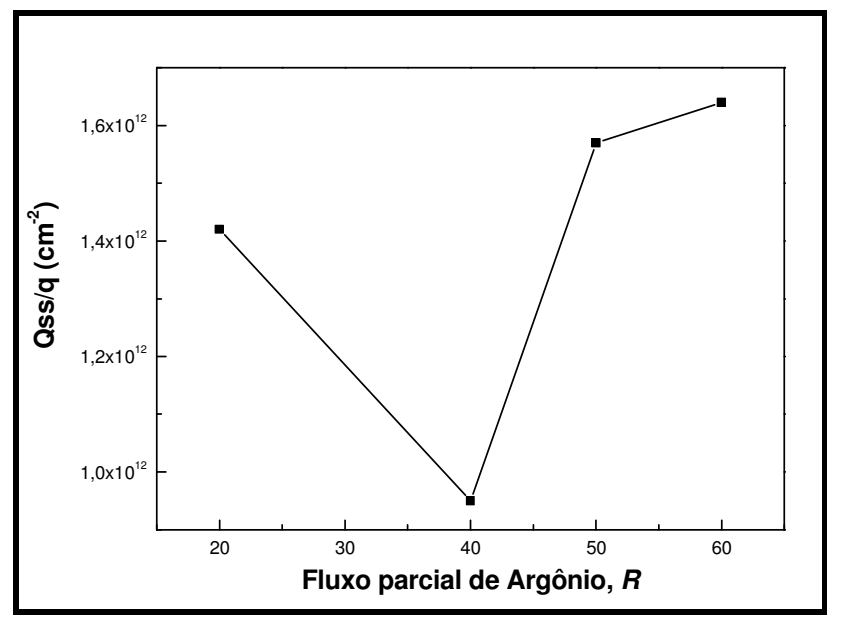

Figura 19 Densidade efetiva de cargas obtidas a partir das curvas CV-AF de capacitores MOS implementados com filmes de óxido de silício, parametrizadas em função do fluxo parcial de argônio, depositados a $30^{\circ} \mathrm{C}$ e com $\mathbf{F}_{\text {TEOs }}=0,5 \mathrm{sccm}$. Foram utilizadas as seguintes proporções de argônio, R: $20,40,50$ e 60 .

De acordo com a Figura 19, nota-se que o menor valor da densidade efetiva de cargas foi apresentado pela amostra $R=40$. Nesta condição de deposição, em função dos resultados apresentados pelas curvas de densidade e estequiometria, pela análise do espectro FTIRS e pelo comportamento das curvas CV-AF, presume-se que a distribuição de energia entre as espécies durante a etapa de deposição do filme tenha alcançado um valor suficiente para que a geração de radicais e o tempo de residência das espécies na superfície do substrato favorecessem a formação de uma interface com menor densidade de defeitos e filmes com menor incorporação de subprodutos de TEOS.

Na Figura 20 é apresentado o comportamento da constante dielétrica obtidas a partir das curvas CV-AF, em função da quantidade de argônio na câmara de reações. 


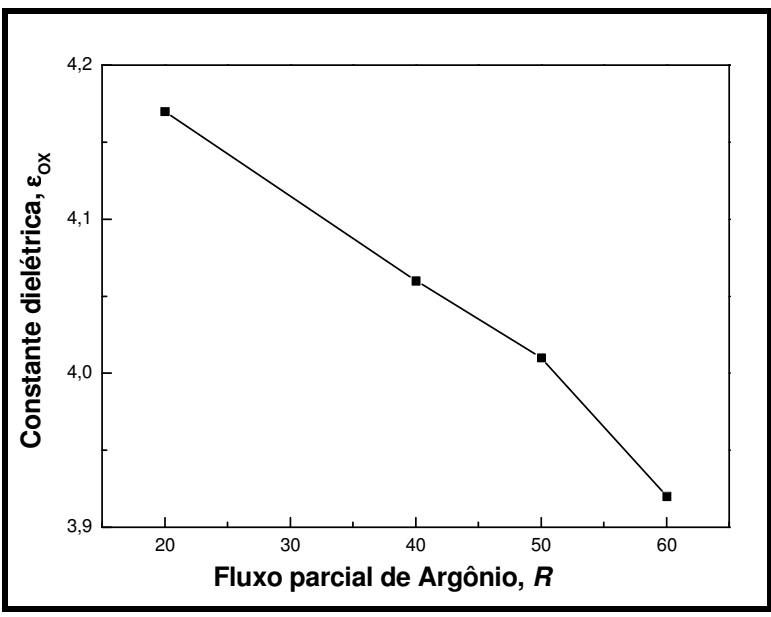

Figura 20 Constante dielétrica obtida a partir das curvas CV-AF de capacitores MOS implementados com filmes de óxido de silício, parametrizadas em função do fluxo parcial de argônio, depositados a $30^{\circ} \mathrm{C}$ e com $\mathbf{F}_{\text {TEOs }}=0,5 \mathrm{sccm}$. Foram utilizadas as seguintes proporções de argônio, R: $20,40,50$ e 60 .

Na Figura 20 pode se observar que os valores da constante dielétrica dos filmes depositados são ligeiramente maiores que do óxido de silício estequiométrico $\left(\varepsilon_{0 x}=3,9\right)$, indicando que, no aspecto geral, os filmes depositados são ricos em silício. Nota-se uma diminuição dos valores da constante dielétrica, de acordo com o aumento do fluxo parcial de argônio, indicando que os filmes apresentam maior concentração de defeitos estruturais resultando em materiais porosos e com maior estresse residual.

O comportamento da densidade efetiva de cargas em relação a espessura dos filmes de óxido de silício depositados é apresentado na Figura 21. 


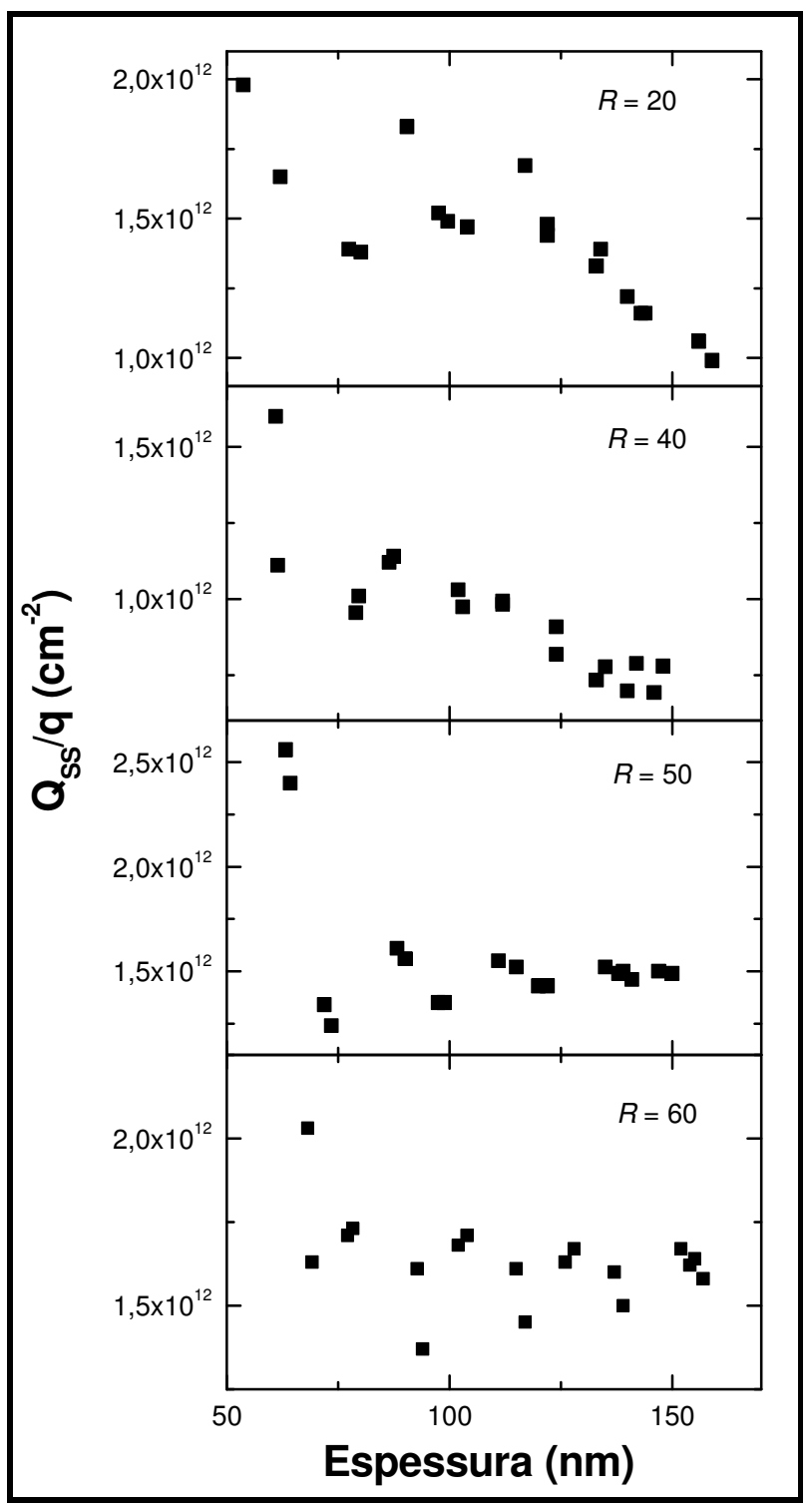

Figura 21 Densidade efetiva de cargas em função da espessura, obtidas a partir das curvas CV-AF de capacitores MOS implementados com filmes de óxido de silício em diferentes espessuras, parametrizadas em função do fluxo parcial de argônio, depositados a $30^{\circ} \mathrm{C}$ e com $\mathbf{F}_{\text {TEOS }}=0,5 \mathrm{sccm}$. Foram utilizadas as seguintes proporções de argônio, R: 20, 40, 50 e 60 .

Nota-se, a partir da Figura 21, que não existe uma variação significativa no comportamento da densidade efetiva de cargas para filmes com espessuras maiores que $100 \mathrm{~nm}$. Na região onde os filmes apresentam uma espessura média inferior a $100 \mathrm{~nm}$, verifica-se um aumento da 
densidade efetiva de cargas ocasionado, principalmente, pela influência de cargas localizadas na interface $\mathrm{Si} / \mathrm{SiO}_{\mathrm{x}}$. Dessa forma, com base nos resultados apresentados na Figura 18, supõe-se, principalmente nos processos onde o material é depositado com $R$ menor ou igual a 50, que exista uma densidade muito baixa de cargas móveis ou cargas armadilhadas na estrutura do material depositado. Portanto, pode-se afirmar que a região da interface $\mathrm{Si} / \mathrm{SiO}_{x}$ é a região mais sensível à variação das condições do processo de deposição, onde se localiza a maior concentração de cargas provenientes da presença de defeitos estruturais dos filmes de óxido de silício depositados.

Na Figura 22 são apresentadas as curvas J-E representando uma série de 18 capacitores medidos em cada uma das amostras depositadas em função do fluxo parcial de argônio.

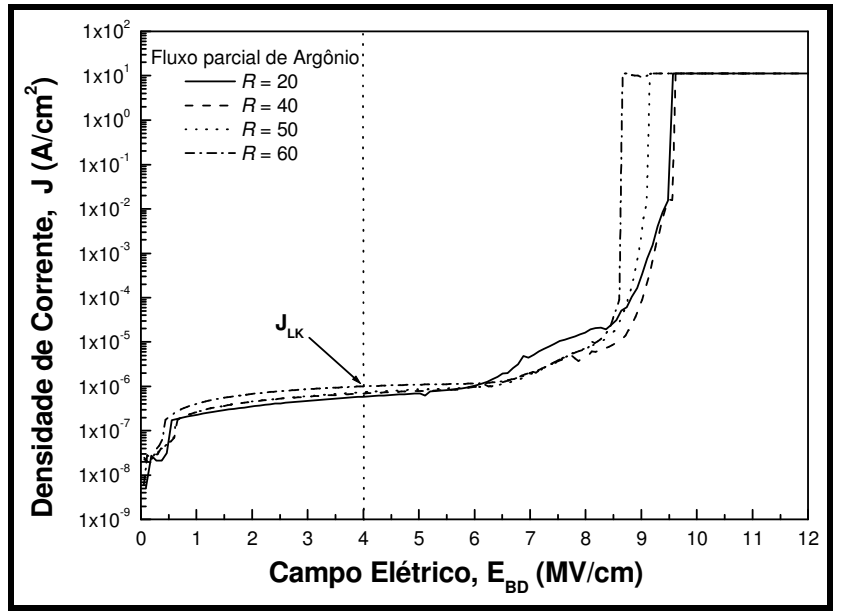

Figura 22 Curvas J-E obtidas a partir de capacitores MOS implementados com filmes de óxido de silício, parametrizadas em função do fluxo parcial de argônio, depositados a $30^{\circ} \mathrm{C}$ e com $\mathbf{F}_{\mathrm{TEO}}=0,5 \mathrm{sccm}$. Foram utilizadas as seguintes proporções de argônio, R: 20, 40, 50 e 60.

A partir das curvas J-E, Figura 22, observou-se que o filme depositado 
com fluxo parcial de argônio $R=60$ apresentou o maior valor médio da densidade de corrente de fuga a $4 \mathrm{MV} / \mathrm{cm}\left(\mathrm{J}_{\mathrm{LK}}\right)$ e menor valor médio do campo elétrico de ruptura $\left(E_{\mathrm{BD}}\right), \quad 8,82 \cdot 10^{-7} \mathrm{~A} / \mathrm{cm}^{2}$ e $8,83 \mathrm{MV} / \mathrm{cm}$ respectivamente.

Na maior parte das curvas extraídas da amostra depositada com fluxo parcial de argônio $R=20$, não obstante de apresentar o menor valor médio de $J_{L K}\left(4,71 \cdot 10^{-7} \mathrm{~A} / \mathrm{cm}^{2}\right)$, foi observada a presença de uma deformação abrupta antes da ruptura do material, indicando a influência das cargas armadilhadas na interface $\mathrm{Si} / \mathrm{SiO}_{x}$ [5], [12], [23].

Na Figura 23 é apresentado o comportamento da densidade da corrente de fuga média das amostras depositadas com $F_{\text {TEOS }}=0,5 \mathrm{sccm}$.

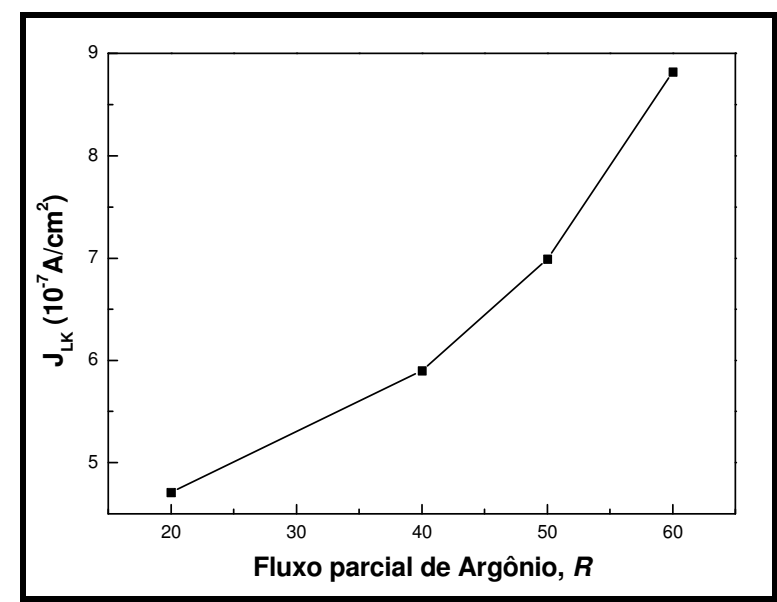

Figura 23 Densidade de corrente de fuga média obtida a partir das curvas J-E de capacitores MOS implementados com filmes de óxido de silício, parametrizadas em função do fluxo parcial de argônio, depositados a $30^{\circ} \mathrm{C}$ e com $\mathbf{F}_{\text {TEOs }}=0,5 \mathrm{sccm}$. Foram utilizadas as seguintes proporções de argônio, R: $20,40,50$ e 60 .

A amostra depositada com fluxo parcial de argônio $R=40$ apresentou um dos menores valores médios de $J_{L K}$, e o campo de ruptura da rigidez 
dielétrica médio foi um dos maiores dessa série de experimentos (Figura 24), demonstrando que o material, depositado nessas condições, apresenta um melhor comportamento elétrico comparativamente às outras amostras.

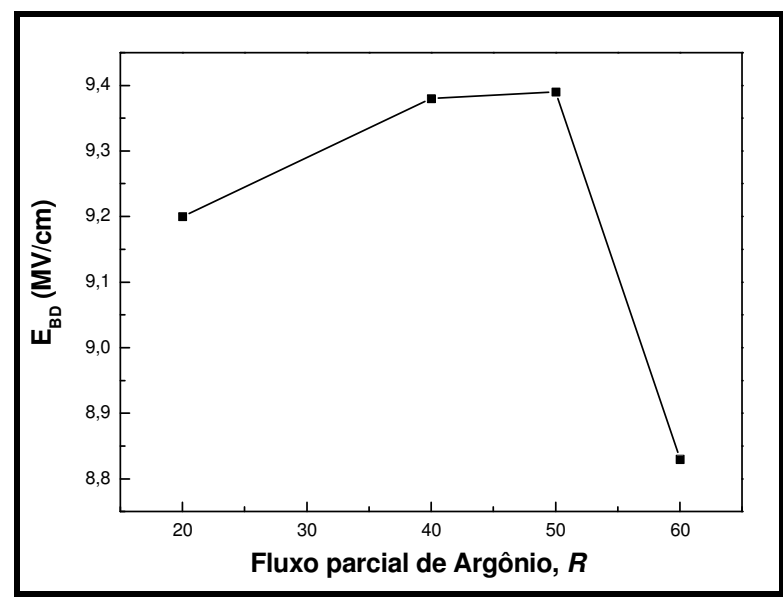

Figura 24 Campo elétrico de ruptura da rigidez dielétrica médio obtidas a partir das curvas J-E de capacitores MOS implementados com filmes de óxido de silício, parametrizados em função do fluxo parcial de argônio, depositados a $30^{\circ} \mathrm{C}$ e com $\mathbf{F}_{\text {TEOS }}=0,5 \mathrm{sccm}$. Foram utilizadas as seguintes proporções de argônio, R: 20, 40, 50 e 60.

\subsubsection{Temperatura do processo de deposição, $T=150^{\circ} \mathrm{C}$}

Nessa série de experimentos, foram caracterizados filmes de óxido de silício depositados por HD-PECVD a uma temperatura de $150^{\circ} \mathrm{C}$ e $F_{\text {TEOS }}=0,5 \mathrm{sccm}$, de acordo com os parâmetros especificados na Tabela 2.

Na Figura 25, são apresentados os índices de refração dessa série de experimentos. 


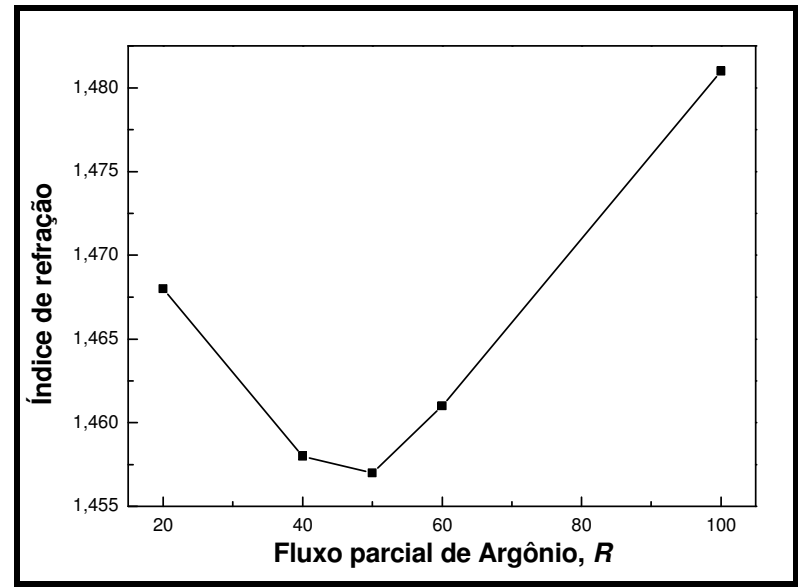

Figura 25 Índice de refração médio dos filmes de óxido de silício, em função do fluxo parcial de argônio, depositados a $150^{\circ} \mathrm{C}$ e com $\mathbf{F}_{\text {TEOs }}=0,5 \mathrm{sccm}$. Foram utilizadas as seguintes proporções de argônio, R: 20, 40, 50, 60 e 100.

Observa-se, a partir da Figura 25, que os filmes depositados com maiores fluxos parciais de argônio apresentam índice de refração maiores, apontando que a diminuição da parcela de oxigênio durante a etapa de deposição favorece a formação de filmes ricos em silício. Nota-se que as filmes depositados com $R=40,50$ e 60 apresentaram valores do índice de refração próximos a 1,46, indicando uma semelhança na composição estrutural e estequiometria destas amostras.

Na Figura 26, são apresentas as taxas de deposição e corrosão das amostras depositadas a $150^{\circ} \mathrm{C}$. 


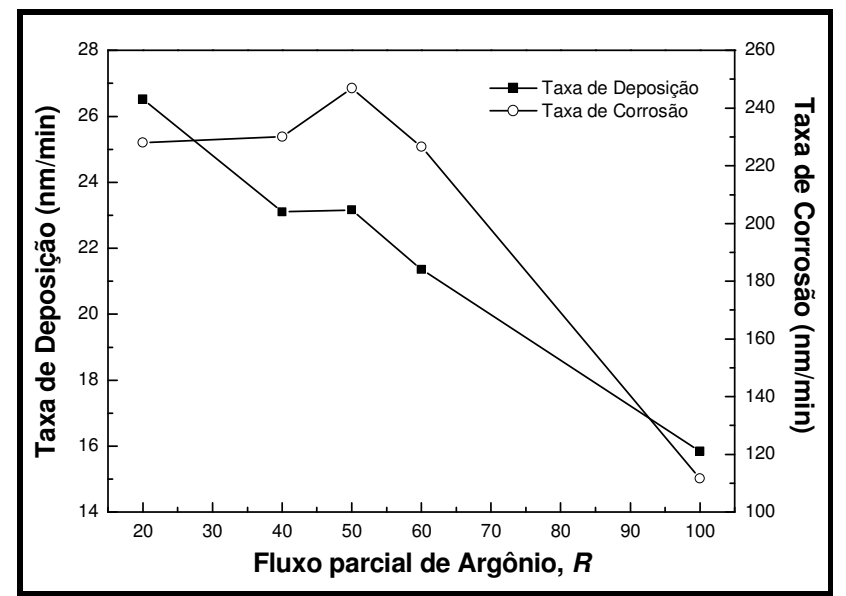

Figura 26 Taxa de deposição e de corrosão dos filmes de óxido de silício, em função do fluxo parcial de argônio, depositados a $150^{\circ} \mathrm{C}$ e com $\mathbf{F}_{\text {TEOS }}=0,5 \mathrm{sccm}$. Foram utilizadas as seguintes proporções de argônio, R: $20,40,50,60$ e 100.

Observa-se, na Figura 26, que as taxas de deposição e de corrosão sofrem uma diminuição progressiva, de acordo com o aumento da parcela de argônio admitida no reator durante a deposição dos filmes de óxido de silício, indicando uma provável mudança composicional que resulta na deposição de filmes ricos em silício ou com uma provável incorporação de subprodutos de TEOS.

Comparando-se estes resultados aos obtidos para a série de amostras depositadas a $30^{\circ} \mathrm{C}$, os valores das taxas de deposição e de corrosão mantiveram-se na mesma ordem de grandeza e com o mesmo comportamento em função do fluxo parcial de argônio $R$, indicando uma semelhança no comportamento estrutural e químico das duas séries de experimentos.

Na série de amostras depositadas a $150^{\circ} \mathrm{C}$, nota-se um aumento significativo na intensidade de absorção dos picos correspondentes ao $\mathrm{CO}_{2}$. 
como é indicado na Figura 27.

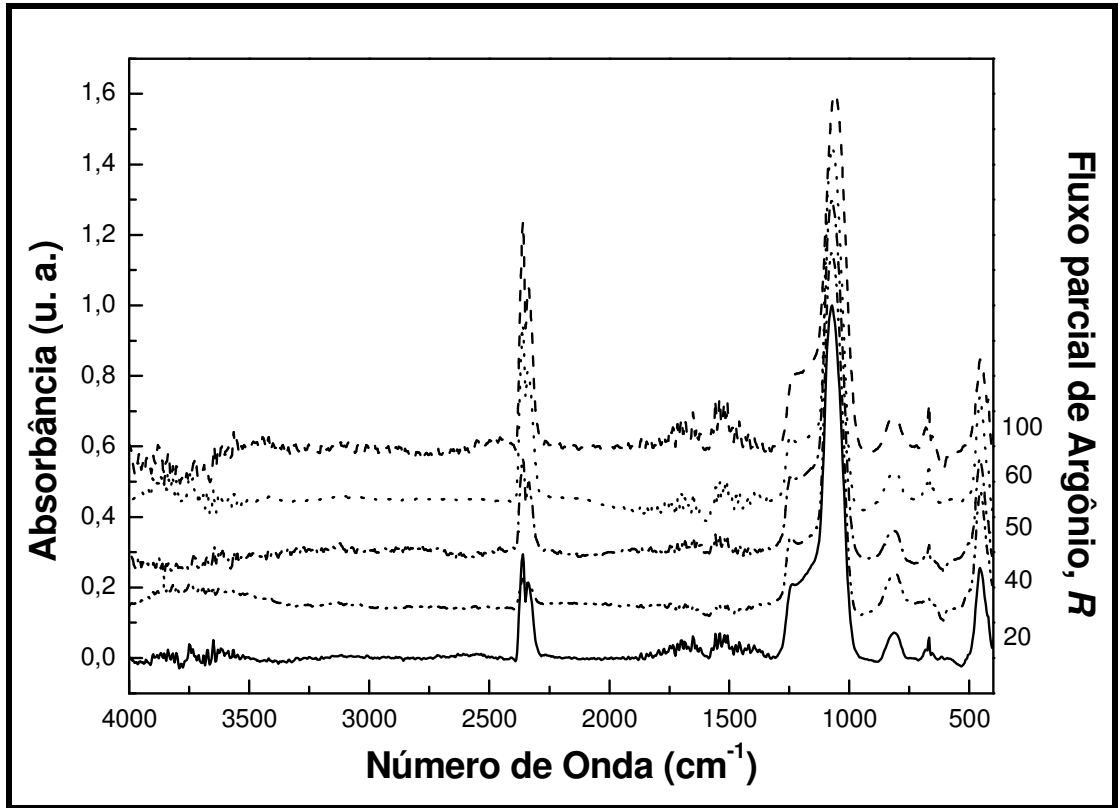

Figura 27 Espectros FTIRS dos filmes de óxido de silício, em função do fluxo parcial de argônio, depositados a $150^{\circ} \mathrm{C}$ e com $\mathbf{F}_{\text {TEOS }}=0,5 \mathrm{sccm}$. Foram utilizadas as seguintes proporções de argônio, R: 20, 40, 50, 60 e 100.

Na região que compreende 3500 e $4000 \mathrm{~cm}^{-1}$, são observados picos que indicam a provável presença de água e ligações do tipo $\mathrm{OH}$; assim como os picos relacionados à presença de $\mathrm{H}_{2} \mathrm{O}$ e ligações $\mathrm{C}=\mathrm{O}$ e $\mathrm{CH}_{\mathrm{x}}$ na região entre 1300 e $1800 \mathrm{~cm}^{-1}$ [40]-[42].

Na amostra depositada com $R=40$, observa-se uma diminuição da intensidade de absorção do pico de $\mathrm{CO}_{2}\left(\sim 2300 \mathrm{~cm}^{-1}\right)$ e também dos picos relacionados a espécies $\mathrm{OH}$ e $\mathrm{CH}_{\mathrm{x}}$, indicando uma menor incorporação de subprodutos de TEOS desta amostra em relação às demais.

A partir de uma imagem mais detalhada, apresentada na Figura 28, são observados os picos característicos do modo vibracional "bending" de ligações Si-H na banda de absorção compreendida entre $650-660 \mathrm{~cm}^{-1} \mathrm{em}$ 
praticamente todas as amostras desta série de experimentos, com apenas uma diminuição de intensidade na amostra onde $R=40$.

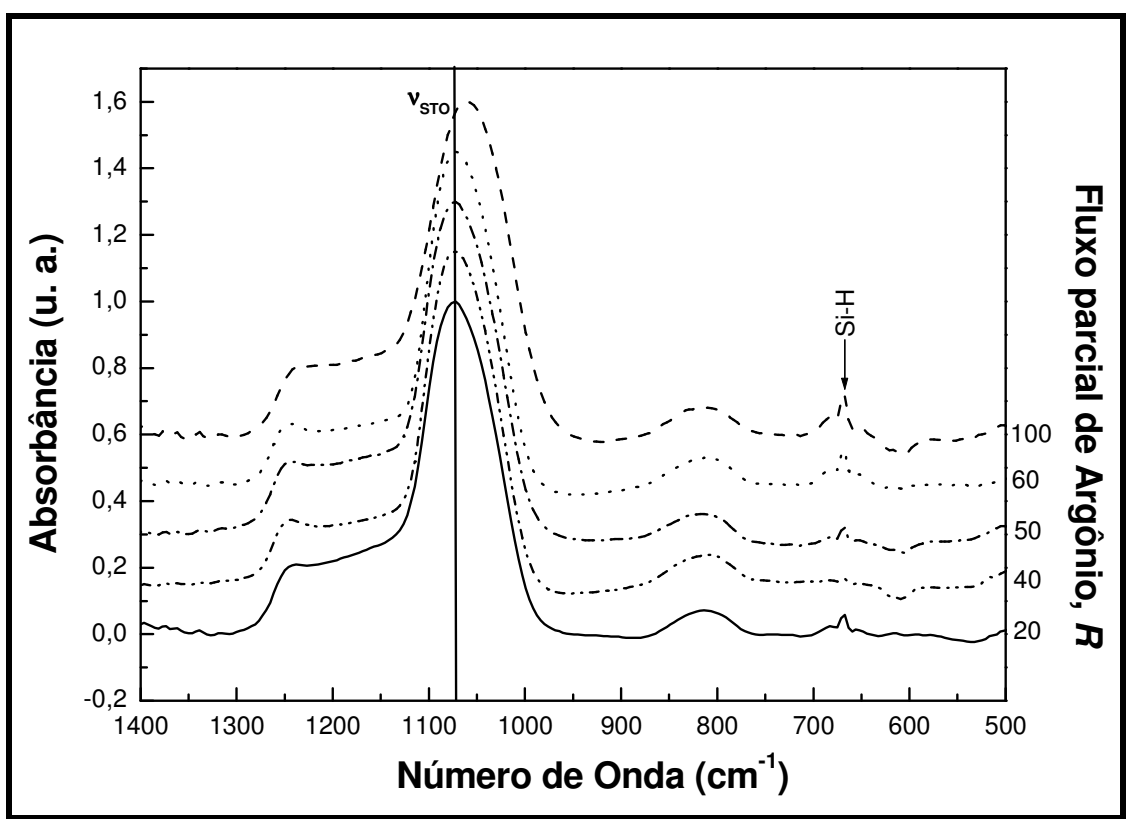

Figura 28 Detalhe dos espectros FTIRS dos filmes de óxido de silício, em função do fluxo parcial de argônio, depositados a $150^{\circ} \mathrm{C}$ e com $\mathbf{F}_{\text {TEOS }}=0,5 \mathrm{sccm}$. Foram utilizadas as seguintes proporções de argônio, $\mathbf{R}$ : $20,40,50,60$ e 100.

A partir dos dados apresentados na Figura 28, nota-se um deslocamento da posição do pico correspondente às ligações Si-O

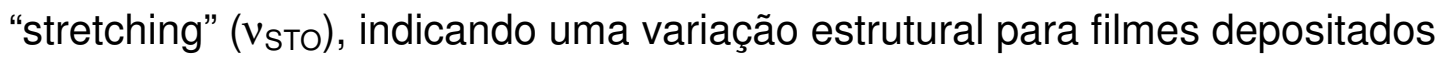
em processos com maiores fluxos parciais de argônio.

Na Figura 29 é apresentado o comportamento de FWHM das amostras depositadas a $150^{\circ} \mathrm{C}$. 


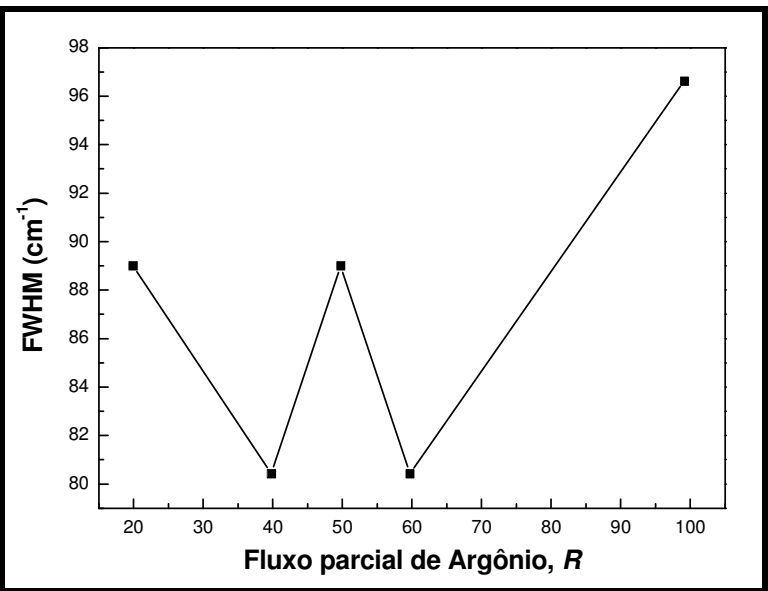

Figura 29 Comportamento da largura à meia altura (FWHM), atribuída a uma variação na composição estrutural e estresse residual, dos filmes de óxido de silício depositados a $150^{\circ} \mathrm{C}$ e com $\boldsymbol{F}_{\text {TEOS }}=0,5 \mathrm{sccm}$. Foram utilizadas as seguintes proporções de argônio, R: 20, 40, 50, 60 e 100.

A partir da análise da Figura 29, para maiores valores de $R$, o valor de FWHM torna-se maior, indicando uma provável variação da densidade e estresse dos filmes depositados. Na condição onde $R=50$, um aumento abrupto no valor de FWHM aponta que o filme apresenta uma variação significativa no estresse residual e densidade, quando comparado às outras amostras [46],[47].

\subsubsection{Temperatura do processo de deposicão, $T=250^{\circ} \mathrm{C}$}

Nessa série de experimentos, foram caracterizados filmes de óxido de silício depositados por HD-PECVD a uma temperatura de $250^{\circ} \mathrm{C}$ e $F_{\text {TEOS }}=0,5 \mathrm{sccm}$, de acordo com os parâmetros especificados na Tabela 2.

Na Figura 30, são apresentados os índices de refração dessa série de experimentos. 


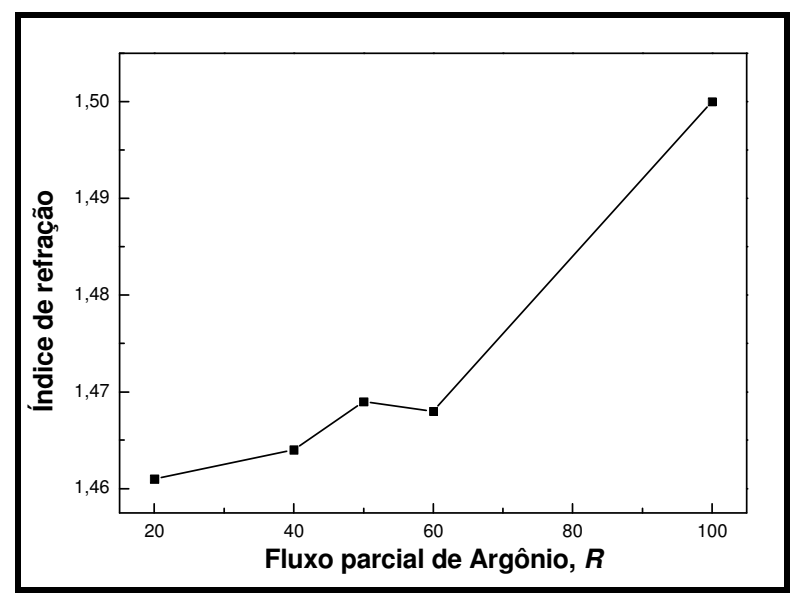

Figura 30 Índice de refração médio dos filmes de óxido de silício, em função do fluxo parcial de argônio, depositados a $250^{\circ} \mathrm{C}$ e com $\mathbf{F}_{\text {TEos }}=0,5 \mathrm{sccm}$. Foram utilizadas as seguintes proporções de argônio, R: 20, 40, 50, 60 e 100.

Na condição de deposição onde $R=20$, Figura 30 , observa-se que 0 valor do índice de refração é muito próximo ao índice de refração do óxido de silício térmico. Nessa condição, uma maior quantidade de oxigênio é admitido na câmara de reações, como consta na Tabela 2. No geral, com exceção da amostra depositada com $R=100$, os valores dos índices de refração são muito próximos a 1,46, evidenciando a contribuição da temperatura do processo de deposição no comportamento estrutural dos filmes.

Na Figura 31 são apresentadas as taxas de deposição e corrosão da série de amostras depositadas a $250^{\circ} \mathrm{C}$. 


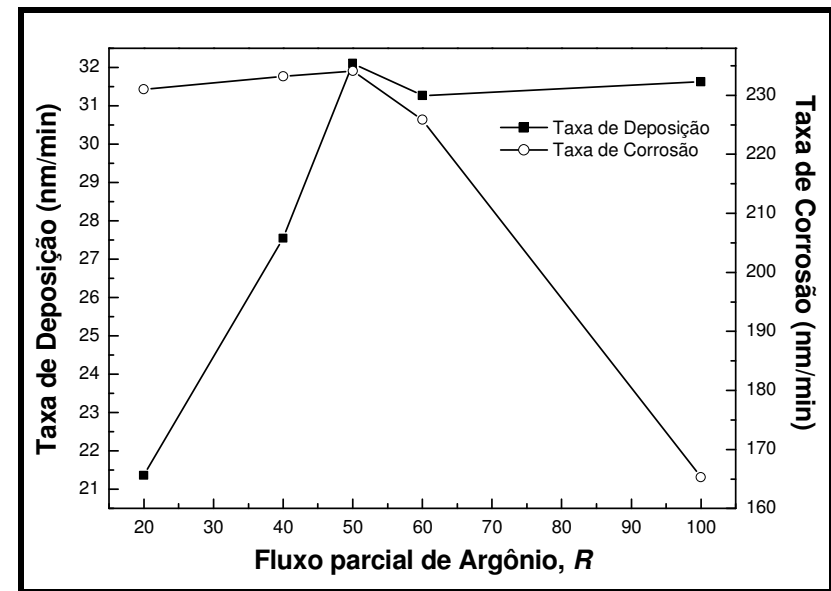

Figura 31 Taxa de deposição e de corrosão dos filmes de óxido de silício, em função do fluxo parcial de argônio, depositados a $250^{\circ} \mathrm{C}$ e com $\mathbf{F}_{\text {TEOS }}=0,5 \mathrm{sccm}$. Foram utilizadas as seguintes proporções de argônio, R: $20,40,50,60$ e 100.

A partir da Figura 31, observa-se nas amostras cujo valor $R$ é compreendido entre 20 e 50, a taxa de deposição apresenta os menores valores e o contrário ocorre com os valores da taxa de corrosão. Nestas amostras, com o aumento da quantidade de espécies oxidantes $\left(\mathrm{O}_{2}{ }^{+}\right)$e com o aumento da disponibilidade de sítios ativos na superfície da amostra, favorecido pelo do aquecimento do substrato, os filmes de óxido de silício foram depositados de uma maneira mais estruturada de forma que a quantidade de ligações do tipo Si-O predominassem.

A partir da condição onde $R=50$, nota-se que os valores da taxa de deposição mantêm-se praticamente constantes enquanto os valores da taxa de corrosão diminuem gradativamente com o aumento de $R$, apontando uma maior incorporação de subprodutos de TEOS em função da diminuição da concentração de oxigênio durante a etapa de deposição, como consta na Tabela 2. 
São apresentados na Figura 32 e na Figura 33, os espectros FTIRS da série de amostras depositadas a $250^{\circ} \mathrm{C}$ e com fluxo de TEOS a $0,5 \mathrm{sccm}$.

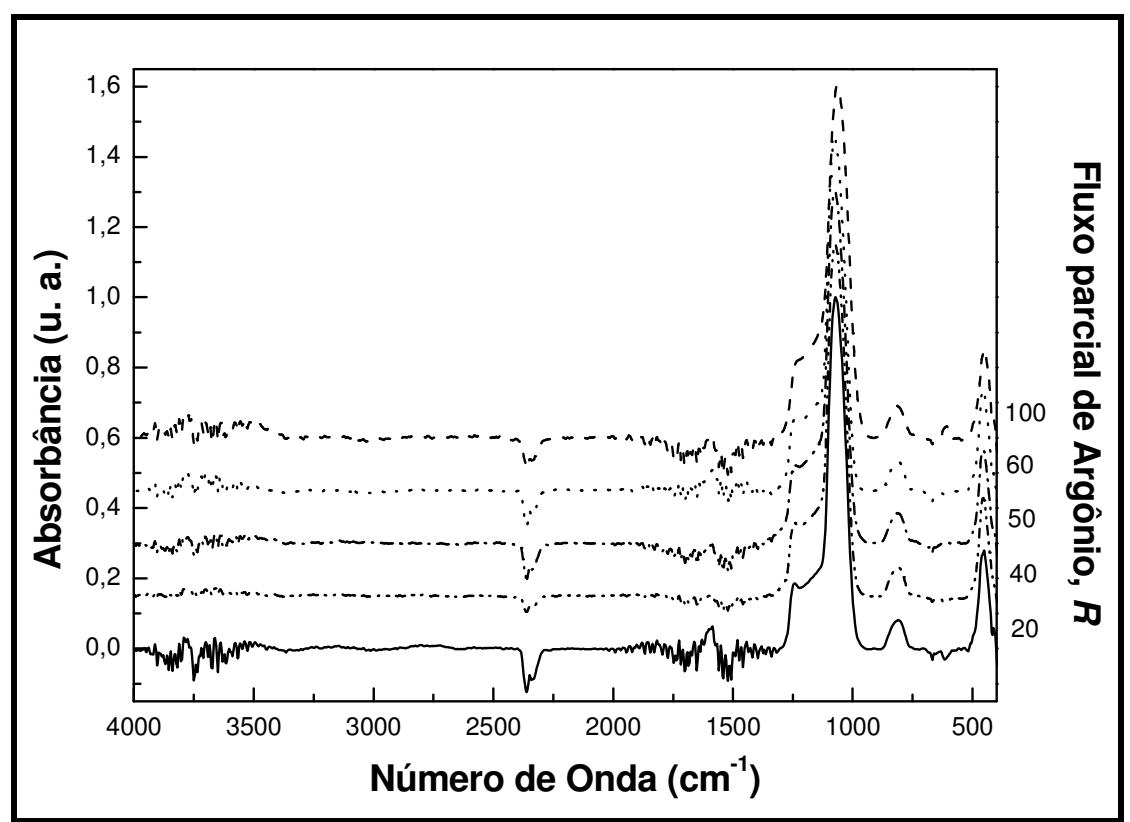

Figura 32 Espectros FTIRS dos filmes de óxido de silício, em função do fluxo parcial de argônio, depositados a $250^{\circ} \mathrm{C}$ e com $\mathbf{F}_{\text {TEOs }}=0,5 \mathrm{sccm}$. Foram utilizadas as seguintes proporções de argônio, R: 20, 40, 50, 60 e 100.

De acordo com os dados apresentados na Figura 32, são observados os picos de absorção característicos de $\mathrm{CO}_{2}, \mathrm{H}_{2} \mathrm{O}$ e $\mathrm{CH}_{\mathrm{x}}$ em todas as amostras. Na condição $R=40$, observa-se que estes picos apresentam os seus menores valores de intensidade, apontando um favorecimento da decomposição de moléculas de TEOS e menor incorporação de subprodutos nesta condição de processo.

Nesta série de amostras, observa-se uma diminuição significativa da intensidade do pico de absorção relacionado ao modo vibracional "bending" de ligações Si-H (650-660 cm $\left.{ }^{-1}\right)$, como é apresentado na Figura 33. 


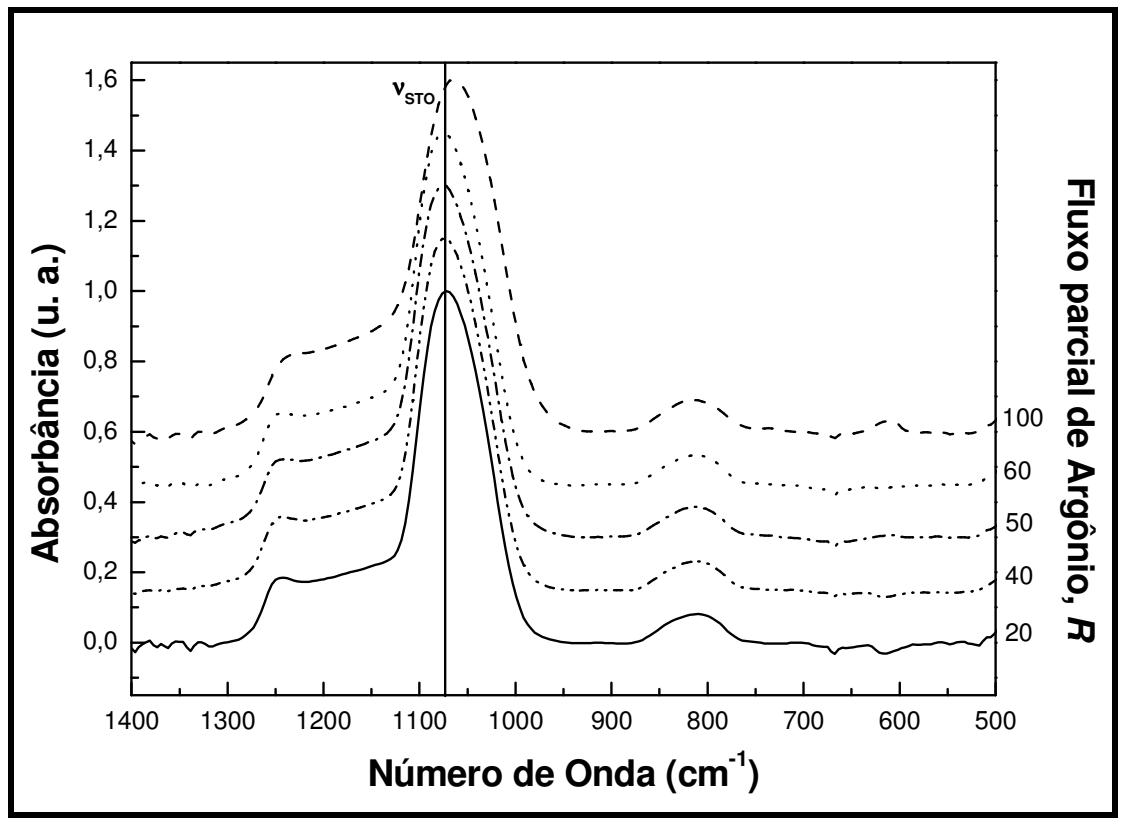

Figura 33 Detalhe dos espectros FTIRS dos filmes de óxido de silício, em função do fluxo parcial de argônio, depositados a $250^{\circ} \mathrm{C}$ e com $\mathbf{F}_{\text {TEOS }}=0,5 \mathrm{sccm}$. Foram utilizadas as seguintes proporções de argônio, $\mathbf{R}$ : $20,40,50,60$ e 100.

De acordo com a Figura 33, nota-se um pequeno deslocamento do pico relativo ao modo vibracional "stretching" $\left(v_{\text {STO }}\right)$ na amostra onde $R=100$. Este tipo de deslocamento está associado a uma mudança estrutural [46] e também ao estresse residual do material [47].

Na Figura 34 é apresentado o comportamento de FWHM para as amostras depositadas a $250^{\circ} \mathrm{C}$ e com $\mathrm{F}_{\text {TEOS }}=0,5 \mathrm{sccm}$. 


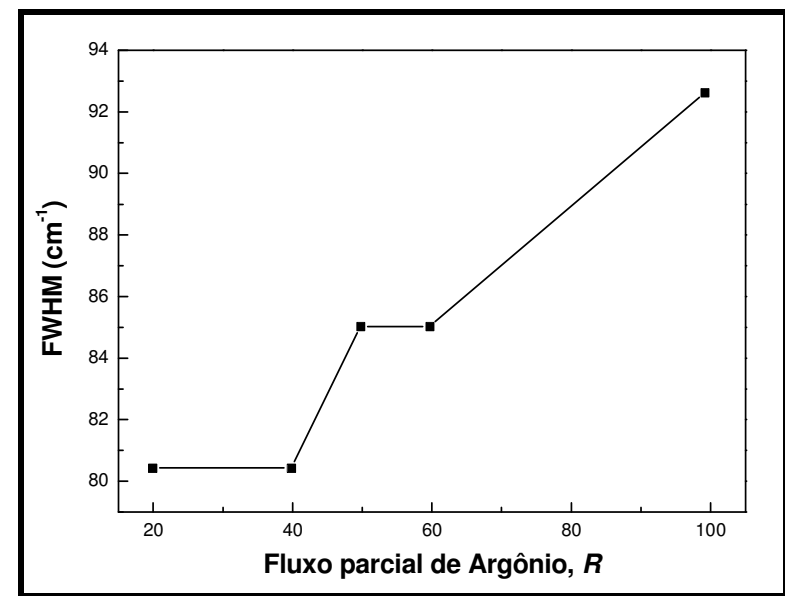

Figura 34 Comportamento da largura à meia altura (FWHM), atribuída a uma variação na composição estrutural e estresse residual, dos filmes de óxido de silício depositados a $250^{\circ} \mathrm{C}$ e com $\mathbf{F}_{\mathrm{TEOS}}=0,5 \mathrm{sccm}$. Foram utilizadas as seguintes proporções de argônio, R: 20, 40, 50, 60 e 100.

A partir da Figura 34, verifica-se uma variação gradativa de FWHM para amostras depositadas com fluxos parciais de argônio cada vez maiores, seguindo praticamente o mesmo comportamento dos valores da taxa de deposição (Figura 31). Nota-se que os valores de FWHM das amostras depositadas nas condições $R=20$ e 40 mantêm-se constantes até a condição onde $R$ assume o valor de 50; a partir desta condição, surge um novo patamar e então o valor de FWHM aumenta novamente a partir de $R=60$. Este comportamento aponta uma variação sensível ao fluxo parcial de argônio e, conseqüentemente, à distribuição de energia no plasma nas propriedades estruturais e do estresse residual dos filmes depositados nesta série de amostras.

De acordo com os resultados apresentados anteriormente, nas amostras depositadas com $\mathrm{R}=20$ e 40 , por haver uma oferta maior de oxigênio durante a etapa de deposição e com o favorecimento da mobilidade 
dos radicais pelos sítios ativos na superfície do substrato decorrente do aumento na temperatura, pressupõe-se que os filmes de óxido de silício apresentem uma concentração maior de ligações Si-O. Assim, verifica-se que estas amostras apresentam um bom equilíbrio das propriedades estruturais, em relação às séries de experimentos realizadas anteriormente, tornando evidente a influência da temperatura do substrato durante a deposição dos filmes de óxido de silício através do sistema HD-PECVD.

A seguir, Figura 35, são apresentadas as curvas referentes à variação de $v_{\text {Sto, }}$ pico de "stretching" das ligações Si-O-Si, nas amostras depositadas em diferentes condições de temperatura.

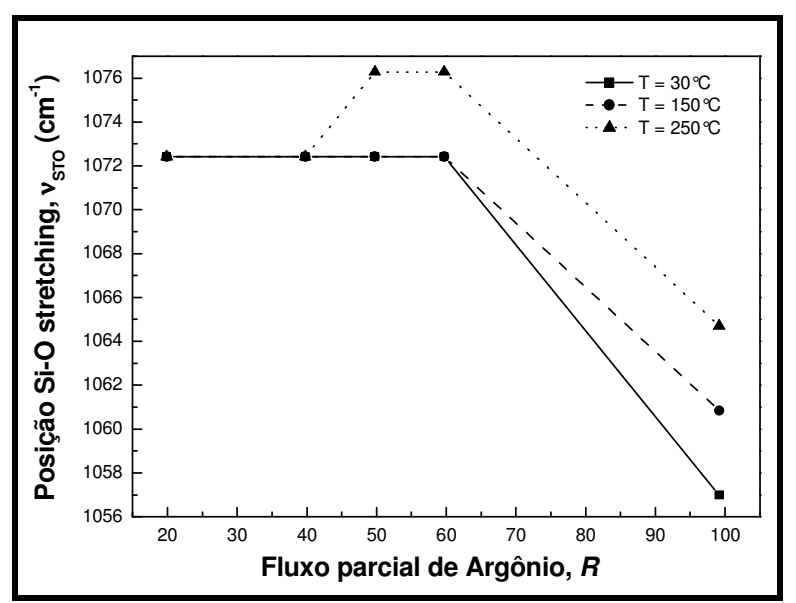

Figura 35 Variação do pico Si-O "stretching" dos filmes de óxido de silício, em função do fluxo parcial de argônio, parametrizados de acordo com a temperatura de deposição: 30,150 e $250^{\circ} \mathrm{C}$ e com $\mathbf{F}_{\text {TEOS }}=0,5 \mathrm{sccm}$. Foram utilizadas as seguintes proporções de argônio, R: 20, 40, 50, 60 e 100.

A densidade de átomos de oxigênio na estrutura dos filmes de $\mathrm{SiO}_{x}$ está intimamente ligada à posição e comportamento de $v_{\text {STO }}$ nos espectros de infravermelho. Quando o valor de $v_{\text {STO }}$ se aproxima de $1075 \mathrm{~cm}^{-1}$ significa que a estrutura do material está mais próxima da formação básica 
tetraédrica $\mathrm{SiO}_{4 / 2}$ devido à interação dos movimentos em fase, com a onda eletromagnética do feixe de infravermelho, dos átomos de oxigênio com o movimento fora de fase dos átomos de silício vizinhos. Quando a densidade de átomos de oxigênio é afetada pela má formação estrutural ("dangling bonds"), e afetando conseqüentemente a estequiometria do filme, o valor da banda de absorção "stretching" característica (vSTO) e a largura à meia altura (FWHM) sofrem uma variação e distanciam-se do valor de $1075 \mathrm{~cm}^{-1} \mathrm{e}$ $80 \mathrm{~cm}^{-1}$ respectivamente [46].

Assim, de acordo com a Figura 35 e com os resultados anteriormente apresentados, nota-se que, mesmo com variação da temperatura do processo, a relação dos fluxos de argônio e oxigênio influenciam diretamente na estequiometria e nas propriedades dos filmes de óxido de silício depositados.

Através dos espectros de infravermelho foi possível determinar uma condição de trabalho onde os filmes depositados ofereçam um comportamento estrutural que corresponda efetivamente aos objetivos deste trabalho. Essa janela trabalho compreende processos de deposição com fluxos parciais de argônio $R$ entre 50 a 40 .

\subsection{Amostras depositadas com $\mathrm{F}_{\mathrm{TEOS}}=1 \mathrm{sccm}$}

Nesta série de experimentos, os filmes de óxido de silício foram depositados a partir de um fluxo de $1 \mathrm{sccm}$ de TEOS e a temperatura de $30^{\circ} \mathrm{C}$.

Na Figura 36 são apresentados os índices de refração obtidos para as 
amostras depositadas com $\mathrm{F}_{\mathrm{TEOS}}=1 \mathrm{sccm}$ a $30^{\circ} \mathrm{C}$.

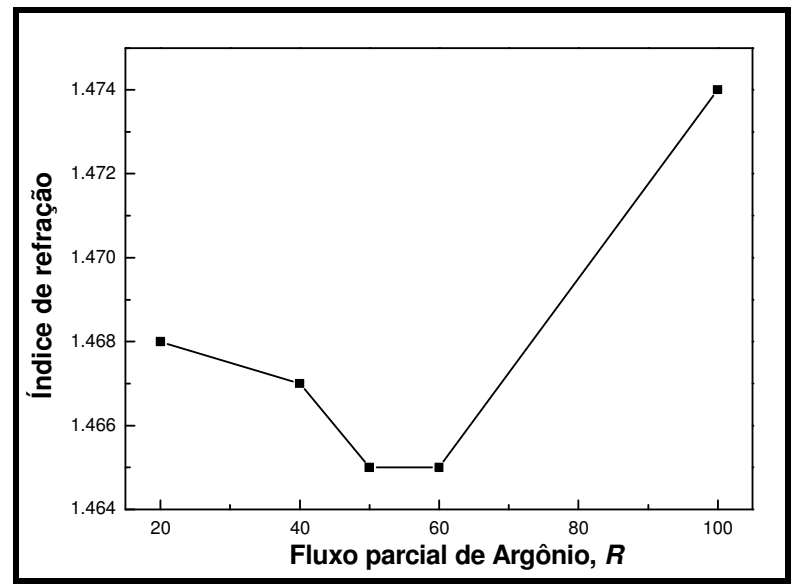

Figura 36 Índice de refração dos filmes de óxido de silício, em função do fluxo parcial de argônio, depositados a $30^{\circ} \mathrm{C}$ e com $\mathbf{F}_{\mathrm{TEO}}=1 \mathrm{sccm}$. Foram utilizadas as seguintes proporções de argônio, R: 20, 40, 50, 60 e 100.

A partir dos resultados apresentados na Figura 36, observa-se que os valores dos índices de refração desta série de amostras são muito próximos ao índice de refração de filmes de $\mathrm{SiO}_{2}$ térmicos, com exceção da amostra $R=100$. De acordo com o gráfico, os filmes depositados com $\mathrm{R}=50$ e 60 apresentam os valores mais próximos a 1,46.

Na Figura 37, é apresentada a taxa de deposição das amostras depositadas com $\mathrm{F}_{\mathrm{TEOS}}=1 \mathrm{sccm}$. 


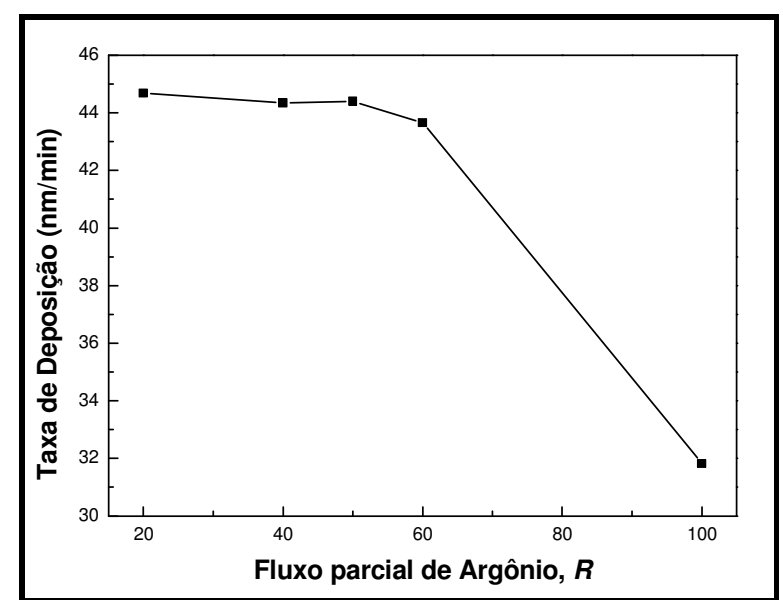

Figura 37 Taxa de deposição e de corrosão dos filmes de óxido de silício, em função do fluxo parcial de argônio, depositados a $30^{\circ} \mathrm{C}$ e com $\mathbf{F}_{\text {TEOS }}=1 \mathrm{sccm}$. Foram utilizadas as seguintes proporções de argônio, $\mathbf{R}: 20$, $40,50,60$ e 100.

De acordo com a Figura 37, a taxa de deposição dos filmes de óxido de silício sofre uma diminuição a partir do ponto onde $R$ assume valores maiores que 50, indicando que o aumento na proporção de argônio, e conseqüente diminuição da proporção de oxigênio, resulta em filmes eventualmente ricos em silício.

A partir dos resultados apresentados na Figura 37, verifica-se a influência do aumento do fluxo de TEOS, onde os valores da taxa de deposição desta série de amostras são, aproximadamente, o dobro dos valores apresentados na série de amostras depositadas com $F_{\text {TEOS }}=0,5 \mathrm{sccm}$ a $30^{\circ} \mathrm{C}$ (Figura 13).

Na Figura 38 são apresentados os espectros FTIRS das amostras depositadas com fluxo de $1 \mathrm{sccm}$ de TEOS. 


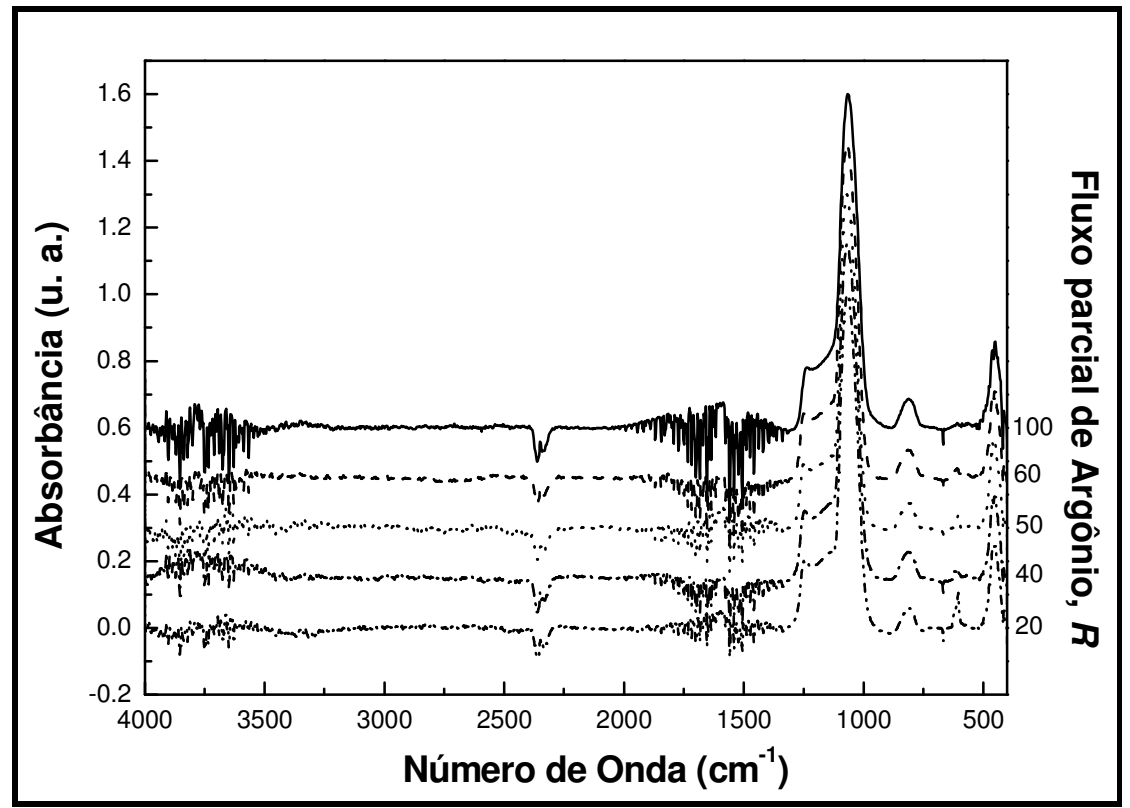

Figura 38 Espectros FTIRS dos filmes de óxido de silício, em função do fluxo parcial de argônio, depositados a $30^{\circ} \mathrm{C}$ e com $\mathbf{F}_{\text {TEOS }}=1 \mathrm{sccm}$. Foram utilizadas as seguintes proporções de argônio, R: 20, 40, 50, 60 e 100.

A partir dos resultados obtidos pela análise FTIRS, observa-se em todas as amostras a presença dos picos relativos à presença de $\mathrm{CO}_{2}$, na banda que abrange os comprimentos de onda $2200-2300 \mathrm{~cm}^{-1}$, dos picos relacionados às espécies $\mathrm{CH}_{\mathrm{x}}, \mathrm{H}_{2} \mathrm{O}$ e ligações $\mathrm{C}=\mathrm{O}$ na região entre 1300 e $1800 \mathrm{~cm}^{-1}$ e dos picos relacionados à $\mathrm{OH}$ e $\mathrm{H}_{2} \mathrm{O}$ na região compreendida entre 3500 e $3800 \mathrm{~cm}^{-1}$; tornando evidente a incorporação de subprodutos de TEOS nas amostras depositadas nesta série de experimentos.

Através da análise de uma imagem mais detalha, como mostra a Figura 39, observa-se na região entre $650-660 \mathrm{~cm}^{-1}$, o pico característico do modo vibracional "bending" das ligações Si-H. A intensidade dos picos de absorção característicos de ligações Si-H é significativamente menor para a amostra depositada com o fluxo parcial de argônio $R=50$. 


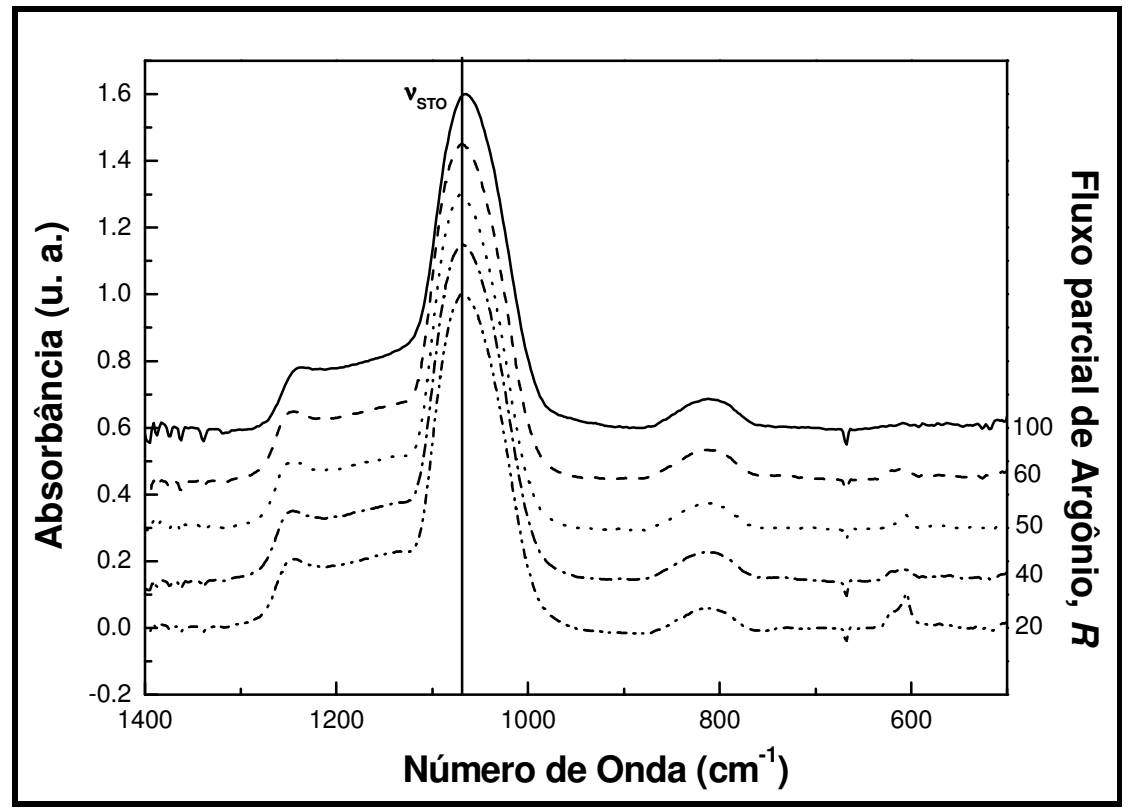

Figura 39 Detalhe dos espectros FTIRS dos filmes de óxido de silício, em função do fluxo parcial de argônio, depositados a $30^{\circ} \mathrm{C}$ e com $\mathbf{F}_{\text {TEOS }}=1 \mathrm{sccm}$. Foram utilizadas as seguintes proporções de argônio, R: 20, $40,50,60$ e 100.

De acordo com os resultados apresentados na Figura 39, nota-se que houve um deslocamento mínimo da posição do pico relacionado ao modo vibracional "stretching" ( $v_{\text {STO}}$ ) da ligação Si-O-Si para amostras depositadas com valores de $R$ superiores a 50, indicando que os filmes depositados com fluxo de $1 \mathrm{sccm}$ de TEOS apresentem, eventualmente, comportamento estequiométrico semelhante.

De acordo com os resultados apresentados pela Figura 40, nota-se que a amplitude da variação de FWHM, para a série de amostras depositadas com $F_{\text {TEOS }}=1 \mathrm{sccm}$, não alcança valores elevados de modo que, nos pontos mais distantes observa-se uma amplitude de $4 \mathrm{~cm}^{-1}$, correspondendo exatamente ao limite de resolução adotada durante a realização das medidas dos espectros FTIRS. 


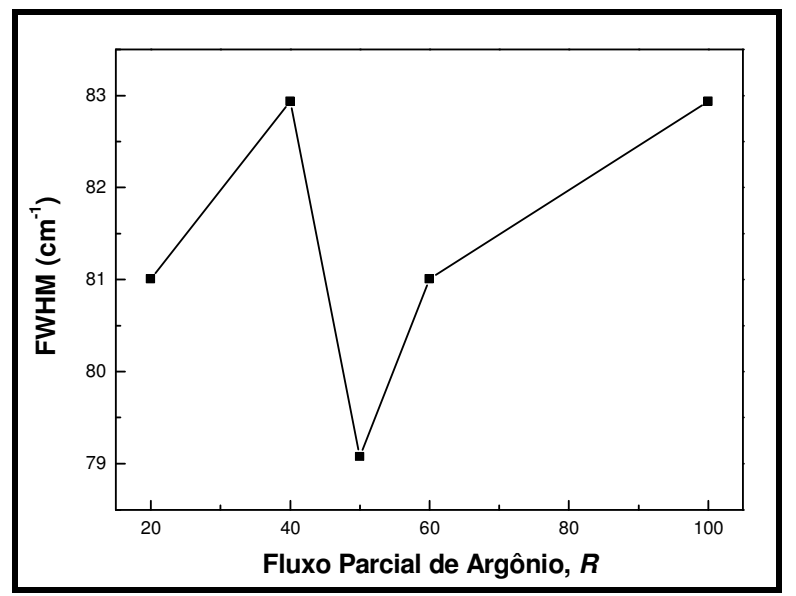

Figura 40 Comportamento da largura à meia altura (FWHM), atribuída a uma variação na composição estrutural e estresse residual, dos filmes de óxido de silício depositados a $30^{\circ} \mathrm{C}$ e com $\mathbf{F}_{\text {TEOS }}=1 \mathrm{sccm}$. Foram utilizadas as seguintes proporções de argônio, R: 20, 40, 50, 60 e 100.

O valor mínimo de FWHM, apresentado na curva da Figura 40, é obtido para a amostra depositada com $R=50$. Neste ponto, observa-se que o valor de FWHM é próximo de $80 \mathrm{~cm}^{-1}$, indicando que a densidade do filme depositado nesta condição eventualmente seja da ordem da densidade obtida em filmes de óxido de silício depositados térmicamente ou que o estresse residual seja pequeno.

A Figura 41 apresenta as curvas CV-AF obtidas a partir de capacitores MOS (18 em cada amostra) implementados a partir de filmes de óxido de silício depositados com $\mathrm{F}_{\mathrm{TEOS}}=1 \mathrm{sccm}$. 


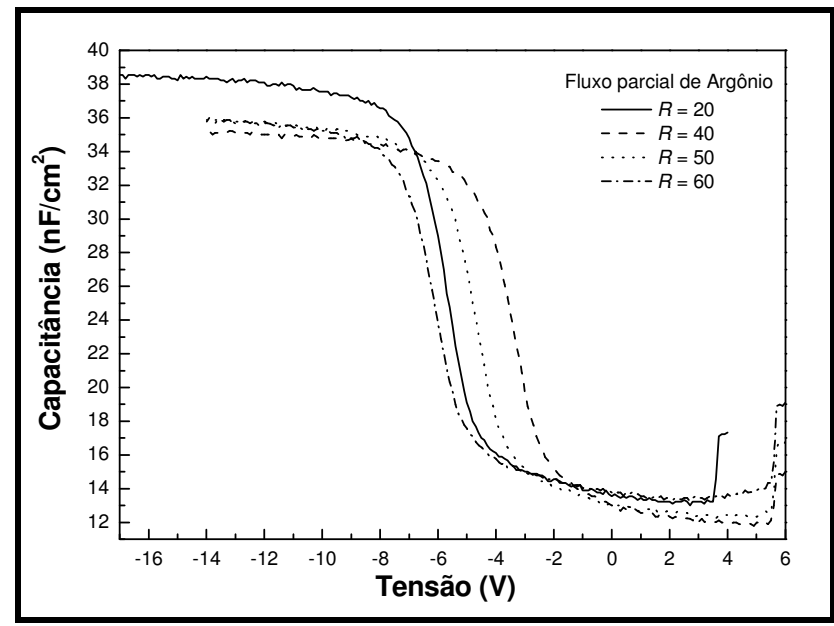

Figura 41 Curvas CV-AF de capacitores MOS implementados com filmes de óxido de silício, parametrizadas em função do fluxo parcial de argônio, depositados a $30^{\circ} \mathrm{C}$ e com $\mathbf{F}_{\text {TEOS }}=1 \mathrm{sccm}$. Foram utilizadas as seguintes proporções de argônio, R: 20, 40, 50 e 60.

Nesta série de experimentos, depositadas com fluxo de TEOS de 1 sccm, os parâmetros extraídos das curvas CV-AF apresentaram uma melhora significativa em relação aos obtidos no processo contendo $\mathrm{F}_{\mathrm{TEOS}}=0,5 \mathrm{sccm}$. Nas curvas CV-AF obtidas, não foram notados efeitos ocasionados pela presença de cargas móveis ou contaminação metálica das amostras. Porém, nesta série, verifica-se nas amostras $R=50$ e 60 uma mínima distorção nas curvas na região de inversão provocada pelo efeito de injeção lateral de portadores minoritários.

A amostra depositada na condição $R=40$ apresentou os menores valores de tensão de banda plana e densidade efetiva de cargas, $V_{F B}=-3,94 V$ e $Q_{S S} / q=6,08 \cdot 10^{11} \mathrm{~cm}^{-2}$ respectivamente; indicando que 0 filme depositado nestas condições apresenta uma melhor estabilidade das propriedades elétricas comparada às demais amostras.

Na Figura 42, é apresentado o comportamento da constante dielétrica 
obtida para a série de amostras depositadas com $F_{\mathrm{TEOS}}=1 \mathrm{sccm}$ e diferentes fluxos parciais de argônio.

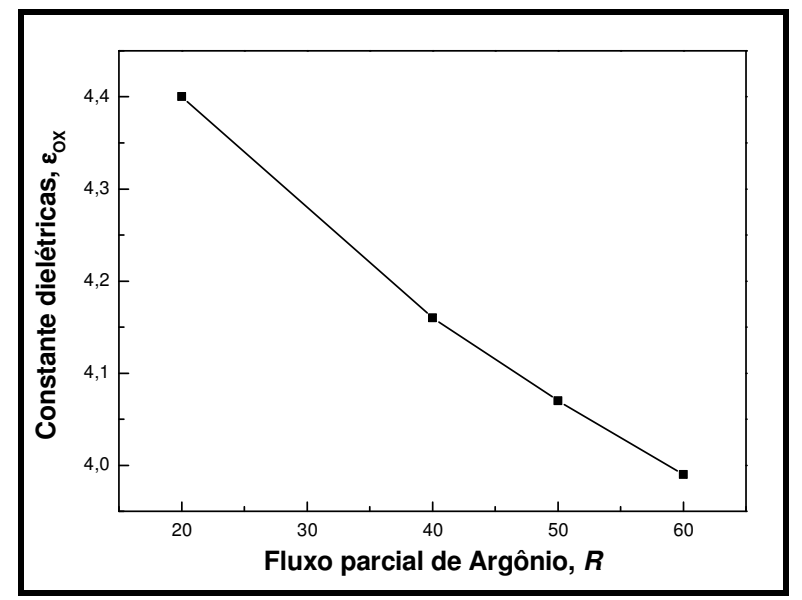

Figura 42 Constante dielétrica obtidas a partir das curvas CV-AF de capacitores MOS implementados com filmes de óxido de silício, parametrizadas em função do fluxo parcial de argônio, depositados a $30^{\circ} \mathrm{C}$ e com $\mathbf{F}_{\text {TEOS }}=1 \mathrm{sccm}$. Foram utilizadas as seguintes proporções de argônio, R: $20,40,50$ e 60 .

De acordo com os resultados apresentados na Figura 42, observa-se que, com o aumento do fluxo parcial de argônio utilizado durante a etapa de deposição, a constante dielétrica do material apresenta valores cada vez menores. Este comportamento não representa necessariamente uma melhora nas propriedades elétricas dos filmes com o aumento do fluxo parcial de argônio. Ou seja, de acordo com os resultados apresentados, filmes depositados em processos onde $R>50$ podem, eventualmente, apresentar uma maior porosidade e densidade de defeitos ocasionados pelo aumento na incorporação de subprodutos de TEOS. Nas amostras depositadas com $R$ entre 50 e 60, os valores de $\varepsilon_{0 x}$ aproximam-se 3,9.

Porém, como é observado na Figura 43, a amostra depositada com 
$\mathrm{R}=40$ foi a que apresentou uma menor densidade efetiva de cargas, indicando que a relação dos fluxos de argônio e oxigênio, durante esta etapa de deposição, favoreceram uma maior eficiência na transferência de energia do sinal de RF para a oxidação das moléculas de TEOS.

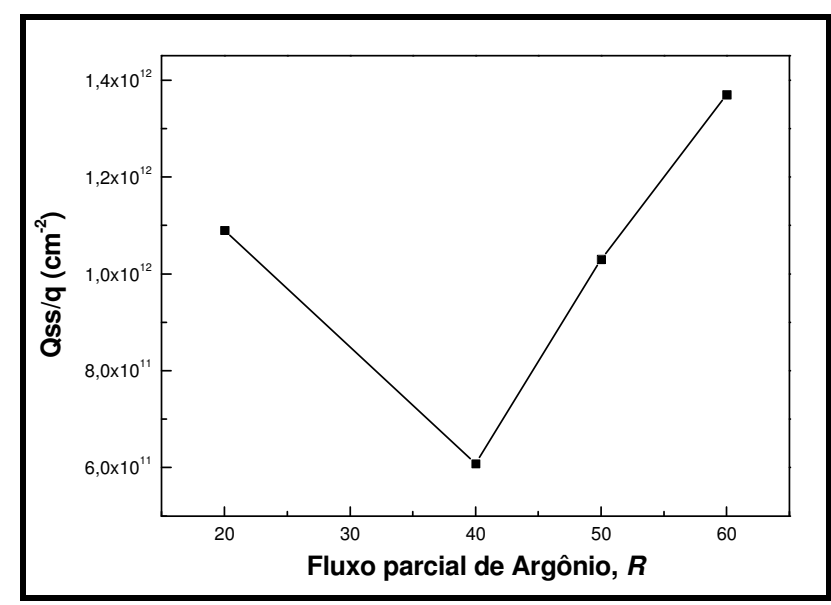

Figura 43 Densidade efetiva de cargas obtidas a partir das curvas CV-AF de capacitores MOS implementados com filmes de óxido de silício, parametrizadas em função do fluxo parcial de argônio, depositados a $30^{\circ} \mathrm{C}$ e com $\mathbf{F}_{\text {TEOS }}=1 \mathrm{sccm}$. Foram utilizadas as seguintes proporções de argônio, R: $20,40,50$ e 60 .

Com exceção do filme depositado com $R=40$, todas as amostras apresentaram densidade efetiva de cargas com valores na ordem de $10^{12} \mathrm{~cm}^{-2}$, como mostra a Figura 43. Embora um ponto mínimo tenha sido observado, os valores de densidade efetiva de cargas ainda são elevados de acordo com as exigências técnicas para a construção de TFTs [3]-[5], [12].

Porém, com a definição de um ponto ideal de trabalho, abre-se uma janela de pesquisa a ser explorada para o desenvolvimento e aprimoramento das futuras etapas de deposição de filmes de óxido de silício a baixas temperaturas. 
O comportamento da densidade efetiva de cargas em relação a espessura dos filmes de óxido de silício depositados é apresentado na Figura 44.

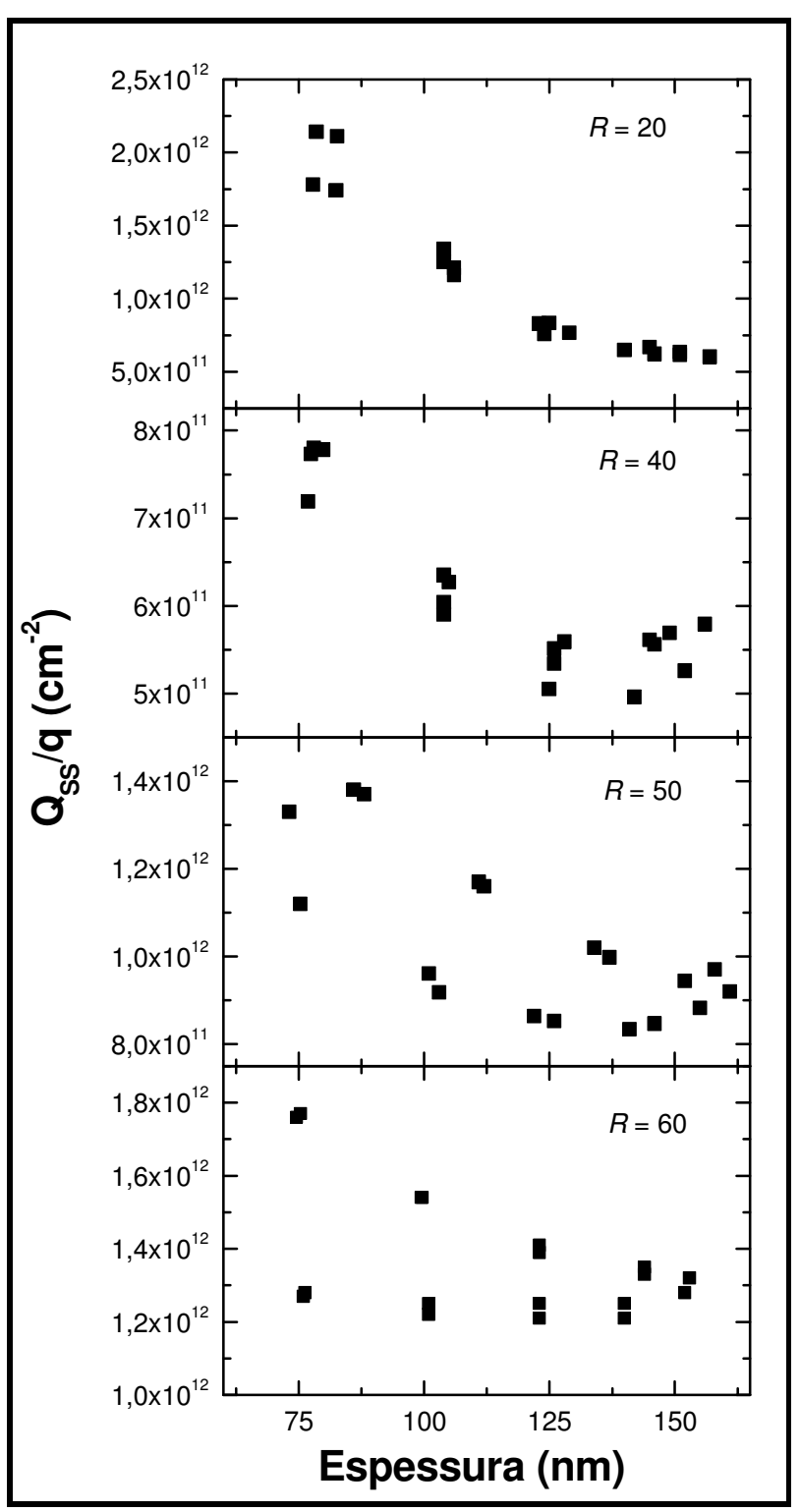

Figura 44 Densidade efetiva de cargas em função da espessura, obtidas a partir das curvas CV-AF de capacitores MOS implementados com filmes de óxido de silício em diferentes espessuras, parametrizadas em função do fluxo parcial de argônio, depositados a $30^{\circ} \mathrm{C}$ e com $\mathbf{F}_{\text {TEOS }}=1 \mathrm{sccm}$. Foram utilizadas as seguintes proporções de argônio, R: 20, 40, 50 e 60.

De acordo com a Figura 44, apesar da distribuição dos dados de 
$Q_{S S / q}$ em função da espessura apresentar uma certa irregularidade para determinadas amostras, observa-se que os valores da densidade efetiva de cargas sofrem um aumento considerável para filmes com espessuras menores que $100 \mathrm{~nm}$, indicando que, de modo geral, a influência das cargas localizadas na interface $\mathrm{Si} / \mathrm{SiO}_{x}$ é significativa no comportamento elétrico dos filmes depositados a baixa temperatura.

A seguir, na Figura 45, são apresentadas as curvas J-E extraídas a partir de capacitores MOS (18 em cada amostra) implementados com filmes de óxido de silício depositados com $\mathrm{F}_{\mathrm{TEOS}}=1 \mathrm{sccm}$.

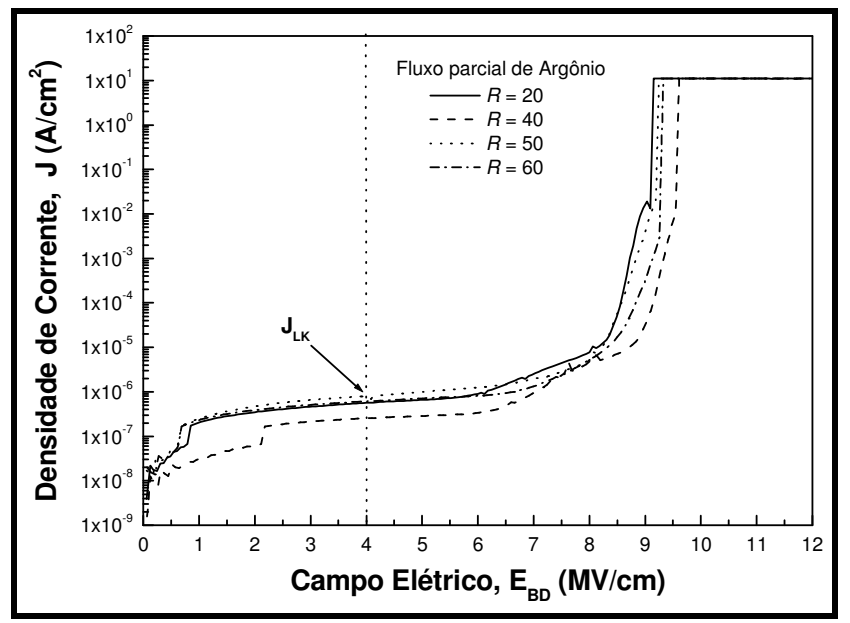

Figura 45 Curvas J-E obtidas a partir de capacitores MOS implementados com filmes de óxido de silício, parametrizadas em função do fluxo parcial de argônio, depositados a $30^{\circ} \mathrm{C}$ e com $\mathbf{F}_{\text {TEOs }}=1 \mathrm{sccm}$. Foram utilizadas as seguintes proporções de argônio, R: 20, 40, 50 e 60.

$\mathrm{Na}$ Figura 45, nota-se que o comportamento elétrico geral dos filmes, nesta série de experimentos, apresentou uma melhora em relação aos filmes depositados com $0,5 \mathrm{sccm}$ de TEOS quanto aos valores da tensão de ruptura da rigidez dielétrica e da corrente de fuga. Porém, em boa parte das amostras, foram observadas deformações nas curvas relacionadas à 
presença de cargas armadilhadas originadas por defeitos estruturais nos filmes, principalmente na região de interface.

Na Figura 46 é apresentado o comportamento da densidade da corrente de fuga média das amostras depositadas $\operatorname{com} \mathrm{F}_{\mathrm{TEOS}}=1 \mathrm{sccm}$.

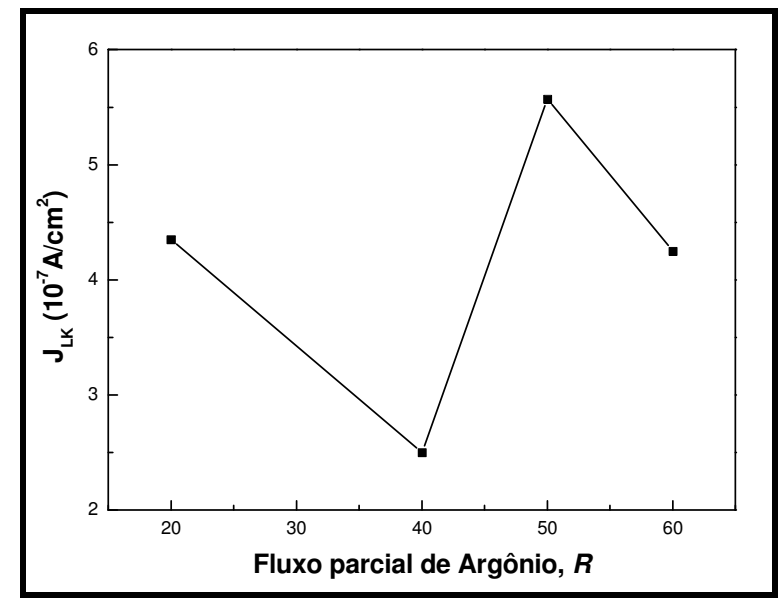

Figura 46 Densidade de corrente de fuga média obtida a partir das curvas J-E de capacitores MOS implementados com filmes de óxido de silício, parametrizadas em função do fluxo parcial de argônio, depositados a $30^{\circ} \mathrm{C}$ e com $\mathbf{F}_{\text {TEOS }}=1 \mathrm{sccm}$. Foram utilizadas as seguintes proporções de argônio, R: $20,40,50$ e 60 .

A menor densidade de corrente de fuga foi observada na amostra depositada com $R=40$, onde $J_{L K}=2,5 \cdot 10^{-7} \mathrm{~A} / \mathrm{cm}^{2}$. O valor do campo de ruptura da rigidez dielétrica desta mesma amostra apresentou um valor médio de $E_{B D}=9,44 \mathrm{MV} / \mathrm{cm}$, Figura 47, indicando uma boa estabilidade das propriedades elétricas do material depositado nestas condições. 


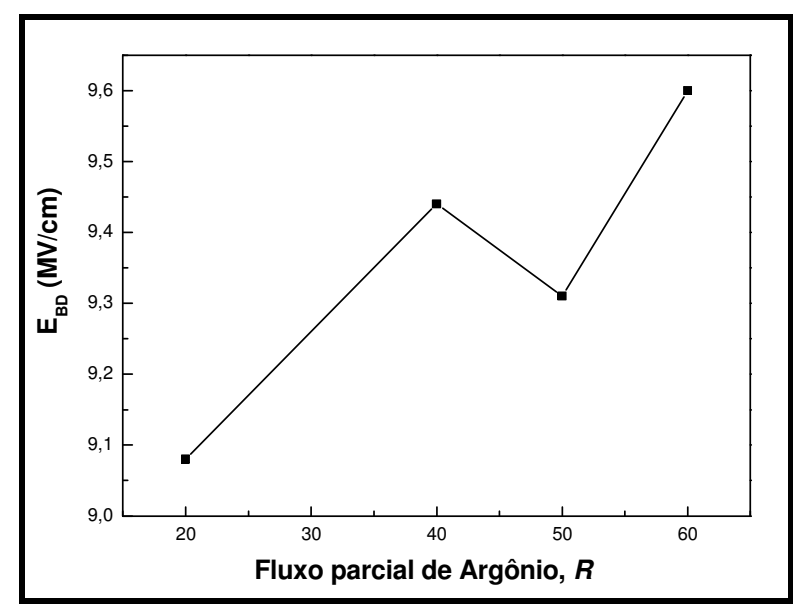

Figura 47 Campo elétrico de ruptura da rigidez dielétrica médio obtidas a partir das curvas J-E de capacitores MOS implementados com filmes de óxido de silício, parametrizados em função do fluxo parcial de argônio, depositados a $30^{\circ} \mathrm{C}$ e com $\mathbf{F}_{\text {TEOS }}=1 \mathrm{sccm}$. Foram utilizadas as seguintes proporções de argônio, R: 20, 40, 50 e 60.

A partir dos resultados apresentados na Figura 47, nota-se que 0 aumento do fluxo parcial de argônio durante a etapa de deposição resulta em filmes com $E_{B D}$ progressivamente mais elevados. Considerando os resultados obtidos através das análises FTIRS e das curvas CV-AF, pode-se associar o aumento no campo de ruptura da rigidez dielétrica de filmes depositados com $R>50$ à mudanças estruturais do material [5], [21], [47].

\subsection{Amostras depositadas com $\mathrm{F}_{\mathrm{TEOS}}=4 \mathrm{sccm}$}

Nesta série experimental, filmes de óxido de silício foram depositados a partir de um fluxo de $4 \mathrm{sccm}$ de TEOS e a temperatura de $30^{\circ} \mathrm{C}$. Na Figura 48 são apresentados os índices de refração obtidos. 


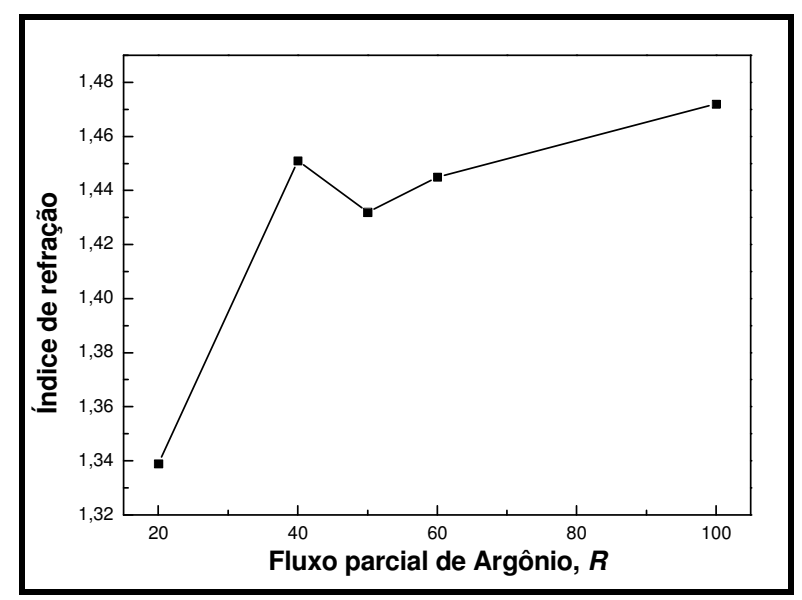

Figura 48 Índice de refração médio dos filmes de óxido de silício, em função do fluxo parcial de argônio, depositados a $30^{\circ} \mathrm{C}$ e com $F_{\text {TEOs }}=4 \mathrm{sccm}$. Foram utilizadas as seguintes proporções de argônio, R: 20, 40, 50 e 60.

De acordo com os dados apresentados pela Figura 48, observa-se que os valores dos índices de refração aumentam e se aproximam de 1,46 com o aumento do fluxo parcial de argônio $R$. Associando este comportamento aos resultados apresentados pela Figura 49, nota-se que 0 material depositado com menor fluxo parcial de argônio, e maior parcela de oxigênio, apresenta indícios de formação desordenada de ligações Si-O ocasionada pelo excesso de agentes oxidantes e radicais de TEOS, resultando em um menor tempo de residência de espécies na superfície do substrato durante a etapa de deposição. 


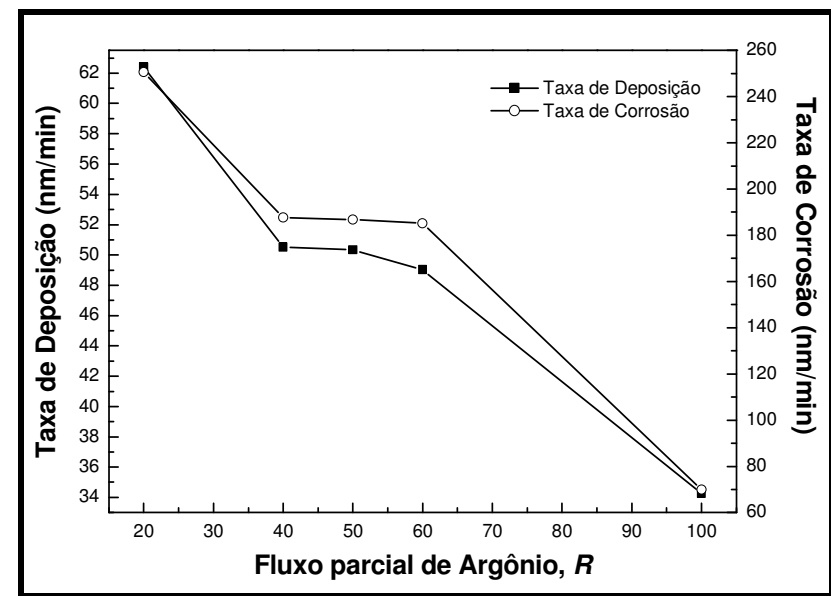

Figura 49 Taxa de deposição e de corrosão dos filmes de óxido de silício, em função do fluxo parcial de argônio, depositados a $30^{\circ} \mathrm{C}$ e com $\mathbf{F}_{\text {TEOS }}=4 \mathrm{sccm}$. Foram utilizadas as seguintes proporções de argônio, R: 20, 40,50 e 60 .

De acordo com os resultados apresentados pela Figura 49, observase que o comportamento das taxas de deposição e corrosão atingem um comportamento aproximadamente estável para filmes depositados com $R$ variando de 40 a 60. Nesta região, o rendimento da distribuição energética entre espécies reativas (dispersas no plasma) atinge eventualmente um grau elevado, garantindo aos filmes depositados propriedades distintas em relação aos filmes obtidos com outros valores de $R$.

A seguir, na Figura 50, são apresentados os espectros de infravermelho da série de amostras depositadas a $30^{\circ} \mathrm{C}$ e com fluxo de TEOS de 4 sccm. 


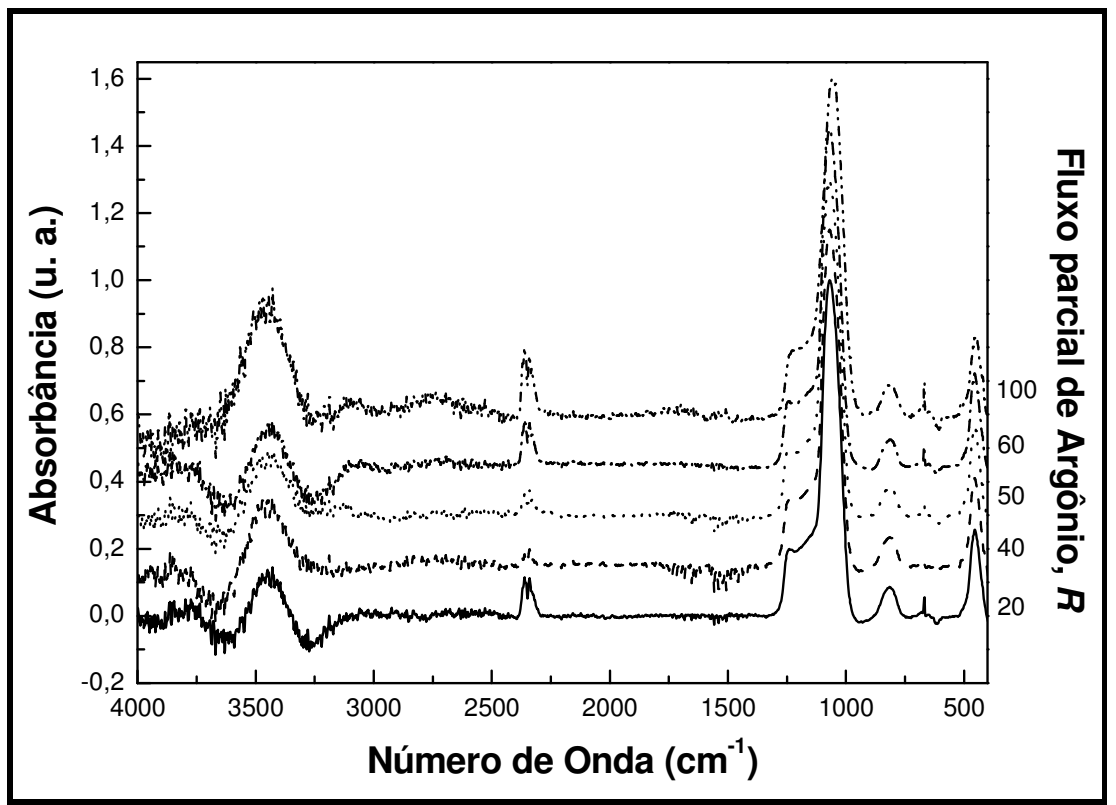

Figura 50 Espectros FTIRS dos filmes de óxido de silício, em função do fluxo parcial de argônio, depositados a $30^{\circ} \mathrm{C}$ e com $\mathbf{F}_{\text {TEOS }}=4 \mathrm{sccm}$. Foram utilizadas as seguintes proporções de argônio, R: 20, 40, 50 e 60.

A partir dos espectros apresentados na Figura 50, são observados picos relacionados ao modo vibracional "stretching" de ligações do tipo $\mathrm{C}-\mathrm{H}$ presentes em grupos como $-\mathrm{CH}_{3}$ e $-\mathrm{CH}_{2}$, na região compreendida entre 2800 e $3000 \mathrm{~cm}^{-1}$ [40],[43]. São também observados picos relativos à banda de absorção de $\mathrm{OH}$ e $\mathrm{H}_{2} \mathrm{O}\left(3300-3400 \mathrm{~cm}^{-1}\right)$, provenientes de subprodutos de TEOS, mais intensos do que os que foram apresentados nas séries de experimentos anteriores, destacando diretamente a influência do aumento no valor de $\mathrm{F}_{\mathrm{TEOS}}$.

De acordo com a Figura 51, observa-se a presença de picos característicos dos modos vibracionais "bending" de ligações do tipo Si-H (650-660 $\left.\mathrm{cm}^{-1}\right)$ em todas as amostras. 


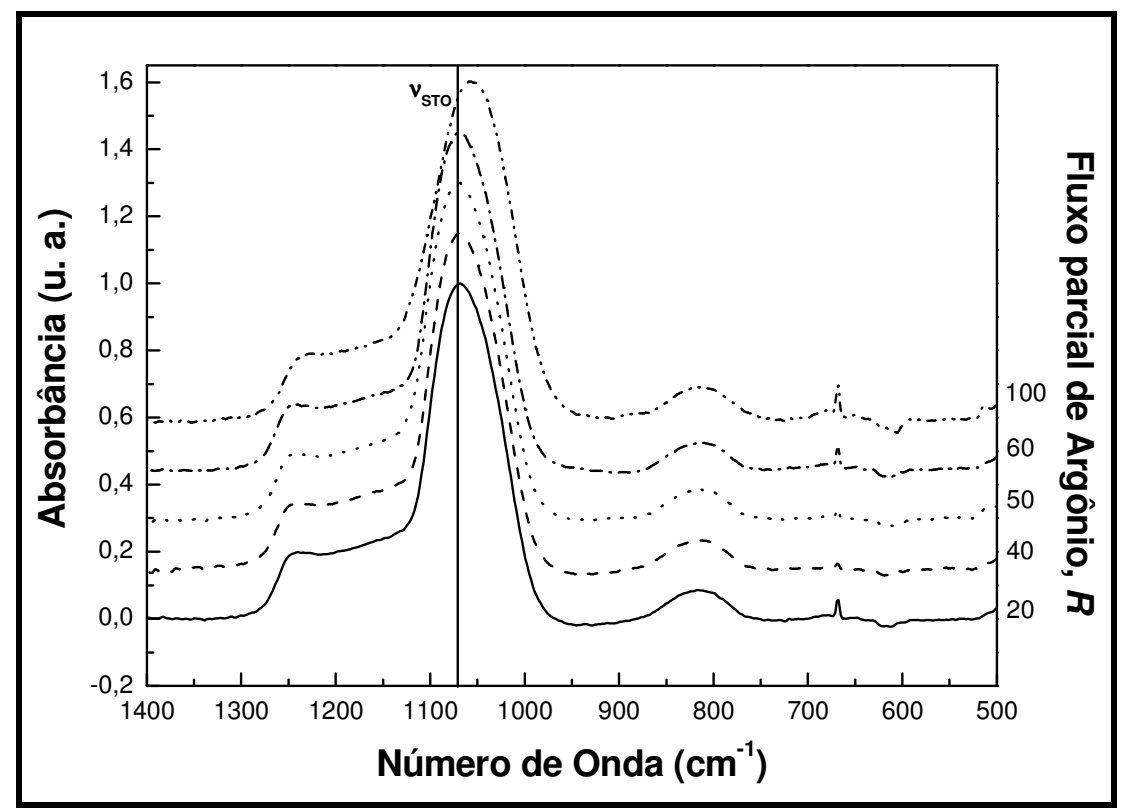

Figura 51 Detalhe dos espectros FTIRS dos filmes de óxido de silício, em função do fluxo parcial de argônio, depositados a $30^{\circ} \mathrm{C}$ e com $\mathbf{F}_{\text {TEOS }}=4 \mathrm{sccm}$. Foram utilizadas as seguintes proporções de argônio, R: 20, 40,50 e 60 .

Realizando-se uma análise mais detalhada das figuras 50 e 51 foi constatada uma diminuição da intensidade de absorção dos picos relacionados às ligações do tipo $\mathrm{Si}-\mathrm{H}$ e dos picos relativos a $\mathrm{CO}_{2}$ $\left(2200-2300 \mathrm{~cm}^{-1}\right)$ nos filmes depositados com $R=40$ e 50 .

A partir da Figura 51, é possível observar um pequeno deslocamento da posição do pico característico Si-O "stretching" ( $\left.\nu_{\text {STO }}\right)$ da amostra depositada com $R=100$, indicando uma eventual alteração na estequiometria do material.

Com base nos resultados obtidos pela análise dos espectros de infravermelho, é apresentado na Figura 52 o comportamento de FWHM das amostras depositadas $c o m F_{\mathrm{TEOS}}=4 \mathrm{sccm}$. 


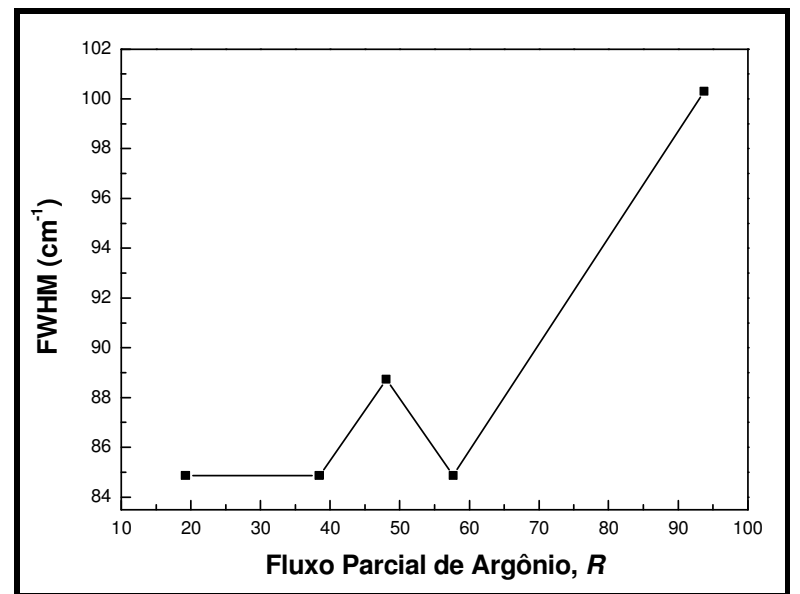

Figura 52 Comportamento da largura à meia altura (FWHM), atribuída a uma variação na composição estrutural e estresse residual, dos filmes de óxido de silício depositados a $30^{\circ} \mathrm{C}$ e com $\mathbf{F}_{\text {TEOS }}=4 \mathrm{sccm}$. Foram utilizadas as seguintes proporções de argônio, R: 20, 40, 50, 60 e 100.

De acordo com os resultados apresentados na Figura 52, observa-se um aumento abrupto no valor de FWHM do filme de óxido de silício obtido na condição $R=50$, apontando que esta amostra possui uma densidade ou estresse residual afetados diretamente pelas condições de deposição [47]. Esta suposição é confirmada a partir dos resultados apresentados na Figura 53, onde observa-se uma variação abrupta do valor da densidade da amostra em questão apontando, desta maneira, que o material depositado apresente, eventualmente, uma densidade ou estresse residual significativamente menor do que as demais amostras. 


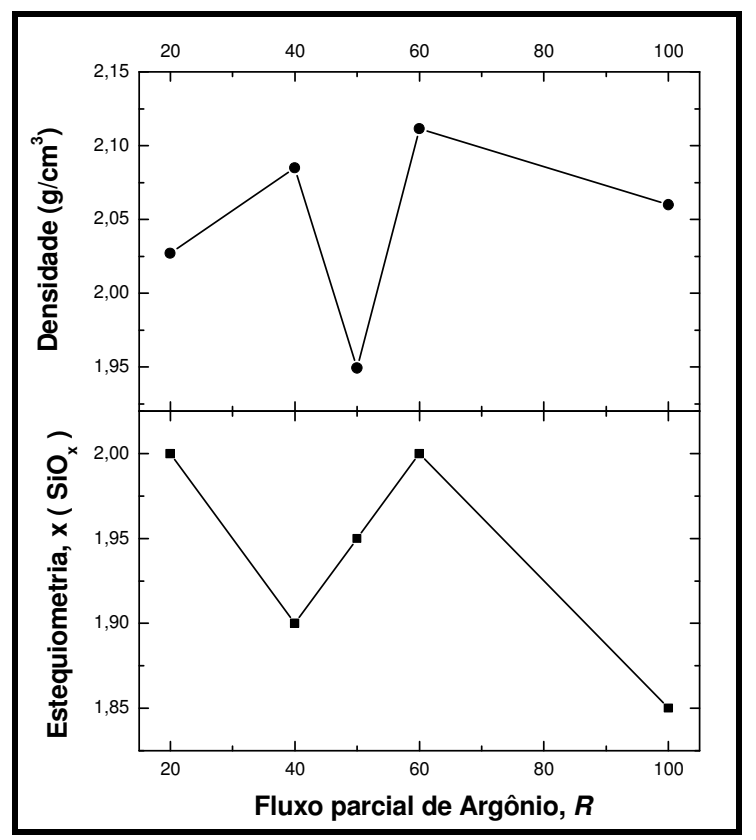

Figura 53 Densidade e estequiometria dos filmes de óxido de silício, em função do fluxo parcial de argônio, depositados a $30^{\circ} \mathrm{C}$ e com $\mathbf{F}_{\text {TEOS }}=4 \mathrm{sccm}$. Foram utilizadas as seguintes proporções de argônio, R: 20, 40,50 e 60 .

Tanto a densidade como a estequiometria dos filmes sofrem alterações de acordo com o fluxo parcial de argônio utilizado na etapa de deposição, como é apresentado na Figura 53. Nota-se que a estequiometria do material é menor para amostra depositada com $R=100$, confirmando, desta forma, a variação da posição do pico Si-O "stretching" observada nos espectros de infravermelho apresentados na Figura 51.

\subsection{Influência do Fluxo de TEOS}

Uma série de amostras foi realizada, mantendo-se a pressão parcial de argônio $R=50$ constante e a temperatura de processo em torno de $30^{\circ} \mathrm{C}$, tendo como objetivo uma avaliação da influência do valor do fluxo de TEOS utilizado durante a deposição dos filmes de óxido de silício por HD-PECVD 
seguindo os parâmetros estabelecidos na Tabela 2. A análise do comportamento dos picos relativos às espécies $\mathrm{OH}, \mathrm{H}_{2} \mathrm{O}, \mathrm{CH}$, Si-H e $\mathrm{CO}_{2}$; os valores de FWHM dos picos de absorção da ligação Si-O-Si "stretching", densidade e estequiometria do material depositado foi o principal foco desta série de resultados.

A Figura 54 apresenta os espectros FTIRS das amostras depositadas com $R=50$ e diferentes fluxos de TEOS.

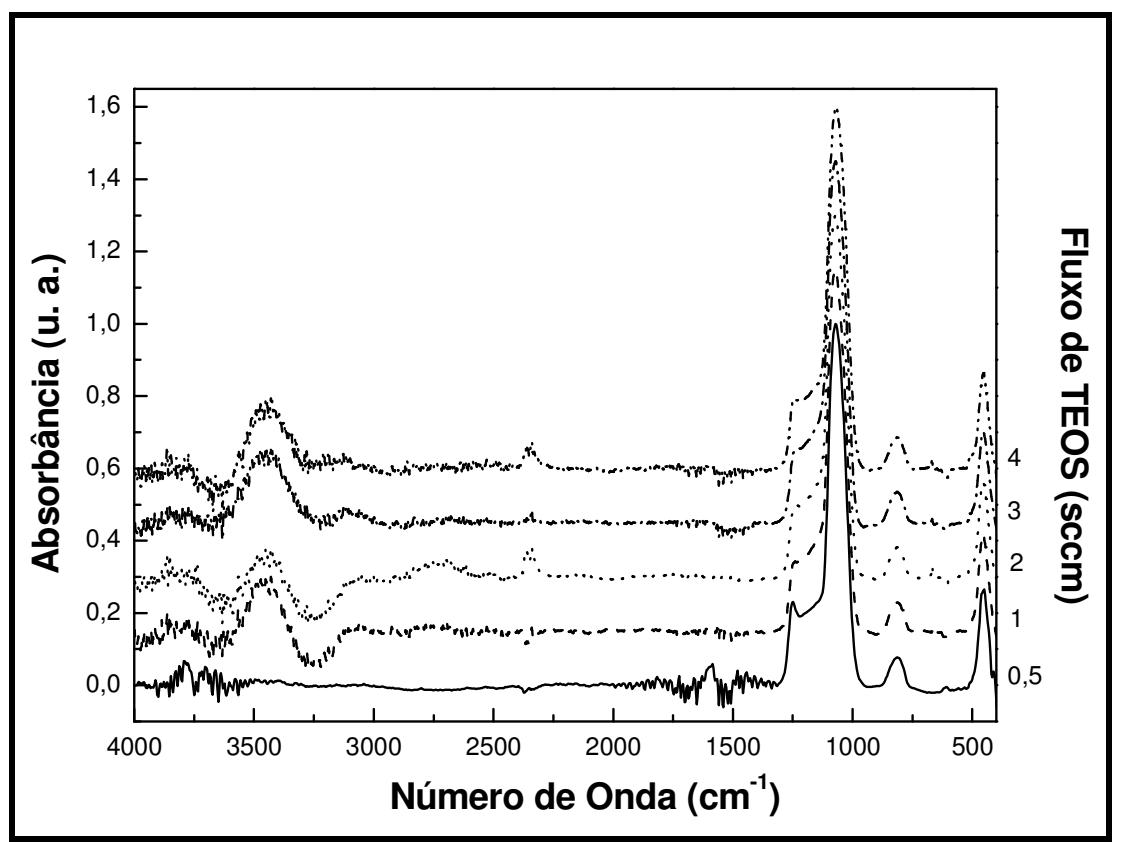

Figura 54 Espectros FTIRS dos filmes de óxido de silício, em função do fluxo de TEOS, depositados a $30^{\circ} \mathrm{C}$ e com $\mathbf{R}=50$.

A partir dos resultados apresentados, observa-se que todas as amostras apresentaram picos relacionados à presença de espécies $\mathrm{OH}$ e $\mathrm{H}_{2} \mathrm{O}$ nas regiões de 1300 e $1800 \mathrm{~cm}^{-1}$ e 3500 e $3800 \mathrm{~cm}^{-1}$, indicando a incorporação de subprodutos de TEOS em filmes depositados a $30^{\circ} \mathrm{C}$, independentemente do valor de F $_{\text {TEOS }}$ utilizado.

Embora a intensidade de absorção dos picos relativos a $\mathrm{CO}_{2}$ 
$\left(2200-2300 \mathrm{~cm}^{-1}\right)$ seja pequena nesta série de experimentos, observa-se em todas as amostras a presença de picos correspondentes a espécies $\mathrm{C}_{\mathrm{x}} \mathrm{H}_{\mathrm{y}}$ na região compreendida entre 2800 e $3000 \mathrm{~cm}^{-1}$, com exceção da amostra onde $\mathrm{F}_{\text {TEOS }}=0,5 \mathrm{sccm}$.

A partir de uma análise detalhada, Figura 55, nota-se a presença pouco significativa do pico de absorção relacionado ao modo vibracional "bending" de ligações do tipo Si-H $\left(650-660 \mathrm{~cm}^{-1}\right)$ nas amostras. Ainda assim, considerando que um aumento da quantidade de TEOS durante a etapa de deposição resulta em um acréscimo na taxa de deposição do material, pode-se associar os picos localizados nas regiões de 1300 e $1800 \mathrm{~cm}^{-1}$ e 3500 e $3800 \mathrm{~cm}^{-1}$ à absorção pronunciada de subprodutos das reações químicas que, por sua vez, favorecem a alteração da densidade e das propriedades elétricas dos filmes.

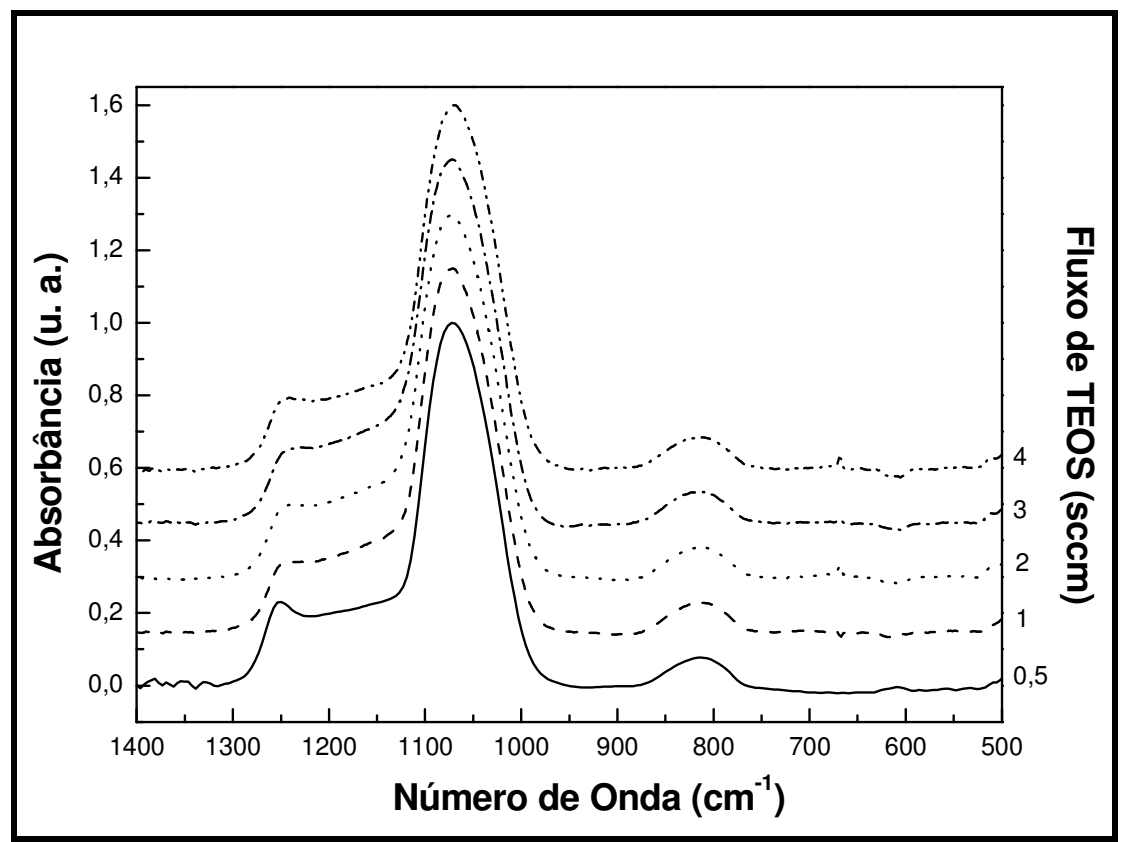

Figura 55 Detalhe dos espectros FTIRS dos filmes de óxido de silício, em função do fluxo de TEOS, depositados a $30^{\circ} \mathrm{C}$ e com $\mathbf{R}=50$. 
Confirmando a discussão dos resultados apresentados pelos espectros de infravermelho, uma análise dos resultados apresentados na Figura 56 indica uma diferença significativa no valor de FWHM de filmes depositados com fluxos baixos de TEOS $(0,5$ e $1 \mathrm{sccm})$ em relação às demais amostras, apontando uma eventual diferença na densidade ou estresse residual dos filmes.

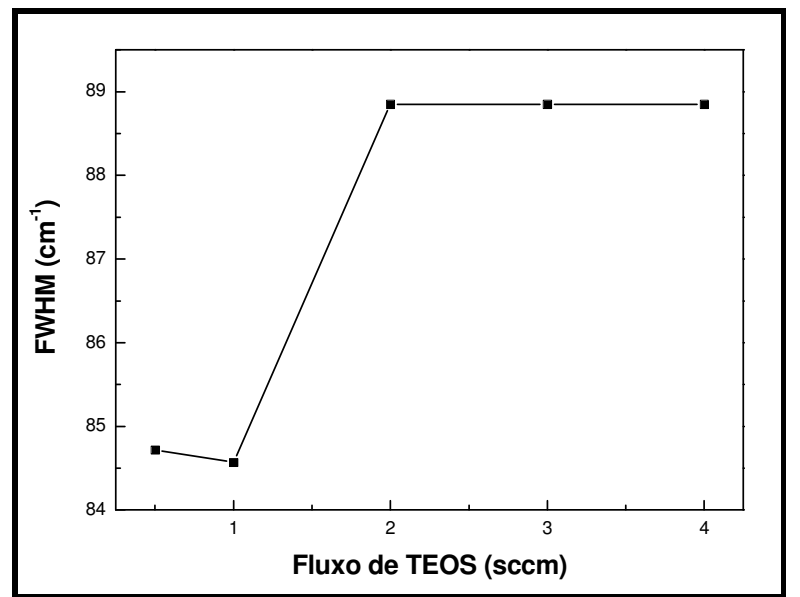

Figura 56 Comportamento da largura à meia altura (FWHM), atribuída a uma variação na composição estrutural e estresse residual, em função do fluxo de TEOS, de filmes de óxido de silício depositados a $30^{\circ} \mathrm{C}$ e com $\mathbf{R}=50$.

Geralmente, o aumento na taxa de deposição de filmes em processos PECVD resulta em má formação estrutural bem como provável incorporação de subprodutos provenientes das reações químicas de oxidação dos reagentes [9],[10],[22],[23],[29],[34].

$\mathrm{Na}$ Figura 57, são apresentadas as curvas de densidade e estequiometria dos filmes de óxido de silício depositados a $30^{\circ} \mathrm{C}$ e com diferentes fluxos de TEOS 


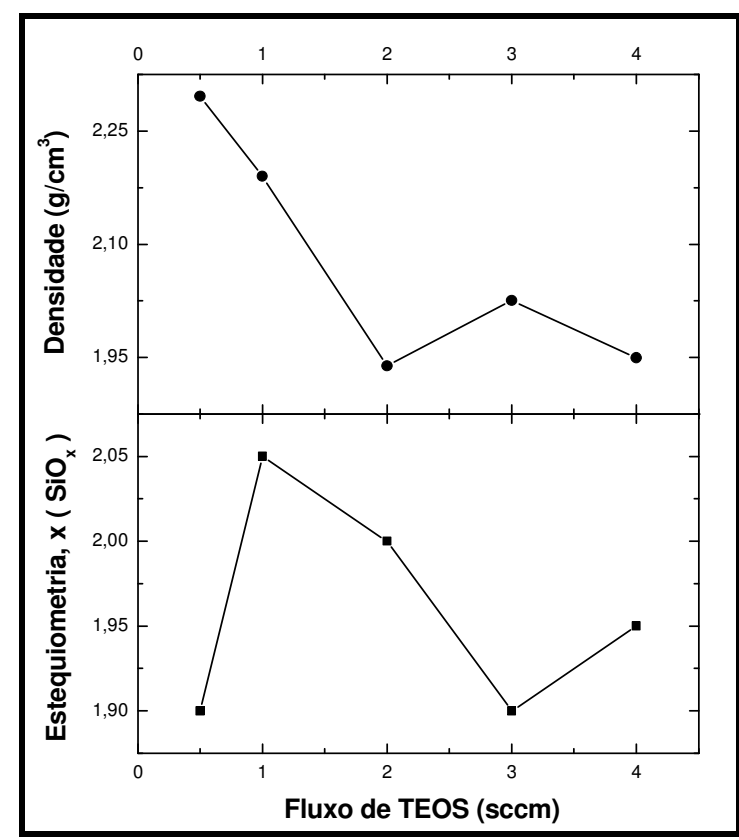

Figura 57 Densidade e estequiometria dos filmes de óxido de silício, em função em função do fluxo de TEOS, depositados a $30^{\circ} \mathrm{C}$ e com $\mathbf{R}=50$.

Observa-se que a densidade do material diminui à medida que os filmes são depositados com maiores fluxos de TEOS. Estes resultados estão de acordo com o estudo feito a partir do comportamento de FWHM para esta série de amostras. Assim, verifica-se que os filmes depositados com 0,5 e $1 \mathrm{sccm}$ de TEOS apresentam densidade significativamente maior quando comparada à densidade dos filmes obtidos com maiores fluxos de TEOS.

A partir da curva de estequiometria apresentada na Figura 57, observa-se que as amostras obtidas com 1 e 2 sccm de TEOS apresentam estequiometria próxima da condição balanceada $\mathrm{SiO}_{2}$, indicando, eventualmente, uma maior eficiência na decomposição das moléculas de TEOS e melhor ordenamento das ligações Si-O na estrutura dos filmes depositados. 


\subsection{Sumário das Principais Propriedades Elétricas}

Neste item, são apresentados os principais parâmetros elétricos extraídos das curvas CV-AF e das curvas J-E (valores médios de 18 capacitores) dos filmes de óxido de silício depositados, de acordo com as condições de deposição mencionadas no capítulo 6.

\subsection{1 $\underline{F}_{\text {TEOS }}=0,5 \mathrm{sccm}$}

Tabela 7 Propriedades elétricas obtidas através de curvas CV-AF de capacitores MOS implementados com filmes de óxido de silício, parametrizadas em função do fluxo parcial de argônio, depositados a $30^{\circ} \mathrm{C}$ e com $\mathbf{F}_{\text {TEOS }}=0,5 \mathrm{sccm}$. Foram utilizadas as seguintes proporções de argônio, R: $20,40,50$ e 60 .

\begin{tabular}{cccc}
\hline \hline \multicolumn{4}{c}{ Amostra com 0,5 sccm de TEOS } \\
\hline Fluxo parcial de Ar, $\boldsymbol{R}$ & $\mathbf{V}_{\mathrm{FB}}(\mathrm{V})$ & $\varepsilon_{\text {óx }}$ & $\mathbf{Q}_{\mathrm{ss}} / \mathbf{q}\left(\mathbf{c m}^{-2}\right)$ \\
\hline 20 & $-7,62$ & 4,17 & $1,42 \cdot 10^{12}$ \\
\hline 40 & $-5,34$ & 4,06 & $9,5 \cdot 10^{11}$ \\
\hline 50 & $-8,49$ & 4,01 & $1,57 \cdot 10^{12}$ \\
\hline 60 & $-9,56$ & 3,92 & $1,64 \cdot 10^{12}$ \\
\hline \hline
\end{tabular}


Tabela 8 Propriedades elétricas obtidas através de curvas J-E de capacitores MOS implementados com filmes de óxido de silício, parametrizadas em função do fluxo parcial de argônio, depositados a $30^{\circ} \mathrm{C}$ e com $\mathbf{F}_{\text {TEOS }}=0,5 \mathrm{sccm}$. Foram utilizadas as seguintes proporções de argônio, R: $20,40,50$ e 60 .

\begin{tabular}{ccc}
\hline \hline \multicolumn{3}{c}{ Amostra com 0,5 sccm de TEOS } \\
\hline Fluxo parcial de $\mathbf{A r}, \boldsymbol{R}$ & $\mathrm{J}_{\mathrm{LK}}\left(\mathbf{A} / \mathbf{c m}^{2}\right) @ \mathbf{~} \mathbf{~ M V} / \mathbf{c m}$ & $\mathrm{E}_{\mathrm{BD}}(\mathbf{M V} / \mathbf{c m})$ \\
\hline 20 & $4,71 \cdot 10^{-7}$ & 9,20 \\
\hline 40 & $5,90 \cdot 10^{-7}$ & 9,38 \\
\hline 50 & $6,99 \cdot 10^{-7}$ & 9,39 \\
\hline 60 & $8,82 \cdot 10^{-7}$ & 8,83 \\
\hline \hline
\end{tabular}

\subsection{2 $\underline{F}_{\text {TEOS }}=1 \mathrm{sccm}$}

Tabela 9 Propriedades elétricas obtidas através de curvas CV-AF de capacitores MOS implementados com filmes de óxido de silício, parametrizadas em função do fluxo parcial de argônio, depositados a $30^{\circ} \mathrm{C}$ e com $\mathbf{F}_{\text {TEOS }}=1 \mathrm{sccm}$. Foram utilizadas as seguintes proporções de argônio, R: $20,40,50$ e 60 .

\begin{tabular}{cccc}
\hline \hline \multicolumn{4}{c}{ Amostra com 1 sccm de TEOS } \\
\hline Fluxo parcial de Ar, $\boldsymbol{R}$ & $\mathbf{V}_{\mathrm{FB}}(\mathrm{V})$ & $\varepsilon_{\text {óx }}$ & $\mathbf{Q}_{\mathbf{s s}} / \mathbf{q}\left(\mathbf{c m}^{-2}\right)$ \\
\hline 20 & $-5,69$ & 4,40 & $1,09 \cdot 10^{12}$ \\
\hline 40 & $-3,94$ & 4,16 & $6,08 \cdot 10^{11}$ \\
\hline 50 & $-6,29$ & 4,07 & $1,03 \cdot 10^{12}$ \\
\hline 60 & $-7,95$ & 3,99 & $1,37 \cdot 10^{12}$ \\
\hline \hline
\end{tabular}

Os principais parâmetros elétricos extraídos das curvas J-E são apresentados nas Tabelas 9 e 10. 
Tabela 10 Propriedades elétricas obtidas através de curvas J-E de capacitores MOS implementados com filmes de óxido de silício, parametrizadas em função do fluxo parcial de argônio, depositados a $30^{\circ} \mathrm{C}$ e com $\mathbf{F}_{\text {TEOS }}=1 \mathrm{sccm}$. Foram utilizadas as seguintes proporções de argônio, R: $20,40,50$ e 60 .

\section{Amostra com $1 \mathrm{sccm}$ de TEOS}

\begin{tabular}{ccc}
\hline Fluxo parcial de $\mathbf{A r}, \boldsymbol{R}$ & $\mathrm{J}_{\mathrm{LK}}\left(\mathbf{A} / \mathbf{c m}^{2}\right) @ \mathbf{4} \mathbf{~ M V} / \mathbf{c m}$ & $\mathrm{E}_{\mathrm{BD}}(\mathbf{M V} / \mathbf{c m})$ \\
\hline 20 & $4,35 \cdot 10^{-7}$ & 9,08 \\
\hline 40 & $2,50 \cdot 10^{-7}$ & 9,44 \\
\hline 50 & $5,57 \cdot 10^{-7}$ & 9,31 \\
\hline 60 & $4,25 \cdot 10^{-7}$ & 9,60 \\
\hline \hline
\end{tabular}




\section{Conclusões e Considerações Finais}

Os resultados gerais apresentados neste trabalho possuem uma grande importância na compreensão dos processos e mecanismos de deposição de filmes a partir da reação de compostos orgânicos em processos assistidos por plasma de alta densidade. Desta forma, foi realizado um estudo das propriedades elétricas e físicas de filmes de óxido de silício depositados através de um sistema HD-PECVD/TEOS a baixas temperaturas visando sua aplicação como dielétrico de porta na construção de TFTs.

Os melhores resultados foram obtidos da amostra depositada a uma temperatura próxima de $30^{\circ} \mathrm{C}$ com fluxo de TEOS de $1 \mathrm{sccm}$; fluxo de argônio de 40 sccm e fluxo de oxigênio de 60 sccm; com potência do sinal de RF aplicada ao plasma de $450 \mathrm{~W}$ e pressão de processo de 60 mtorr.

Através da caracterização elétrica de capacitores MOS com área $9 \cdot 10^{-4} \mathrm{~cm}^{-2}$ construídos sobre filmes de $\mathrm{SiO}_{x}$ com espessura variando de 70 a $150 \mathrm{~nm}$; foram obtidos os valores médios dos seguintes parâmetros: tensão de banda plana $V_{\mathrm{FB}}=-3,94 \mathrm{~V}$; constante dielétrica $\varepsilon_{\mathrm{OX}}=4,16$; densidade efetiva de cargas $Q_{S S} / q=6,08 \cdot 10^{11} \mathrm{~cm}^{-2}$; densidade de corrente de fuga $J_{L K}=2,5 \cdot 10^{-7} \mathrm{~A} / \mathrm{cm}^{-2} @ 4 \mathrm{MV} / \mathrm{cm}$ e campo elétrico de ruptura da rigidez dielétrica $\mathrm{E}_{\mathrm{BD}}=9,44 \mathrm{MV} / \mathrm{cm}$.

Apesar de serem os melhores resultados obtidos com amostras 
depositadas a temperaturas menores que $100^{\circ} \mathrm{C}$, são valores que ainda não correspondem aos exigidos para a construção de TFTs. Porém, estes resultados representam um avanço significativo dentro do estudo de deposição de filmes de $\mathrm{SiO}_{x}$ a baixas temperaturas utilizando TEOS como fonte de silício. Portanto, este trabalho contribui na delimitação do ponto essencial de partida para que sejam feitos, em futuros trabalhos, o desenvolvimento de processos e construção de dispositivos a baixas temperaturas. 


\section{Sugestões para Futuros Trabalhos}

Para a continuação deste trabalho, sugere-se:

a. Realização de medidas de espectrometria de emissão óptica (OES) e espectrometria de massa, para melhor compreensão do processo de decomposição das moléculas de TEOS, bem como e a identificação dos compostos produzidos, que eventualmente são incorporados nos filmes depositados;

b. Realização de medidas de $\mu$-RAMAN, para verificação de eventuais incorporações de compostos orgânicos não identificados pela técnica FTIRS;

c. Estudo do processo de deposição com fluxos de TEOS superiores a $1 \mathrm{sccm}$, de modo a obterem-se filmes mais próximos do óxido de silício estequiométrico, e posterior caracterização elétrica;

d. Estudo do processo de deposição de filmes de óxido de silício a partir da reação de TEOS $+\mathrm{O}_{2}+\mathrm{Ar}$ em um reator HD-PECVD em temperaturas entre 100 a $250{ }^{\circ} \mathrm{C}$ de modo a obterem-se filmes mais próximos do óxido de silício estequiométrico, e posterior caracterização elétrica;

e. Inserção de um distribuidor de gases interno a câmara de reações de modo a fazer com que a maior parte da mistura gasosa passe obrigatoriamente pela região de maior campo elétrico, objetivando- 
se com isso, um aumento da taxa de decomposição de TEOS, bem como, eventualmente da uniformidade dos filmes depositados;

f. Após a realização das sugestões anteriormente citadas, com êxito, implementar transistores de filmes finos a partir dos filmes de óxido de silício depositados a ultra baixa temperatura. 


\section{ANexo A - Modelo de ACOPLAMENTo Indutivo do ReAtor HD-PECVD}

Na Figura 58, um diagrama elétrico ilustra o modelo de acoplamento indutivo do reator HD-PECVD utilizado neste trabalho.

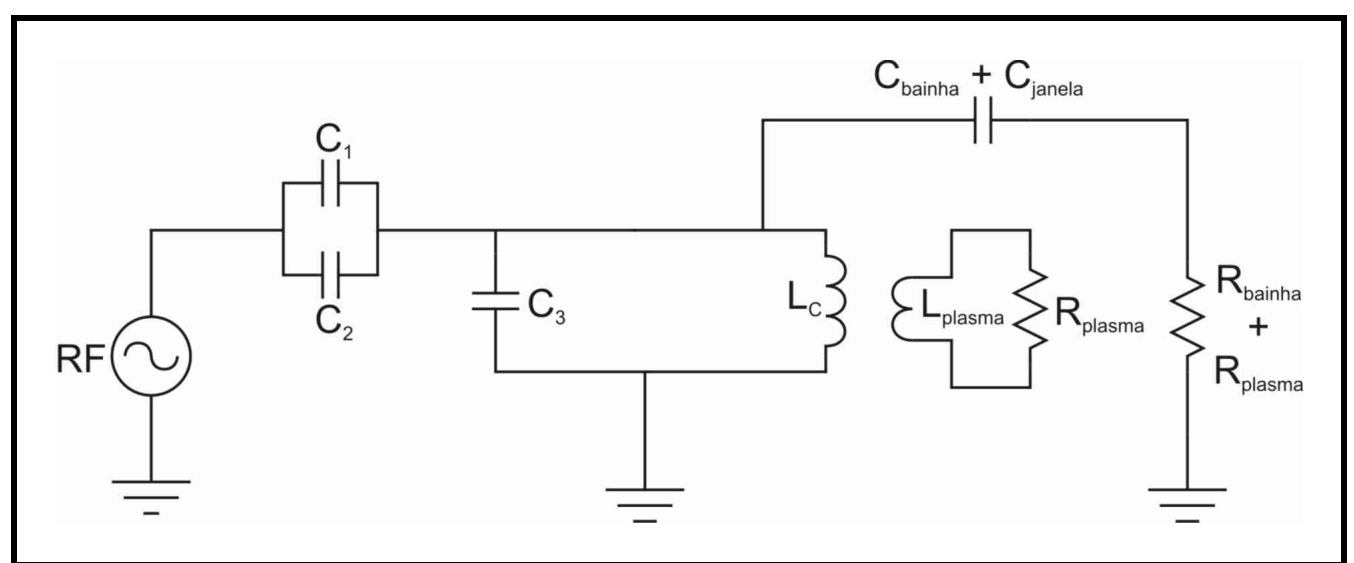

Figura 58 Circuito elétrico equivalente ao modelo de acoplamento indutivo do reator HD-PECVD.

Uma descrição simples do mecanismo de transferência de potência em um sistema de acoplamento indutivo é adotar-se um modelo de circuito onde a bobina que recebe o sinal de RF é considerada como a bobina primária de um transformador $\left(L_{C}\right)$ e o plasma sendo a bobina secundária deste transformador ( $\left.L_{\text {plasma }}\right)$. A potência é acoplada ao plasma de forma indutiva, como um transformador, e de forma capacitiva, por meio da capacitância da janela de isolação $\left(C_{\text {janela }}\right)$ e da capacitância gerada na bainha do plasma ( $\left.\mathrm{C}_{\text {bainha }}\right)$. A dissipação da potência ocorre por meio da resistência do plasma ( $\left.R_{\text {plasma }}\right)$ e da resistência elétrica da bainha ( $\left.R_{\text {bainha }}\right)$. Os capacitores indicados na figura como $\mathrm{C}_{1}, \mathrm{C}_{2}$ e $\mathrm{C}_{3}$ fazem parte da malha 
de acoplamento externa do sinal de RF e possuem, respectivamente, os seguintes valores: 84 pF (2000 V), 300 pF (4000 V) e 300 pF (4000 V). Para efeito de cálculo, não serão consideradas as perdas geradas pela resistência da bobina planar, ou seja, ela será considerada um condutor ideal.

O acoplamento capacitivo neste sistema é eficiente apenas quando a potência aplicada e o potencial elétrico são baixos pois, quando ambos atingem valores elevados, a resistência elétrica do plasma torna-se muito baixa fazendo com que a maior parte da potência seja dissipada na bainha do plasma. Considerando que a potência seja acoplada inicialmente através de um processo indutivo, a impedância da bobina pode ser descrita através da equação que designa a impedância de entrada de um transformador:

Eq. 13

$$
Z_{C}=\frac{\omega^{2} M^{2} R_{p l}}{R_{p l}+\omega^{2} L_{p l}^{2}}+j\left(\omega L_{C}-\frac{\omega^{3} M^{2} L_{p l}}{R_{p l}^{2}+\omega^{2} L_{p l}^{2}}\right)
$$

onde, $\omega$ é a freqüência do sinal de entrada, $j$ é a raiz quadrada de -1 (imaginário), $L_{C}$ é a indutância da bobina, $R_{p l}$ e $L_{p l}$ são, respectivamente, a resistência e a indutância do plasma e $M$ é a indutância mútua entre a bobina planar e o plasma. Utilizando o modelo de um transformador, é possível obter a expressão que designa a potência dissipada no plasma considerando a parte real da impedância da bobina $\left[Z_{C}\right]$, descrita na Eq. 13. Dessa forma, potência induzida no plasma é descrita como:

\section{Eq. 14}

$$
P_{\text {ind }}=I^{2}\left[Z_{C}\right][31]
$$

onde I é a corrente que flui na bobina planar. Fazendo as 
substituições necessárias, a Eq. 14 pode ser escrita como:

Eq. 15

$$
P_{i n d}=B \times \sqrt{I^{2}-I_{t h r}^{2}}
$$

onde $B$ é o campo magnético induzido pela bobina e $l_{\text {thr }}$ é a corrente de limiar ("threshold current") do regime de acoplamento indutivo. Ambos são descritos a partir das seguintes expressões:

Eq. 16

$$
B=\left(R_{p l} P_{\text {ind }}\right)^{1 / 2} \cdot k\left(\frac{L_{C}}{L_{p l}}\right)^{1 / 2}
$$

Eq. 17

$$
I_{t h r}=\frac{\left(R_{p l} P_{i n d}\right)^{1 / 2}}{\omega \cdot k\left(L_{C} L_{p l}\right)^{1 / 2}}[31]
$$

onde $k$ é o coeficiente de acoplamento entre a bobina e o plasma, sendo descrito como:

Eq. 18

$$
k=\frac{\left(R_{p l} P_{i n d}\right)^{1 / 2}}{M}
$$

A resistência elétrica do plasma é inversamente proporcional à densidade do plasma que, por sua vez, varia linearmente com a potência do sinal de RF [31]. Assim, de acordo com as expressões anteriores, nota-se que os valores de $R_{p l} P_{\text {ind, }} B$ e $l_{\text {thr }}$ serão constantes levando-se em conta, obviamente, que o coeficiente de acoplamento e a indutância do plasma também permaneçam constates. Dessa forma, o a descarga do sinal de RF não age em regime indutivo quando a corrente aplicada na bobina planar 
excede o valor da corrente de limiar $\left(I_{t h r}\right)$, ou seja, o quando o valor de $I$ ultrapassa $I_{t h r}$, a potência dissipada torna-se essencialmente uma função da corrente aplicada na bobina. Logo, $I_{\text {thr }}$ representa o valor da corrente aplicada na bobina onde ocorre a transição do regime de acoplamento do sistema. Essa transição reflete na densidade do plasma que, por sua vez, pode variar até duas ordens de grandeza. $\mathrm{O}$ valor da corrente de limiar varia de acordo com a geometria do sistema e com o tipo de bobina utilizada [31]. 


\section{REFERÊNCIAS BIBLIOGRÁFICAS}

[1] ADAMS, A. C., in JANSEN F. and MORT, J.; Plasma Deposited Thin Films; CRC; New York - NY (EUA); 1986.

[2] SCHROPP, R. E. I. et al; New challenges in thin film transistor (TFT) Research; Journal of Non-Crystalline Solids; v. 299-302 (2002); p. 1304-1310.

[3] RASHID, R. et al; Physical and electrical properties of low temperature $\left(<100^{\circ} \mathrm{C}\right) \mathrm{SiO}_{2}$ films deposited by electron cyclotron resonance plasmas; Journal of Vacuum Science and Technology A; v. 3 (2003); p. 728-739.

[4] KUO, Y.; Thin Film Transistors - Materials and Processes. Volume 1: Amorphous Silicon Thin Film Transistors; Kluwer Academic Publishers; Norwell - Massachusetts (EUA); 2004.

[5] RAY, S. K. et al; Properties of silicon dioxide films deposited at low temperatures by microwave plasma enhanced decomposition of tetraethylorthosilicate; Journal of Vacuum Science and Technology B; v. 10 (1992); p. 1139-50.

[6] HERAK, T. V. and THOMSON, D. J.; Effects of substrate temperature on the electrical and physical properties of silicon dioxide films deposited from electron cyclotron resonant microwave plasmas; Journal Applied Physics; v. 67 (1990); p. 6347-52.

[7] TOCHITANI, G. et al; Deposition of silicon oxide films from TEOS by low frequency plasma chemical vapor deposition; Journal of Vacuum Science and Technology A; v. 11 (1993); p. 400-05.

[8] SHERMAN, A.; Chemical Vapor Deposition for Microelectronics: Principles, Technology and Applications; Noyes; Park Ridge - NJ (EUA); 1987.

[9] WOLF, S. and TAUBER, R. N.; Silicon Processing for the VLSI Era Volume 1: Process Integration; Lattice Press; Sunset Beach - CA (EUA); 1990.

[10] CAMPBELL, S. A.; The Science Engineering of Microelectronic Fabrication; Oxford; University of Minnesota (EUA); 1996.

[11] ZUFFO, J. A.; Compêndio de Microeletrônica - Livro-1: Processos e Tecnologias; Guanabara Dois; Rio de Janeiro - RJ (BRA); 1984. 
[12] DESHMUKH, S. C. and AYDIL, E. S.; Investigation of low temperature $\mathrm{SiO}_{2}$ plasma enhanced chemical vapor deposition; Journal of Vacuum Science and Technology B; v. 14 (1996); p. 738-43.

[13] MORIMOTO, N. I., Desenvolvimento de um sistema multicâmaras integrado para deposição e recozimento de filmes de $\mathrm{SiO}_{2}$. São Paulo, 1995. 135p. Tese (Doutorado) Escola Politécnica, Universidade de São Paulo, 1995.

[14] VIANA, C. E.; SILVA, A. N. R.; MORIMOTO, N. I.; "Argon flow Effects in the PETEOS Silicon Oxide Thin Films Deposition". In: XIV ICMP99, São Paulo, 1999.

[15] VIANA, C. E.; SILVA, A. N. R.; MORIMOTO, N. I. "Structural Analysis of $\mathrm{SiO} 2$ Thin Films Deposited by PECVD Using an Oxygen-TEOSArgon Mixture". In XX CBRAVIC, Jul. 1990, São Paulo, Brazil, 1999.

[16] VIANA, C. E., A. N. R. SILVA, and N. I. MORIMOTO, "Argon Influence in the PETEOS Silicon Oxide Deposition Process", Proc. of International Conference on Microelectronics and Packaging, Curitiba-PR (Brazil), 1998, p.481-483.

[17] SILVA, A. N. R.; Estudo e Caracterização de Filmes de Óxido de Silício Depositados por PECVD usando TEOS como Fonte de $\mathrm{Si}$, 2001. 107p. Tese (Doutorado) Escola Politécnica, Universidade de São Paulo, 2001.

[18] SILVA, A. N. R.; BONNAUD, O., Tetraethylorthosilicate $\mathrm{SiO}_{2}$ films deposited at low temperature. Microelectronic Reliability, Inglaterra, v.40, p.621-624, 2000.

[19] VIANA, C. E.; SILVA, A. N. R.; MORIMOTO, N. I.; BONNAUD, O. "Analysis of $\mathrm{SiO} 2$ thin films deposited by PECVD using an oxygenTEOS-argon mixture", Brazilian Journal of Physics 31: (2) 299-303, Jun (2001).

[20] PAVELESCU, C. et al; High frequency $C-V$ investigation of metaloxide-semiconductor capacitors prepared by low temperature subatmospheric pressure chemical vapor deposition of $\mathrm{SiO}_{2}$ films on silicon substrates; Thin Solid Films; v.217 (1992); p. 68-74.

[21] PATRICK, W. L. et al; Plasma-enhanced chemical vapor deposition of silicon dioxide films using tetraethoxysilane and oxygen: characterization and properties of films; Journal of Electrochemical Society; v. 139 (1992); p. 2604-13.

[22] VIANA, C. E.; Caracterização elétrica de filmes finos de $\mathrm{SiO}_{2}$-TEOS depositados por PECVD; Dissertação (Mestrado); 72p. Escola Politécnica da Universidade de São Paulo - Departamento de Engenharia de Sistemas Eletrônicos; São Paulo - SP; 1998. 
[23] VIANA, C. E.; Estudo e desenvolvimento de uma tecnologia CMOS-TFT à baixa temperatura $\left(<600^{\circ} \mathrm{C}\right)$; São Paulo, 150p. Tese (Doutorado) Escola Politécnica, Universidade de São Paulo, 2002.

[24] VIANA, C. E. et al; High Density-PECVD Silicon Dioxide Deposition by TEOS and Oxygen at Low Temperature $\left(375^{\circ} \mathrm{C}\right)$; XVII SBMICRO; 2002.

[25] GRANIER, A. et al; Diagnostics in $\mathrm{O}_{2}$ helicon Plasmas for $\mathrm{SiO}_{2}$ Deposition; Plasma Sources Science and Technology; v. 6 (1997); p. 147-56.

[26] DESHMUKH, S. C. and AYDIL, E. S.; Investigation of Low Temperature $\mathrm{SiO}_{2}$ Films From Tetraethoxysilane-Sourced Remote Microwave Plasma-Enhanced Chemical Vapor Deposition; Journal of Vacuum Science and Technology A; v. 13 (1996); p. 676-80.

[27] INOUE, I. et al; In Situ Observation of Behavior of Organosilicon Molecules I Low Temperature Plasma Enhanced CVD; Thin Solid Films; v. 345 (1999); p. 90-93.

[28] KIM, M. T.; Calculation of Apparent Activation Energy for the Deposition of TEOS-SiO 2 Films by PECVD; Thin Solid Films; v. 347 (1999); p. 112-16.

[29] RAUPP, G. B. et al; The Role of Oxygen Excitation and Loss in Plasma-Enhanced Deposition Silicon Dioxide form Tetraethylorthosilicate; Journal of Vacuum Science and Technology B; v. 10 (1992); p. 37-45.

[30] HORII, N. M. et al; Investigation of $\mathrm{SiO}_{2}$ deposition processes with mass spectrometry and optical emission spectroscopy in plasma enhanced chemical vapor deposition using tetraethoxysilane; Thin Solid Films; v. 343-44 (1999); p. 148-151.

[31] POPOV, O. A.; High Density Plasma Sources - Design, Physics and Performance; Noyes; Park Ridge - NJ (EUA); 1995.

[32] RAUPP, G. B. et al; Conformability of $\mathrm{SiO}_{2}$ Films From Tetraethoxysilane-Sourced Remote Microwave Plasma-Enhanced Chemical Vapor Deposition; Journal of Vacuum Science and Technology A; v. 13 (1995); p. 676-80.

[33] MORIMOTO, N. I. and SWART, J. W.; A Cluster Tool System for Silicon oxide Deposition; X Congresso da Sociedade Brasileira de Microeletrônica; Julho; p. 393-409 (1995).

[34] SILVA, A. N. R.; Estudo e caracterização do processo PECVD-TEOS para a deposição de filmes de óxido de silício e estudo das interfaces; Tese (Doutorado); Escola Politécnica da Universidade de São Paulo - Departamento de Engenharia de Sistemas Eletrônicos; São Paulo - SP; 2000. 
[35] KANE, P. F. and LARRABEE, G. B.; Characterization of Semiconductor Materials; McGraw Hill; New York - NY (EUA); 1970.

[36] LOPES, J. C. D.; Curso de Espectroscopia no infravermelho; Instituto de Química da Universidade de São Paulo; São Paulo - SP; Setembro; 1993.

[37] CHU, W. K., MAYER, J. W. and NICOLET, M. A.; Backscattering Spectrometry; Academic Press; New York - NY (EUA); 1978.

[38] NICOLLIAN, E. H. and BREWS J. R.; MOS (Metal Oxide Semiconductor) Technology; John Wiley \& Sons; New York - NY (EUA); 1982.

[39] SANO, K.; HAYASHI, S.; WICKRAMANAYAKA, S.; HATANAKA, Y., High quality $\mathrm{SiO}_{2}$ depositions from TEOS by ECR plasma. Thin Solid Films, v.281-2, p.397-400, 1996.

[40] GOULLET, A. et al; Optical spectroscopic analyses of $\mathrm{OH}$ incorporation into $\mathrm{SiO}_{2}$ films deposited from $\mathrm{O}_{2}$ /tetraethoxysilane plasmas; Journal of Vacuum Science and Technology A; v. 18; n. 5; (2000); p. 2452-58.

[41] TORRES, V. M. and KHAZI-SYED, A.; Effect of film thickness and annealing temperature on the carbon induced interfacial charge of tetraethoxyorthosilicate based oxide films on p-type Si(100); Journal of Vacuum Science and Technology B; v. 23; n. 5; (2005); p. 2078-83.

[42] BOGART, K. H. A. et al; Plasma enhanced chemical vapor deposition of $\mathrm{SiO}_{2}$ using novel alkoxysilane precursors; Journal of Vacuum Science and Technology A; v. 13; n. 2; (1995); p. 476-80.

[43] IZGORODIN, V. M. et al; Composition and Surface Properties of a Silicon Dioxide Film Deposited by a Plasma-Chemical Technique; High Energy Chemistry; v. 36; n. 6; (2002); p. 426-430.

[44] OKUYAMA, M. et al; Photo-Induced Chemical Vapor Deposition of $\mathrm{SiO}_{2}$ Film Using Direct Excitation Process by Deuterium Lamp; Japanese Journal of Applied Physics; v. 23; no. 2; (1984); p. L97-99.

[45] SASSELA, A. et al; Infrared study of Si-rich silicon oxide films deposited by plasma-enhanced chemical vapor deposition; Journal of Vacuum Science and Technology A; v. 15; n. 2; (1997); p. 377-89.

[46] PAI, P. G. et al; Infrared spectroscopic study of $\mathrm{SiO}_{x}$ films produced by plasma enhanced chemical vapor deposition; Journal of Vacuum Science and Technology A; v. 4; n. 3; (1986); p. 689-94. 
[47] GONÇALVES, L. C. D. et al; Mechanical properties of silicon oxide films deposited by PECVD-TEOS for application sin MEMS structures and sensors; Microelectronics Technology and Devices - Proceedings of SBMICRO 2002; p. 117; 2002. 